\title{
ENGENHARIA: A MÁQUINA QUE
}

CONSTRÓI O FUTURO

VOLUME IV 
Frederico Celestino Barbosa

Engenharia: a máquina que constrói o futuro

$1^{\text {a }}$ ed.

Piracanjuba-GO

Editora Conhecimento Livre

Piracanjuba-GO 
$1^{\mathrm{a}} \mathrm{ed}$

\section{Dados Internacionais de Catalogação na Publicação (CIP)}

Barbosa, Frederico Celestino
B238E Engenharia: a máquina que constrói o futuro

/ Frederico Celestino Barbosa. - Piracanjuba-GO

Editora Conhecimento Livre, 2021

162 f.: il

DOI: $10.37423 / 2021$.edcl291

ISBN: 978-65-89955-45-0

Modo de acesso: World Wide Web

Incluir Bibliografia

1. desenvolvimento 2. projeto 3. construção I. Barbosa, Frederico Celestino II. Título

CDU: 620

https://doi.org/10.37423/2021.edc1291

O conteúdo dos artigos e sua correção ortográfica são de responsabilidade exclusiva dos seus respectivos autores. 


\title{
EDITORA CONHECIMENTO LIVRE
}

\section{Corpo Editorial}

\author{
Dr. João Luís Ribeiro Ulhôa \\ Dra. Eyde Cristianne Saraiva-Bonatto \\ Dr. Anderson Reis de Sousa \\ MSc. Frederico Celestino Barbosa \\ MSc. Carlos Eduardo de Oliveira Gontijo
}

$\underline{\text { MSc. Plínio Ferreira Pires }}$

Editora Conhecimento Livre

Piracanjuba-GO 


\section{SUMÁRIO}

CAPÍTULO 1

ANÁLISE DE DADOS SOBRE EVASÃO, RETENÇÃO E FORMAÇÃO NO CURSO DE

ENGENHARIA CIVIL DO INSTITUTO FEDERAL DE EDUCAÇÃO, CIÊNCIA E TECNOLOGIA DO CEARÁ

José C. C. B. Carneiro

George É. P. Farias

Jéssica R. R. Pontes

Anderson da S. Barros

Carlos A. M. de Sousa

DOI 10.37423/210704430

CAPÍTULO 2

CONSIDERAÇÕES SOBRE VESTIBULANDOS INGRESSANTES NA FACULDADE DE

ENGENHARIA DE BAURU/UNESP E SUA DESISTÊNCIA DO CURSO DURANTE O PROCESSO

DE MATRÍCULA

José Francisco Rodrigues

Renato Crivellari Creppe

Luiz Gongaza Campos Porto

José Ricardo Calheiros da Silva

DOI 10.37423/210704440

CAPÍTULO 3

CONCEITO E APLICAÇÕES DA INTERNET DAS COISAS: A TECNOLOGIA DA

GLOBALIZAÇÃO.

ANTONIO JOSÉ DIAS SILVA

GERALDO MOTTA AZEVEDO JUNIOR

WALLACE NUNES DA SILVA MARQUES

AURELIANO FERNANDES

DOI 10.37423/210704446

CAPÍTULO 4

FERRAMENTA EDUCACIONAL DESENVOLVIDA NO SCILAB PARA AUXÍLIO NA DISCIPLINA DE SISTEMAS DE CONTROLE DINÂMICO

Lucivando Ribeiro de Araújo

Vandilberto Pereira Pinto

Rômulo Nunes de Carvalho Almeida

Muriel Martins Aragão

DOI 10.37423/210704448

CAPÍTULO 5

O MODELO SWAN COMO FERRAMENTA ÚTIL NA PREVISÃO DE ONDA EM RECINTO

FECHADO - ESTUDO DE CASO NO LAGO DA BARRAGEM DE ILHA SOLTEIRA - S.P

Adriana Silveira Vieira

Geraldo de Freitas Maciel

Conceição Juana Espinosa Morais Fortes

DOI 10.37423/210704450 
APLICAÇÃO DA TERMOGRAFIA NA MANUTENÇÃO PREDITIVA

Antônio Lucas Frazão Santos

Daniela dos Santos da Silva

Roberth Hyther Paulo dos Santos

Eduardo Henrique Castro Mendes

DOI 10.37423/210704452

CAPÍTULO 7

O GUINDASTE: UMA METODOLOGIA ATIVA PARA ASENGENHARIAS COMPATÍVEL COM A

INDÚSTRIA 4.0

Daniel Martins Papini Mota

Dayse Nascimento Anselmo

Lucas Silvestre Chaves

Maria Marta Ribeiro da Costa

Silvana Julia da Silveira Diniz

DOI 10.37423/210704466

CAPÍTULO 8

AVALIAÇÃO ERGONÔMICA DO AMBIENTE CONSTRUIDO: ESTUDO NA CENTRAL DE

MATERIAIS E ESTERILIZAÇÃO DE UM HOSPITAL UNIVERSITÁRIO

Marilande Carvalho de Andrade Silva

Waldelourdes de Melo Souto Maior

Marcelo Francisco Gomes

Alaíde Farias de Almeida Filha

Vilma Maria Villarouco Santos

DOI 10.37423/210704468

CAPÍTULO 9

INOVAÇÃO, EMPREENDEDORISMO E FORMAÇÃO DO ENGENHEIRO

Elisabeth Flávia Roberta Oliveira Motta

Emmanuel Paiva de Andrade

DOI 10.37423/210704469

CAPÍTULO 10

ESTUDO DO COMPORTAMENTO DA MRV OPERANDO COMO MOTOR/GERADOR

Augusto Wohlgemuth Fleury Veloso da Silveira

Darizon Alves de Andrade

Augusto Fleury Veloso da Silveira

Luciano Coutinho Gomes

Carlos Augusto Bissochi Junior

Renato Jayme Dias

DOI 10.37423/210704475 
USO DE IMAGENS DE PROFUNDIDADE NA BIOMECÂNICA

Ivana Marcia Oliveira Maia

Yasmin Sousa Silva

Karoline Viana Leão

Anselmo Cardoso de Paiva

DOI 10.37423/210704491

CAPÍTULO 12

CONSCIENTIZAÇÃO INFANTIL NO USO RACIONAL E SEGURO DA ENERGIA ELÉTRICA

Yuri da G. Santos

Raphael D. C. Silva

Filipe D. Oliveira

Edcleide S. P. Pereira

Michele M. Sales

Débora P. Mercês

DOI 10.37423/210704527

CAPÍTULO 13

TRILHA ECOLÓGICA PARA PRESERVAÇÃO DAS ABELHAS (HYMENOPTERA: APOIDEA)

Maildo Barbosa Coelho

Nádilla Gonçalves Andrade

Joelson Sousa Junior

Laiza Bezerra Lima

Waldesse Piragé de Oliveira Junior

DOI 10.37423/210704540 


\section{Capítulo 1}

doi) 1037428210704400

\section{ANÁLISE DE DADOS SOBRE EVASÃO, RETENÇÃO E FORMAÇÃO NO CURSO DE} ENGENHARIA CIVIL DO INSTITUTO FEDERAL DE EDUCAÇÃO, CIÊNCIA E TECNOLOGIA DO CEARÁ

José C. C. B. Carneiro

George É. P. Farias

Jéssica R. R. Pontes

Anderson da S. Barros

Carlos A. M. de Sousa
Instituto Federal de Educação, Ciência e

Tecnologia do Ceará - IFCE

Instituto Federal de Educação, Ciência e Tecnologia do Ceará - IFCE

Instituto Federal de Educação, Ciência e Tecnologia do Ceará - IFCE

Instituto Federal de Educação, Ciência e Techologia do Ceará - IFCE

Instituto Federal de Educação, Ciência e Tecnologia do Ceara - IFCE 
Resumo: Este trabalho apresenta uma análise de dados relacionados à evasão, retenção e formação de alunos no curso de Engenharia Civil do Instituto Federal do Ceará, campus Fortaleza. Os dados em questão foram fornecidos pela Coordenação de Controle Acadêmico do campus. Este artigo visa contribuir, por meio da análise qualitativa dos índices estatísticos encontrados, como um incentivo para a criação de melhorias que visem otimizar os índices de formação no curso de Engenharia Civil, para, posteriormente, repetir estes estudos e melhorias para outros cursos da Instituição. Os resultados mostraram que a média de evasão no curso em análise, levando em consideração a média de todos os semestres que já atingiram o período regular de formação, é de 30\%, estando abaixo da média de evasão nacional em engenharias, que é de $43 \%$ na rede pública e de $62 \%$ na rede privada. A média de retenção dentre todas as turmas é de 47\%, uma taxa maior que a de evasão e a de formação, que é de 29\%. Esses resultados, salve o bom índice em evasão, indicam que métodos, tais como novos estudos, precisam ser repensados e aplicados em busca da melhoria desses indicadores.

Palavras-chave: Evasão. Retenção. Formação. Engenharia. Índices. 


\section{INTRODUÇÃO}

A educação superior no Brasil hoje é cada vez mais importante na busca por uma melhoria na qualidade de vida, tendo em vista que, segundo dados da $8^{\circ}$ edição do Mapa do Ensino Superior no Brasil, publicado pelo Sindicato das Mantenedoras de Ensino Superior, dentre os anos de 2013 e 2016, o número de empregos formais para aqueles com ensino superior completo aumentou $9,1 \%$, chegando a quase 10 milhões. Considerando o mesmo período, para os indivíduos que possuem ensino médio completo, em contrapartida, houve uma queda da empregabilidade de $3,1 \%$ e, com ensino fundamental completo, queda de $8,6 \%$ (SINDICATO DAS MANTENEDORAS DE ENSINO SUPERIOR, 2018).

Tendo em vista o aumento dessa importância, é necessário buscar métodos que otimizem o ensino superior nas mais diversas esferas que o ofertam. O desafio não é apenas o ingresso do aluno, mas índices de evasão e retenção provam que a conclusão da graduação também está se tornando mais difícil ou demorada nos últimos anos. Na rede pública de ensino superior, a porcentagem de concluintes obteve uma pequena queda de $2,5 \%$ (de 15,7 mil concluintes para 15,3 mil). A taxa de evasão dos cursos presenciais no país, em 2016, atingiu o índice de 30,1\% na rede privada e 18,5\% na rede pública (SINDICATO DAS MANTENEDORAS DE ENSINO SUPERIOR, 2018).

Por evasão, no sentido mais simplista do termo, compreende-se o ato de evadir-se, fugir, abandonar; sair, desistir; não permanecer em algum lugar (RIFEL; MALACARNE, 2010). Por outro lado, retenção, segundo Freitas (2010), significa um mecanismo de suspensão da progressão regular no processo de formação do estudante, geralmente associado a rendimento, como em aproveitamento e frequência, insatisfatório. Além disso, trancamento de matrícula também é enquadrado na categoria de retenção.

Frequentemente, os motivos que levam à retenção e à evasão acadêmica estão associados a problemas de caráter emocional ou socioeconômico que influenciam, de forma determinante, no desempenho desses estudantes, a maioria nos períodos iniciais dos cursos, quando os ingressantes se defrontam perante dificuldades adicionais de adaptação à rotina como universitário (WATANABE et al., 2016).

Tendo em vista os cursos de engenharia, os dados sobre formação, evasão e retenção são ainda mais alarmantes. Na década de 2001 a 2011 apenas 44\% dos estudantes de engenharia concluíram seus cursos superior (CONFEDERAÇÃO NACIONAL DA INDÚSTRIA, 2013). Este artigo visa contribuir, por meio da análise qualitativa dos índices estatísticos encontrados, como um incentivo para a criação de 
melhorias que visem otimizar os índices de formação no curso de Engenharia Civil, para, posteriormente, repetir estes estudos e melhorias para outros cursos da Instituição.

\section{METODOLOGIA}

Para a análise sobre formação, evasão e retenção do curso de engenharia civil do Instituto Federal do Ceará, campus Fortaleza, foram consideradas todas as turmas que já concluíram seu período regular de formação, ou seja, de 2012.2 a 2014.1, para os índices de formação e retenção. Para a taxa de evasão, foram consideradas todas as turmas a partir do primeiro semestre ofertado, 2012.2, até a última turma que concluiu o primeiro semestre, a de 2018.2. Todos os dados foram fornecidos pela Coordenação de Controle Acadêmico, departamento da Instituição, sintetizados na tabela 1, abaixo:

Tabela 1 - Número de ingressos, evadidos, retidos e formados por turma.

\begin{tabular}{c|c|c|c|c}
\hline Período & Ingressos (TM) & Evadidos (AE) & Retidos (AR) & Formados (AF) \\
\hline 2012.2 & 33 & 11 & 7 & 15 \\
\hline 2013.1 & 25 & 8 & 10 & 7 \\
\hline 2013.2 & 34 & 16 & 12 & 6 \\
\hline 2014.1 & 31 & 9 & 14 & 8 \\
\hline 2014.2 & 43 & 18 & 0 & 0 \\
\hline 2015.1 & 40 & 8 & 0 & 0 \\
\hline 2015.2 & 35 & 10 & 0 & 0 \\
\hline 2016.1 & 51 & 18 & 0 & 1 \\
\hline 2016.2 & 45 & 13 & 0 & 0 \\
\hline 2017.1 & 40 & 13 & 0 & 0 \\
\hline 2017.2 & 32 & 11 & 0 & 0 \\
\hline 2018.1 & 38 & 7 & 0 & 0 \\
\hline 2018.2 & 33 & 5 & 0 & 0 \\
\hline
\end{tabular}

Fonte: Autores

O cálculo do índice de formação (IF), equação 2, abaixo, de cada semestre foi feito pela razão entre o total de formados (AF), dentro e fora do prazo regular de formação, de todos os semestres que já atingiram o tempo regular de formação, pelo total de alunos matriculados (TM) no primeiro semestre daquela turma. Por conseguinte, o cálculo do índice de evasão (IE), equação 1 , foi feito pela razão entre o número de alunos que, por algum motivo, se evadiram do curso (AE), pelo número total de estudantes que ingressaram no primeiro semestre daquela turma. Por fim, o cálculo do índice de retenção, equação 3, foi feito pela razão entre o número de alunos que, por algum motivo, adiaram 
sua formação em tempo regular e ainda possuem vínculo de matrícula com a Instituição (AR), sobre o total de matriculados no início da turma.

$$
\begin{aligned}
& I E=\left(\frac{A E}{T M}\right) \times 100 \\
& I F=\left(\frac{A F}{T M}\right) \times 100 \\
& I R=\left(\frac{A R}{T M}\right) \times 100
\end{aligned}
$$

As categorias que inserimos os alunos enquadrados como evadidos ou retidos estão presentes na tabela abaixo. É importante salientar que alguns alunos que se formaram, podem também estar enquadrados, nos cálculos dos índices, como alunos retidos, caso tenham ultrapassado o período regular de formação. Assim, entrariam na estatística de formados e na estatística de retido caso satisfaçam os dois requisitos.

Tabela 2 - Categorias de alunos evadidos e retidos dos dados analisados

\begin{tabular}{c|c}
\hline Retido & Evadido \\
\hline $\begin{array}{c}\text { Aguardando colação } \\
\text { de grau }\end{array}$ & Cancelado voluntariamente \\
\hline Trancado & Cancelado compulsoriamente \\
\hline $\begin{array}{c}\text { Matriculado após } \\
\text { período regular de } \\
\text { formação }\end{array}$ & Abandono \\
\hline
\end{tabular}

Fonte: Autores

Por fim, dentre todas as médias utilizadas para gerar a média dos índices de evasão, retenção e formação, foram geradas tabelas para comparar o comportamento das taxas encontrados no decorrer de cada semestre, tal como foram gerados dados estatísticos de variância a fim de saber o quão distante cada valor do conjunto está da média. A equação (4), descrita abaixo, representa o valor da variância, $S^{2}$, onde $X i$ representa o valor de todos os índices calculados para cada semestre, posteriormente subtraídos individualmente da média, $\bar{X}$. A variável $\mathrm{n}$ representa o número de índices utilizados na média: 


$$
S^{2}=\frac{\sum_{i=1}^{n}\left(X_{i}-\bar{X}\right)^{2}}{n-1}
$$

\section{RESULTADOS E DISCUSSÕES}

Primeiramente, trataremos dos resultados relacionados ao índice de evasão. A média do índice de evasão do curso de Engenharia Civil do Instituto Federal do Ceará, campus Fortaleza, foi de 30\%, considerando uma aproximação sem valor decimal. O resultado é bastante satisfatório, tendo em vista que está abaixo da média de evasão nacional em engenharias, que é de $43 \%$ na rede pública e de $62 \%$ na rede privada. A variância foi de 91 . A alta variância se dá pelo fato de que a evasão é mais notável em turmas mais avançadas, gerando um contraste do índice entre as turmas mais antigas e as mais novas, onde estas tendem a aumentar a evasão no decorrer dos próximos semestres, mesmo que em menor intensidade. Como prova dessa tendência, calculou-se a variância dentre as taxas de evasão dos quatro primeiros semestres, com período regular de formação já concluído, este índice estatístico caiu para 53, provando que, com o tempo, há uma infeliz tendência de a evasão crescer para as turmas mais recentes.

Figura 1 - Porcentagens de alunos evadidos de cada turma de acordo com cada semestre analisado

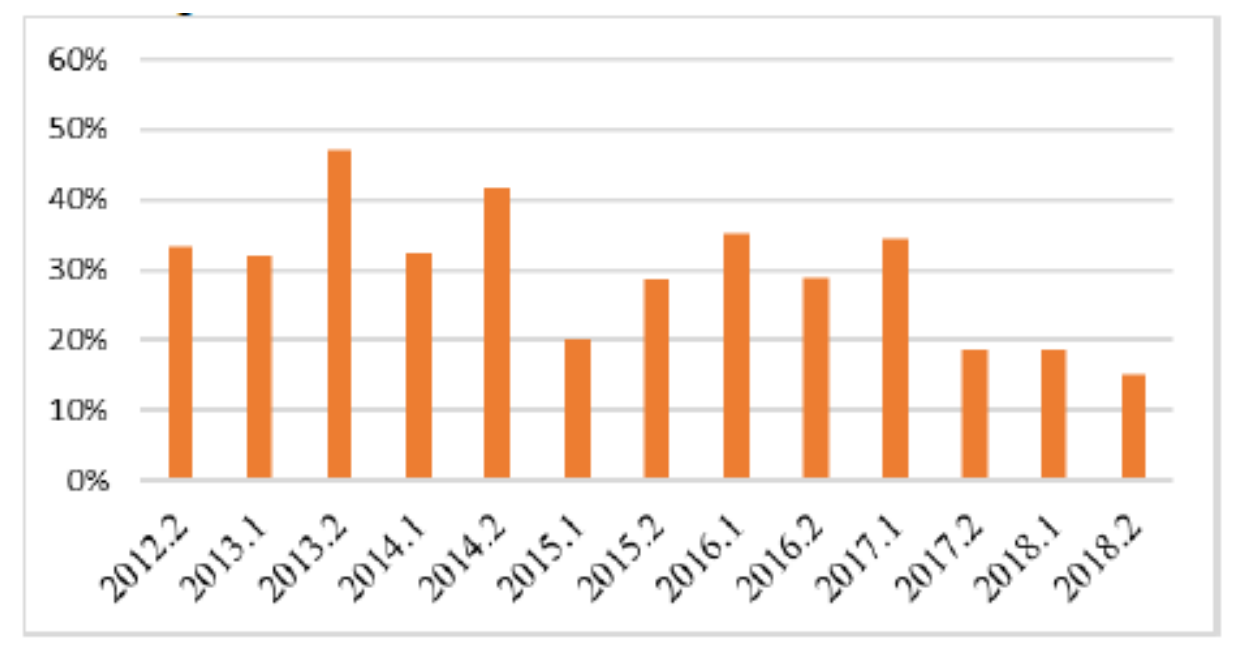

Fontes: Autores

Por conseguinte, trataremos dos resultados relacionados ao índice de formados. A taxa média de formação no curso em questão foi de apenas $29 \%$, resultado consideravelmente abaixo do índice nacional, que é de 44\% (CONFEDERAÇÃO NACIONAL DA INDÚSTRIA, 2013). A variância do índice de formação dentre as turmas com tempo regular de formação já atingido foi de 137, esta enorme 
discrepância em torno da média pode se dá pelo fato de que as turmas ingressas em 2013.1, 2013.2 e 2014.1 decresceram bastante este índice se comparadas com a primeira turma, veja na imagem 2.

O início da recessão econômica nacional em meados de 2013 e 2014 pode ter incentivado a uma maior evasão, tendo em vista que a engenharia civil é muito sensível a oscilações macroeconômicas (MORENO, 2017). Segue abaixo a tabela contrapondo a porcentagem de formados e o respectivo semestre de início da turma em questão.

Figura 2 - Contraposição entre a porcentagem dos formados e o respectivo semestre

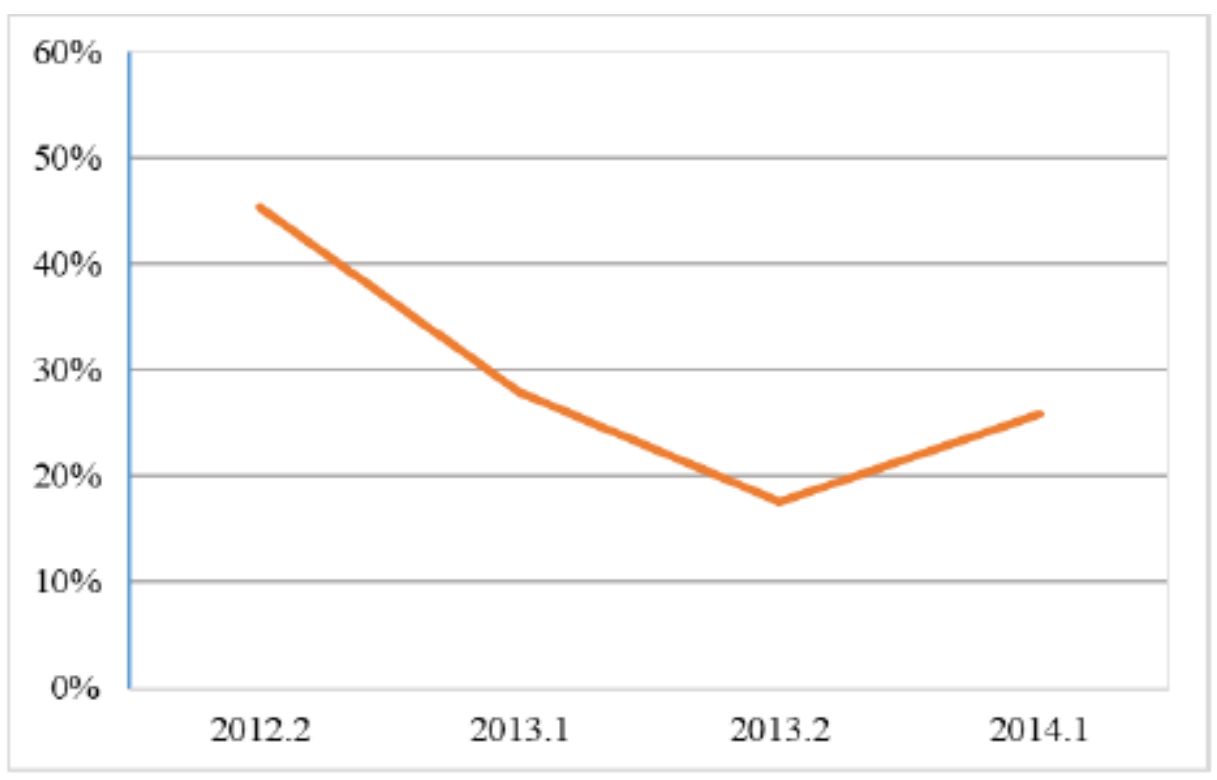

Fonte: Autores

Por fim, o índice de retenção médio, ilustrado semestralmente abaixo por meio da tabela 4, foi de 47\%. Apresentando uma variância de 5. 0 índice demonstra que quase metade dos alunos de cada turma, quando não desistem do curso, ainda tendem a não se formar no tempo certo. Um dado preocupante para a saúde financeira da Instituição, tendo em vista que o custo anual de um estudante do ensino superior é de aproximadamente $R \$ 14.763,00$ (MELO, 2017). Um custo que perdura mais tempo que o previsto, fomentando um maior sucateamento desse espaço público, devido à entrada de novos alunos ser feita de forma regular, um número fixo semestral, sem a contrapartida satisfatória nas colações de grau, onde não há um índice de formação em tempo regular. 
Figura 3 - Contraposição entre a porcentagem dos retidos e o respectivo semestre

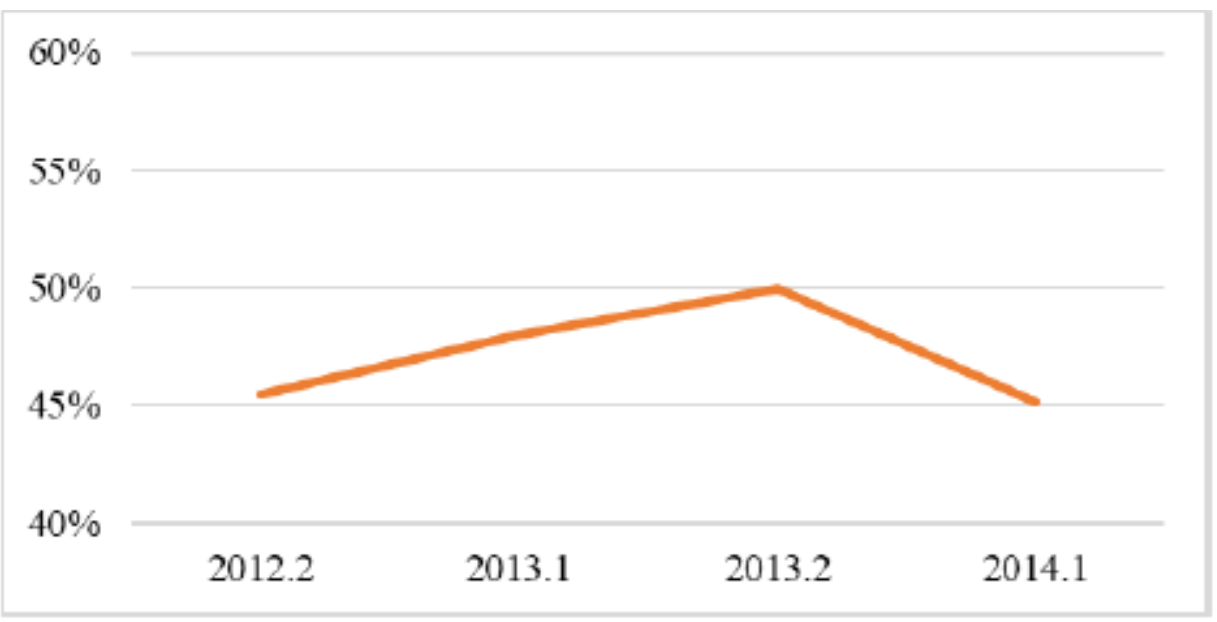

Fonte: Autores

\section{CONSIDERAÇÕES FINAIS}

Dentre os índices médios de evasão, retenção e formação, o curso de Engenharia Civil do Instituto Federal do Ceará, campus Fortaleza, mostrou um bom índice de formação quando comparado a dados nacionais, porém demonstrou uma urgente necessidade de analisar os motivos, por parte dos alunos e da Instituição, que estão fomentando dados insatisfatórios nos quesitos de retenção e evasão. Espera-se, que a partir dos dados constatados neste artigo, a busca por melhorias seja fomentada internamente pelos responsáveis pedagógicos do curso, a fim de entender as problemáticas internas, e, a longo prazo, reproduzir este estudo para outros cursos a fim de constatar os desafios que circundam o processo de formação no ensino superior de uma forma cada vez mais ampla.

\section{AGRADECIMENTOS}

À Coordenação de Controle Acadêmico do Instituto Federal de Educação, Ciência e Tecnologia do Ceará, campus Fortaleza, pelos dados cedidos. 


\section{REFERÊNCIAS}

CARVALHO, Lara de O.; MEIRA, Manoel M. C.; SANTOS, Polyane A.; PIAU, Deise D. N. D. Análise das causas e efeitos da evasão acadêmica do curso de engenharia elétrica no Instituto Federal da Bahia Campus Vitória da Conquista. In: XXVIII Congresso Brasileiro de Educação em Engenharia, 2016, Rio Grande do Norte. Anais. Natal, 2016.

CONFEDERAÇÃO NACIONAL DA INDÚSTRIA (Brasil). "Só $44 \%$ dos alunos de engenharia da última década terminaram o curso". Julho de 2013. Disponível em: http://zip.net/bqtKRK. Acesso em: 03 de junho de 2017.

FREITAS, D.N.T. Retenção escolar. In: OLIVEIRA, D.A.; DUARTE, A.M.C.; VIEIRA, L.M.F. DICIONÁRIO: trabalho, profissão e condição docente. Belo Horizonte: UFMG/Faculdade de Educação, 2010. CDROM.

MELO, Mirella S. P. de.; SILVA, Dione L. da.; FEITOSA, Marcílio A.F.; CAVALCANTI, Gustavo O. Análise de evasão nos cursos de engenharia da Universidade de Pernambuco. In: XLV Congresso Brasileiro de Educação em Engenharia, 2017, Santa Catarina. Anais. Joinville, 2017.

MORENO, A. C. Alta das demissões na engenharia civil é retrato da crise e não deve 'assustar' candidatos, dizem especialistas. G1, 21 set. 2017. Disponível em:

https://g1.globo.com/educacao/guia-de-carreiras/noticia/alta-das-demissoes-na-engenharia-civil-eretrato-da-crise-e-nao-deve-assustar-candidatos-dizem-especialistas.ghtml. Acesso em: 05 abr. 2019.

RIFFEL, S. M.; MALACARNE, V. Evasão escolar no ensino médio: o caso do Colégio Estadual Santo Agostinho no município de Palotina, PR, 2010.

SINDICATO DAS AMNTENEDORAS DE ENSINO SUPERIOR. Mapa do Ensino Superior no Brasil, 8a Edição, 2018, Disponível em:

https://www.semesp.org.br/wp-content/uploads/2018/10/AF-Mapa_do_Ensino_Superior-web.pdf. Acesso em: 05 de abril de 2019.

WATANABE, Flávio Y.; ANTONIALLI, Armando Í. S.; AROCA, Rafael V.; FRANCO, Vitor R. O ingresso no ensino superior: Desafios e preocupações com o desempenho acadêmico e o equilíbrio emocional dos estudantes. In: XLIV Congresso Brasileiro de Educação em Engenharia, 2016, Rio Grande do Norte. Anais. Natal, 2016. 


\section{Capitulo 2}

doi) $10.37423 / 210704440$

\section{CONSIDERAÇÕES SOBRE VESTIBULANDOS INGRESSANTES NA FACULDADE DE ENGENHARIA DE BAURU/UNESP E SUA DESISTÊNCIA DO CURSO DURANTE O PROCESSO DE MATRÍCULA}

José Francisco Rodrigues

Renato Crivellari Creppe

Luiz Gongaza Campos Porto

José Ricardo Calheiros da Silva
Universidade Estadual Paulista - Faculdade de Engenharia de Bauru

Universidade Estadual Paulista - Faculdade de Engenharia de Bauru

\section{Universidade Estadual Paulista - Faculdade de Engenharia de Bauru}

Universidade Estadual Paulista - Faculdade de Engenharia de Bauru 
Resumo: Há anos se tem observado que os quatro cursos de engenharia da Faculdade de Engenharia de Bauru/FEB/UNESP recebem uma pequena quantidade de vestibulandos para realizarem a matrícula nos seus respectivos cursos, em primeira convocação. Mesmo após a segunda convocação, notou-se que ainda havia vagas remanescentes a ser preenchidas, aspecto analisado e resolvido através da publicação de uma relação adicional de convocados para integralizar o preenchimento dos ingressantes. Este artigo tem como objetivo detectar e esclarecer os fatores que ocasionaram a saída dos alunos ingressantes e que desistiram do curso antes de iniciarem o mesmo, durante o período de 1999 a 2008 nos cursos de engenharia da FEB/UNESP. Desta forma, buscou-se conhecer as razões que levaram os alunos da FEB/UNESP recém chegados e ingressantes por vestibular a não permanecerem no curso. Pode-se afirmar que os resultados foram satisfatórios e demonstraram que é possível através do emprego de procedimentos simples encontrarem-se alguns possiveis motivos que levam os alunos a desistirem do ingresso. No momento novas sugestões e procedimentos estão sendo incorporados na abordagem do tema.

Palavras-chave: Desistência de curso, Matrícula de vestibulandos, Alunos ingressantes, Alunos desistentes 


\section{INTRODUÇÃO}

Os vestibulares das Instituições de Ensino Superior-IES em todo país são práticas adotadas há dezenas de anos por praticamente todas elas, embora algumas outras propostas tivessem surgido mais recentemente. Uma das questões da dificuldade de acesso aos cursos de interesse dos vestibulandos está diretamente vinculada à relação candidato/vaga, quanto maior for essa relação maior é o grau de complexidade para ingressar no respectivo curso. Independentemente se a IES é pública ou privada essa realidade é constatada, e desta forma os cursos de engenharia oferecidos pela Faculdade de Engenharia de Bauru-FEB/UNESP enquadram-se nessa escala.

Para se ter uma idéia apresenta-se a seguir os índices do parâmetro candidato/vaga, no caso específico dos cursos de engenharia civil, elétrica, mecânica e produção da FEB/UNESP para os anos de 2008 e 2009, sendo os mesmos, respectivamente de: 14,8; 14,7; 24,4 e 28,8 para 2008 e 22,1; 13,8; 22,9 e 28,1 para 2009.

Porém, mesmo com os valores acima apresentados, que não são desprezíveis, se percebeu ao longo dos anos que a quantidade de alunos matriculados em primeira chamada é relativamente pequena, o que proporciona evidentemente uma segunda chamada dos vestibulandos que se encontram na lista de espera. Entretanto, se após a segunda chamada o número de vagas não for integralmente preenchido, para os diversos cursos, existirá ainda uma última chamada. Essa questão chamou a atenção de professores e funcionários técnico/administrativos que se interessaram na busca e investigação dos reais motivos que levam os vestibulandos a desistirem de suas matrículas evadindose do futuro curso e abandonando seu efetivo ingresso.

Desta forma, a Seção de Graduação da FEB/UNESP, que além de prestar o tradicional atendimento aos docentes e alunos de graduação nas questões relacionadas às atividades acadêmicas, bem como possuir a responsabilidade de assessorar as atividades de apoio à Comissão Permanente de Ensino e aos Coordenadores dos Cursos de Graduação ministrados por esta Faculdade, interessou-se também nesse aspecto e realizou uma coleta de dados de grande interesse visando detectar o problema relacionado com a desistência pelo acadêmico no primeiro mês de aula, conforme será apresentado os seus detalhes nos próximos itens deste artigo.

Com a respectiva análise e compilação de resultados, acredita-se que estes fornecerão uma linha de atuação que ajude a identificar as principais características que levam a saída desses alunos ingressantes. 
O corpo do artigo será composto basicamente de seis itens principais. O primeiro, conforme já descrito e apresentado acima, encontra-se a Introdução. No segundo comentar-se-á os Objetivos seguido do item Evasão de Alunos Ingressantes. No quarto será apresentado As Causas da Desistência Segundo os Próprios Alunos Evadidos e no quinto a Convocação da Lista de Chamada para Matrícula. Considerações Finais encerram-se a abordagem específica do artigo finalizada com as Referências Bibliográficas.

\section{OBJETIVOS}

Este estudo teve como principal objetivo detectar e esclarecer os fatores que ocasionaram a saída dos alunos ingressantes e que desistiram do curso antes de iniciarem o mesmo, no período de 1999 a 2008 nos cursos de engenharia da FEB/UNESP. Desta forma, buscaram-se conhecer as razões que levaram os alunos da FEB/UNESP, ingressantes por vestibular, a abandonarem o curso.

A amostra estudada consiste em $44,7 \%$ da população total de desistentes no período (591 alunos). Para atingir os objetivos foram utilizadas estratégias de pesquisa documental e de levantamento de informações em arquivos eletrônicos e no tradicional fichário.

Foi delineado o perfil do aluno evadido no período, considerando as suas características predominantes e os fatores apontados pelos alunos como determinantes para sua saída. Foi solicitado de forma espontânea e individual aos alunos desistentes que justificassem de forma descritiva os motivos para tal ato, muito embora mais da metade dos evadidos não atenderam a esse pedido.

A pesquisa documental teve como base as informações contidas nas solicitações de matrícula e cancelamento dos alunos. A pesquisa de levantamento bibliográfico foi realizada através de busca de dados nos diversos arquivos do Sistema Acadêmico da Seção de Graduação da FEB/UNESP.

\section{EVASÃO DE ALUNOS INGRESSANTES}

A Fundação para o Vestibular da Universidade Estadual Paulista - VUNESP é uma fundação pública, com personalidade jurídica de direito privado, sem fins lucrativos, criada em 26 de outubro de 1979 pelo Conselho Universitário da UNESP.

As principais atividades da VUNESP são: planejar, organizar, executar e supervisionar o concurso Vestibular da UNESP; realizar vestibulares e concursos diversos para outras instituições públicas ou privadas; coletar, organizar, analisar e encaminhar ao Conselho Universitário da UNESP informações técnicas e dados estatísticos relativos ao seu vestibular; promover atividades de pesquisa e extensão 
de serviços à comunidade, na área educacional; desenvolver outras atividades compatíveis com suas finalidades. Nesta organização/planejamento a VUNESP elabora um calendário de vestibular desde a inscrição até a data limite para convocação dos últimos vestibulandos, não excedendo os primeiros 27 dias letivos para o regime de matrícula semestral. É importante registrar que a primeira e segunda chamada do vestibular da UNESP é realizada pela VUNESP. Tanto os vestibulandos de primeira como de segunda chamadas têm necessariamente de confirmar sua matrícula, dentro de um período que é previamente estabelecido pelo calendário de vestibular. Desta forma, os vestibulandos que realizam matrículas em primeira e segunda chamada e não a confirmam são considerados desistentes e outros são convocados. A convocação dos vestibulandos da lista "Relação Adicional" para o preenchimento das últimas vagas ainda existentes nos cursos é realizada internamente nas unidades da UNESP pela Seção de Graduação e não mais pela VUNESP.

Conforme já mencionado, o estudo da desistência dos alunos oriundos do vestibular que chegam a realizar matrícula bem como aqueles que ainda podem ingressar até os primeiros 27 dias letivos, dos cursos de engenharia, será o escopo deste trabalho. Para a composição da amostra, tomou-se o universo dos alunos evadidos dos cursos de engenharia que realizaram matrícula, mas desistirem antes do seu início, em um período compreendido entre o primeiro semestre de 1999 até e o segundo semestre de 2008.

\section{AS CAUSAS DA DESISTÊNCIA SEGUNDO OS PRÓPRIOS ALUNOS EVADIDOS}

Após a avaliação de todas as informações colhidas e dos dados preenchidos pelos alunos desistentes da vaga no respectivo curso, seus resultados foram compilados e divulgados, conforme se observa em FEB (2008).

\subsection{AS EVASÕES NOS ANOS LETIVOS}

A estratégia elaborada para a análise da questão, individualmente para cada ano desde 1999 a 2008, foi à montagem de alguns quadros que contenham informações voltadas para o entendimento do problema enfocado. A fim de exemplificar apresenta-se a seguir, apenas para os anos letivos de 1999, início do levantamento, e 2008, fechamento do estudo, os resultados obtidos.

No ano de 1999, o primeiro estudado, os três cursos de graduação da FEB/UNESP ofereceram 180 vagas e destas houve um total de 67 desistências. Portanto 37,2\% dos alunos convocados e matriculados neste ano desistiram do curso, conforme mostra os quadros 1 e 2 . 
Quadro 1 - Total de alunos desistentes por curso e sexo em 1999

\begin{tabular}{lcccc}
\hline \multicolumn{1}{c}{ Curso } & $\begin{array}{c}\text { Vagas } \\
\text { Oferecidas }\end{array}$ & $\begin{array}{c}\text { Desistentes } \\
\text { Masculino }\end{array}$ & $\begin{array}{c}\text { Desistentes } \\
\text { Feminino }\end{array}$ & $\begin{array}{c}\text { Total } \\
\text { Desistentes }\end{array}$ \\
Engenharia Civil & 60 & 19 & 03 & 22 \\
Engenharia Mecânica & 60 & 17 & 00 & 17 \\
Engenharia Elétrica & 60 & 26 & 02 & 28 \\
\hline Total & $\mathbf{1 8 0}$ & $\mathbf{6 2}$ & $\mathbf{0 5}$ & $\mathbf{6 7}$ \\
\hline
\end{tabular}

No quadro 2 observam-se os motivos alegados pelos alunos desistentes da vaga, quando da solicitação de cancelamento por escrito junto a Seção de Graduação.

Quadro 2 - Justificativas para o cancelamento em 1999

\begin{tabular}{lccccccccc}
\hline \multicolumn{1}{c}{ Curso } & USP & $\begin{array}{c}\text { Uni- } \\
\text { camp }\end{array}$ & $\begin{array}{c}\text { UFSCa } \\
\mathrm{r}\end{array}$ & Outra & $\begin{array}{c}\text { Outro } \\
\text { Estado }\end{array}$ & $\begin{array}{c}\text { Não Confirmou } \\
\text { Matrícula }\end{array}$ & $\begin{array}{c}\text { Não } \\
\text { Justificou }\end{array}$ & $\begin{array}{c}\text { Não se } \\
\text { Adaptou }\end{array}$ & Total \\
Eng ${ }^{\text {C Civil }}$ & 01 & 02 & 01 & 02 & 00 & 00 & 16 & 00 & 22 \\
Eng ${ }^{\text {Mec. }}$ & 02 & 02 & 00 & 03 & 00 & 01 & 09 & 00 & 17 \\
Eng'Elétrica & 02 & 00 & 00 & 02 & 02 & 05 & 16 & 01 & 28 \\
\hline Total & $\mathbf{0 5}$ & $\mathbf{0 4}$ & $\mathbf{0 1}$ & $\mathbf{0 7}$ & $\mathbf{0 2}$ & $\mathbf{0 6}$ & $\mathbf{4 1}$ & $\mathbf{0 1}$ & $\mathbf{6 7}$ \\
\hline
\end{tabular}

A fim de se obter uma análise mais detalhada sobre as cidades e regiões nas quais os alunos desistentes residiam no ato de sua desistência, montou-se o quadro 3. Embora se observe no quadro 3 uma coluna relativa ao curso de engenharia de produção que não apresenta nenhuma informação, tal situação é justificada pela inexistência do curso nesse ano, uma vez que o mesmo teve início de funcionamento apenas em 2003. 
Quadro 3 - Cidade de origem do ingressante/desistente em 1999

\begin{tabular}{|c|c|c|c|c|c|c|c|}
\hline & Cidade & $\begin{array}{l}\text { Eng }^{a} \\
\text { Civil }\end{array}$ & $\begin{array}{c}\text { Eng }^{a} \\
\text { Mecânica }\end{array}$ & $\begin{array}{c}\text { Eng }^{\mathrm{a}} \\
\text { Elétrica }\end{array}$ & $\begin{array}{c}\text { Eng }^{a} \text { de } \\
\text { Produção }\end{array}$ & TOTAL & $\%$ \\
\hline 1 & Barra Bonita & 1 & 0 & 0 & 0 & 1 & \\
\hline 1 & Bauru & 1 & 0 & 0 & 0 & 1 & \\
\hline 1 & Bocaina & 0 & 0 & 1 & 0 & 1 & \\
\hline 1 & Botucatu & 2 & 0 & 0 & 0 & 2 & \\
\hline 1 & Lençóis Paulista & 0 & 1 & 1 & 0 & 2 & 16,4 \\
\hline 1 & Lins & 0 & 0 & 1 & 0 & 1 & \\
\hline 1 & Marília & 0 & 0 & 2 & 0 & 2 & \\
\hline \multirow[t]{2}{*}{1} & Pirajui & 1 & 0 & 0 & 0 & 1 & \\
\hline & & & & & Total & 11 & \\
\hline 2 & Araraquara & 0 & 1 & 0 & 0 & 1 & \multirow{4}{*}{6,0} \\
\hline 2 & Leme & 0 & 0 & 1 & 0 & 1 & \\
\hline 2 & Ribeirão Preto & 0 & 0 & 1 & 0 & 1 & \\
\hline \multirow[t]{2}{*}{2} & São Carlos & 1 & 0 & 0 & 0 & 1 & \\
\hline & & & & & Total & 04 & \\
\hline 3 & Campinas & 2 & 1 & 5 & 0 & 8 & \multirow{6}{*}{22,4} \\
\hline 3 & Itapira & 0 & 1 & 0 & 0 & 1 & \\
\hline 3 & Itu & 1 & 0 & 0 & 0 & 1 & \\
\hline 3 & Limeira & 0 & 0 & 1 & 0 & 1 & \\
\hline 3 & Piracicaba & 1 & 1 & 1 & 0 & 3 & \\
\hline \multirow[t]{2}{*}{3} & Tietê & 1 & 0 & 0 & 0 & 1 & \\
\hline & & & & & Total & 15 & \\
\hline 4 & Atibaia & 0 & 0 & 1 & 0 & 1 & \multirow{9}{*}{34,3} \\
\hline 4 & Jundiaí & 0 & 0 & 2 & 0 & 2 & \\
\hline 4 & Santo André & 0 & 0 & 1 & 0 & 1 & \\
\hline 4 & Santos & 0 & 1 & 0 & 0 & 1 & \\
\hline 4 & São Bernardo do Campo & 1 & 0 & 0 & 0 & 1 & \\
\hline 4 & São Caetano do Sul & 0 & 0 & 1 & 0 & 1 & \\
\hline 4 & Sao Paulo & 5 & 5 & 4 & 0 & 14 & \\
\hline 4 & São Roque & 0 & 0 & 1 & 0 & 1 & \\
\hline \multirow[t]{2}{*}{4} & Taboão da Serra & 0 & 1 & 0 & 0 & 1 & \\
\hline & & & & & Total & 23 & \\
\hline 5 & Adamantina & 0 & 1 & 0 & 0 & 1 & \multirow{8}{*}{13,4} \\
\hline 5 & Avaré & 1 & 0 & 0 & 0 & 1 & \\
\hline 5 & Batatais & 0 & 1 & 0 & 0 & 1 & \\
\hline 5 & Conchas & 1 & 0 & 0 & 0 & 1 & \\
\hline 5 & Igarapava & 0 & 1 & 0 & 0 & 1 & \\
\hline 5 & Mocóca & 0 & 1 & 1 & 0 & 2 & \\
\hline 5 & Monte Alto & 1 & 0 & 0 & 0 & 1 & \\
\hline \multirow[t]{2}{*}{5} & São José do Rio Pardo & 0 & 0 & 1 & 0 & 1 & \\
\hline & & & & & Total & 09 & \\
\hline 6 & Araguaina/TO & 0 & 0 & 1 & 0 & 1 & \multirow{5}{*}{7,5} \\
\hline 6 & Campo Grande/MS & 0 & 1 & 0 & 0 & 1 & \\
\hline 6 & Cornélio Procópio/PR & 1 & 0 & 0 & 0 & 1 & \\
\hline 6 & Goiânia/GO & 1 & 0 & 0 & 0 & 1 & \\
\hline \multirow[t]{3}{*}{6} & Rio de Janeiro/RJ & 0 & 0 & 1 & 0 & 1 & \\
\hline & & & & & Total & 05 & \\
\hline & TOTAL GERAL & 22 & 17 & 28 & 00 & 67 & 100 \\
\hline
\end{tabular}


Adicionalmente para melhor entendimento do quadro 3 a distribuição por cidade foi realizada da seguinte maneira:

- Região 1: contempla as cidades próximas da cidade de Bauru num raio de $100 \mathrm{~km}$;

- Região 2: contempla as cidades próximas da cidade de São Carlos (UFSCar) num raio de $100 \mathrm{~km}$;

- Região 3: contempla as cidades próximas da cidade de Campinas (UNICAMP) num raio de $100 \mathrm{~km}$ :

- Região 4: contempla as cidades próximas da cidade de São Paulo (USP) num raio de 100 $\mathrm{km}$;

- Região 5: contempla as cidades fora das proximidades das regiões identificadas na relação acima;

- Região 6: contempla outros estados.

A seguir, de maneira semelhante à anteriormente descrita, apresentam-se os resultados da análise para o ano letivo de 2008.

No ano de 2008, último ano do estudo, das 220 vagas oferecidas 46 alunos desistiram do curso. Logo, $21 \%$ dos alunos convocados e matriculados nesse ano desistiram, conforme indicam os quadros 4 e 5.

Quadro 4 - Total de alunos desistentes por curso e sexo em 2008

\begin{tabular}{lcccc}
\hline \multicolumn{1}{c}{ Curso } & $\begin{array}{c}\text { Vagas } \\
\text { Oferecidas }\end{array}$ & $\begin{array}{c}\text { Desistentes } \\
\text { Masculino }\end{array}$ & $\begin{array}{c}\text { Desistentes } \\
\text { Feminino }\end{array}$ & $\begin{array}{c}\text { Total } \\
\text { Desistentes }\end{array}$ \\
Engenharia Civil & 60 & 07 & 02 & 09 \\
Engenharia Mecânica & 60 & 19 & 02 & 21 \\
Engenharia Elétrica & 60 & 14 & 01 & 15 \\
\hline Engenharia Produção & 40 & 01 & 00 & 01 \\
\hline Total & $\mathbf{2 2 0}$ & $\mathbf{4 1}$ & $\mathbf{0 5}$ & $\mathbf{4 6}$ \\
\hline
\end{tabular}

No quadro 5, observam-se os motivos alegados pelos alunos pela opção de desistência da vaga, quando da solicitação de cancelamento por escrito junto a Seção de Graduação.

Quadro 5 - Justificativas para o cancelamento em 2008

\begin{tabular}{|c|c|c|c|c|c|c|c|c|c|}
\hline Curso & USP & Unicamp & $\begin{array}{l}\text { UFSCa } \\
\text { r }\end{array}$ & Outra & $\begin{array}{l}\text { Outro } \\
\text { Estado }\end{array}$ & $\begin{array}{l}\text { Não Confirmou } \\
\text { Matrícula }\end{array}$ & $\begin{array}{c}\text { Não } \\
\text { Justificou }\end{array}$ & $\begin{array}{l}\text { Não se } \\
\text { Adaptou }\end{array}$ & Total \\
\hline Enga Civil & 00 & 01 & 02 & 01 & 00 & 00 & 05 & 00 & 09 \\
\hline EngāMecânica & 01 & 01 & 01 & 06 & 00 & 04 & 08 & 00 & 21 \\
\hline Eng $^{\text {a }}$ Elétrica & 01 & 02 & 00 & 02 & 00 & 02 & 08 & 00 & 15 \\
\hline Enga'Produção & 00 & 00 & 00 & 00 & 00 & 00 & 01 & 00 & 01 \\
\hline Total & 02 & 04 & 03 & 09 & 00 & 06 & 22 & 00 & 46 \\
\hline
\end{tabular}


Conforme o mesmo procedimento na elaboração do quadro 3, o quadro 6 também possui uma análise detalhada sobre as cidades e regiões nas quais os alunos desistentes residiam no ato de sua desistência.

Quadro 6 - Cidade de origem do ingressante/desistente em 2008

\begin{tabular}{|c|c|c|c|c|c|c|c|}
\hline & Cidade & $\begin{array}{l}\text { Eng }^{a} \\
\text { Civil }\end{array}$ & $\begin{array}{c}\text { Eng }^{\mathrm{a}} \\
\text { Mecânica }\end{array}$ & $\begin{array}{c}\text { Eng }^{\mathrm{a}} \\
\text { Elétrica }\end{array}$ & $\begin{array}{c}\text { Enga de }^{\text {de }} \\
\text { Produção }\end{array}$ & TOTAL & $\%$ \\
\hline 1 & Bauru & 0 & 0 & 1 & 0 & 1 & \\
\hline 1 & Botucatu & 1 & 0 & 0 & 0 & 1 & \\
\hline 1 & Jaú & 0 & 1 & 0 & 0 & 1 & 10,9 \\
\hline \multirow[t]{2}{*}{1} & Lençóis Paulista & 2 & 0 & 0 & 0 & 2 & \\
\hline & & & & & & 5 & \\
\hline 2 & Araraquara & 0 & 2 & 0 & 0 & 2 & \\
\hline 2 & Araras & 0 & 1 & 1 & 0 & 2 & \\
\hline 2 & Leme & 0 & 0 & 1 & 0 & 1 & 23,9 \\
\hline 2 & Pirassununga & 0 & 0 & 2 & 0 & 2 & \\
\hline \multirow[t]{2}{*}{2} & Ribeirão Preto & 1 & 3 & 0 & 0 & 4 & \\
\hline & & & & & & 11 & \\
\hline 3 & Campinas & 0 & 3 & 1 & 0 & 4 & \\
\hline 3 & Cordeirópolis & 0 & 1 & 0 & 0 & 1 & \\
\hline 3 & Espírito Sto do Pinhal & 0 & 0 & 1 & 0 & 1 & 19,6 \\
\hline 3 & Piracicaba & 0 & 2 & 0 & 0 & 2 & \\
\hline \multirow[t]{2}{*}{3} & Tietê & 0 & 0 & 1 & 0 & 1 & \\
\hline & & & & & & 9 & \\
\hline 4 & Jundiaí & 1 & 1 & 0 & 0 & 2 & \\
\hline 4 & Mauá & 1 & 0 & 0 & 0 & 1 & \\
\hline 4 & Ribeirão Pires & 0 & 1 & 0 & 0 & 1 & 28,3 \\
\hline 4 & São Bernardo do Cpo & 0 & 0 & 1 & 0 & 1 & \\
\hline \multirow[t]{2}{*}{4} & São Paulo & 2 & 3 & 3 & 0 & 8 & \\
\hline & & & & & & 13 & \\
\hline 5 & Caraguatatuba & 0 & 1 & 0 & 0 & 1 & \\
\hline 5 & Palmital & 0 & 0 & 1 & 0 & 1 & \\
\hline 5 & São João da Boa Vista & 0 & 1 & 1 & 0 & 2 & 13,0 \\
\hline 5 & Taubaté & 0 & 0 & 0 & 1 & 1 & \\
\hline \multirow[t]{2}{*}{5} & Tupã & 1 & 0 & 0 & 0 & 1 & \\
\hline & & & & & & 6 & \\
\hline \multirow[t]{3}{*}{6} & Goiânia/Go & 0 & 1 & 1 & 0 & 2 & 4,3 \\
\hline & & & & & & 2 & \\
\hline & TOTAL GERAL & 09 & 21 & 15 & 01 & 46 & 100 \\
\hline
\end{tabular}

\section{CONVOÇÃO DA LISTA DE CHAMADA PARA MATRÍCULA}

Seguindo o calendário da VUNESP, existem duas datas/chamadas (primeira e segunda chamadas) para que os alunos convocados efetuem suas matrículas juntos aos cursos da FEB/UNESP. Essas datas 
coincidem normalmente com as datas de outras Instituições Públicas, tais como USP, UFSCar e UNICAMP, no Estado de São Paulo.

É esperado que candidatos que irão realizar vestibulares nas universidades públicas se preparem relativamente bem para essa atividade e provavelmente devem realizar inscrições para outros vestibulares incluindo as três universidades públicas do Estado de São Paulo, bem como em outros estados. A expectativa é que os melhores vestibulandos obtenham aprovação na primeira ou segunda chamada. As listas dos candidatos aprovados da VUNESP são divulgadas em um período bem próximo as listas das outras universidades públicas. Nota-se assim no quadro 7 que a vinda dos candidatos aprovados na primeira chamada para realizar matrícula na FEB fica aquém do esperado, deixando evidente que a preferência dos futuros alunos ingressantes é por outras universidades/faculdades.

Quadro 7- Número de alunos matriculados na primeira, segunda chamada e lista adicional, conforme dados VUNESP

\begin{tabular}{|c|c|c|c|c|c|c|c|c|c|c|}
\hline \multicolumn{11}{|c|}{ Engenharia Civil } \\
\hline & 1999 & 2000 & 2001 & 2002 & 2003 & 2004 & 2005 & 2006 & 2007 & 2008 \\
\hline Convocados ( $1^{\text {a }}$ chamada) & $*$ & $*$ & $*$ & $*$ & 09 & 09 & 13 & 09 & 13 & 16 \\
\hline Lista de Espera ( $2^{\mathrm{a}}$ chamada) & * & $*$ & * & * & 36 & 36 & 33 & 33 & 27 & 28 \\
\hline Relação Adicional & $*$ & $*$ & $*$ & $*$ & 15 & 15 & 14 & 18 & 20 & 16 \\
\hline Total & $*$ & $*$ & $*$ & $*$ & 60 & 60 & 60 & 60 & 60 & 60 \\
\hline \multicolumn{11}{|c|}{ Engenharia Elétrica } \\
\hline & 1999 & 2000 & 2001 & 2002 & 2003 & 2004 & 2005 & 2006 & 2007 & 2008 \\
\hline Convocados ( $1^{\mathrm{a}}$ chamada) & $*$ & $*$ & $*$ & $*$ & 05 & 05 & 08 & 11 & 09 & 08 \\
\hline Lista de Espera ( $2^{\mathrm{a}}$ chamada) & * & $*$ & * & * & 37 & 37 & 36 & 41 & 25 & 27 \\
\hline Relação Adicional & * & $*$ & $*$ & $*$ & 18 & 18 & 16 & 08 & 26 & 25 \\
\hline Total & $*$ & $*$ & $*$ & $*$ & 60 & 60 & 60 & 60 & 60 & 60 \\
\hline \multicolumn{11}{|c|}{ Engenharia Mecânica } \\
\hline & 1999 & 2000 & 2001 & 2002 & 2003 & 2004 & 2005 & 2006 & 2007 & 2008 \\
\hline Convocados ( $1^{\mathrm{a}}$ chamada) & $*$ & $*$ & $*$ & $*$ & 09 & 09 & 05 & 07 & 05 & 02 \\
\hline Lista de Espera ( $2^{\mathrm{a}}$ chamada) & $*$ & $*$ & $*$ & $*$ & 33 & 33 & 40 & 31 & 15 & 26 \\
\hline Relação Adicional & $*$ & $*$ & $*$ & $*$ & 18 & 19 & 15 & 22 & 40 & 32 \\
\hline Total & $*$ & $*$ & $*$ & $*$ & 60 & 61 & 60 & 60 & 60 & 60 \\
\hline \multicolumn{11}{|c|}{ Engenharia de Produção } \\
\hline & 1999 & 2000 & 2001 & 2002 & 2003 & 2004 & 2005 & 2006 & 2007 & 2008 \\
\hline Convocados ( $1^{\mathrm{a}}$ chamada) & $*$ & $*$ & $*$ & $*$ & 27 & 22 & 20 & 17 & 23 & 16 \\
\hline Lista de Espera ( $2^{\mathrm{a}}$ chamada) & $*$ & $*$ & $*$ & $*$ & 11 & 16 & 17 & 16 & 9 & 17 \\
\hline Relação Adicional & $*$ & $*$ & $*$ & $*$ & 02 & 02 & 03 & 07 & 08 & 07 \\
\hline Total & $*$ & $*$ & $*$ & $*$ & 40 & 40 & 40 & 40 & 40 & 40 \\
\hline
\end{tabular}

Obs: - O Curso de Engenharia de Produção teve início no ano de 2003.

- Os demais cursos: Não encontrados dados anteriores a 2003, pois não se montavam o Processo de Vestibular. 
Do quadro 7 verifica-se que para o curso de engenharia civil a média de matrículas na primeira chamada foi de $19,2 \%, 53,6 \%$ na segunda chamada completando na lista adicional com $27,2 \%$. Para o curso de engenharia elétrica essa média resultou para a primeira chamada $12,7 \%, 56,4 \%$ na segunda chamada, complementada na lista adicional com 30,9\%. Já para o curso de engenharia mecânica a média de matrículas na primeira chamada foi de 10,3\%, 49,4\% na segunda chamada completando na lista adicional com 40,3\%.

Antes da apresentação dos resultados para o caso do curso de engenharia de produção é importante mencionar que o mesmo é oferecido somente no segundo semestre de cada ano e, portanto, não há grande concorrência entre vestibulares, uma vez que poucas IES possuem seus vestibulares no meio do ano letivo. Trata-se então de uma realidade diferente dos demais cursos na FEB/UNESP. Os valores médios de matrículas na primeira chamada, segunda chamada e relação adicional para a o curso de engenharia de produção foram, respectivamente, de 52,1\%, 35,8\% e 12,1\%.

Vale mencionar que os valores percentuais acima apresentados são na realidade um pouco menor, pois os alunos que desistiram do curso antes do início do mesmo estão incluídos nesses valores, e desta forma haveria necessidade de uma análise matemática mais específica, porém por falta de espaço no artigo, aqui não é apresentada.

\section{CONSIDERAÇÕES FINAIS}

De uma maneira global pode afirmar que a desistência escolar é um fenômeno constituído por muitas facetas e complexas. Encontram-se aspectos de caráter interno, específicos à estrutura dinâmica de cada curso ou relativos ao processo de admissão de novos alunos, bem como aspectos externos, referentes às componentes de ordem sócio/econômico/cultural.

Com base na análise do fluxo de entrada e saída dos alunos da FEB/UNESP e dos motivos para as saídas descritos pelos alunos evadidos, pôde-se observar que este tipo de desistência é em muitos casos consequência de aspectos intrínsecos a região onde residem os pais dos mesmos, normalmente mais próximos a outras faculdades ou universidades. Em outros casos, o aluno pode ter optado por outra universidade preferencial ou curso de primeira opção, uma vez que o curso escolhido na FEB/UNESP foi segunda ou terceira opção. Nesta condição se o mesmo se encontra em lista de espera em outra universidade e for convocado para matrícula com certeza sua saída é inevitável.

Foram computados 591 alunos desistentes no período estudado de forma que percentualmente foi possível constatar os seguintes resultados: 
- 43,6\% dos ex-alunos (258), não justificaram o motivo de seu desligamento;

- 16,0\% (94), declararam estar ingressando em outra universidade;

- 11,7\% (69), abandonaram o curso sem comunicar a FEB/UNESP;

- 9,4\% (56), optaram pela UNICAMP;

- 9,3\% (55), optaram pela UFSCar;

- 7,1\% (42), optaram pela USP;

- 1,5\% (09), declararam que não se adaptaram ao curso;

- 1,4\% (08), declararam estar optando por universidades de outros estados.

Também foi possível observar que dos alunos desistentes apenas $8,47 \%$ alunos eram da cidade de Bauru ou região. A grande maioria dos alunos era da região da cidade de São Paulo totalizando 34,06\%, seguido da região da cidade de Campinas com 19,12\%. Na seqüencia resultou a região da cidade São Carlos com $16,41 \%$, para as regiões distantes das anteriormente citadas $16,07 \%$ e finalmente 5,92\% dos desistentes eram de outros estados.

Os resultados obtidos demonstraram que é possível através do emprego de metodologias relativamente simples detectarem os possíveis motivos que levam alguns alunos ingressantes a desistirem de seu curso. Atualmente novos procedimentos foram incorporados na abordagem do aluno desistente, onde foi elaborado um formulário próprio com questões direcionadas ao aspecto saída do curso e solicitado ao aluno o seu preenchimento.

Desta pode-se gradativamente aprimorar o estudo específico relacionado com o problema abordado no artigo e sanar possíveis falhas existentes no processo de seleção e recepção dos alunos ingressantes. 


\section{REFERÊNCIAS BIBLIOGRÁFICAS}

FACULDADE DE ENGENHARIA DE BAURU-FEB. Seção de Graduação. Relatório de alunos ingressantes que desistiram do curso no início do semestre em período que ainda havia tempo para convocar outro em seu lugar. Bauru, 2008.

FUNDAÇÃO PARA O VESTIBULAR DA UNIVERSIDADE ESTADUAL PAULISTA - VUNESP. São Paulo. 2008. Disponível em: <http://www.vunesp.com.br>. Acesso em: jan. 2008.

GOOGLE Maps Brasil. Disponível em: <http://maps.google.com.br>. Acesso em: março 2008.

RELATÓRIO DE CURSOS DE GRADUAÇAO PRESENCIAIS - SIEdSUP/INEP. Seção de Graduação da FEB/UNESP, 2002 a 2005. 


\section{Capítulo 3}

doi $10.37423 / 210704446$

CONCEITO E APLICAÇÕES DA INTERNET DAS COISAS: A TECNOLOGIA DA GLOBALIZAÇÃO.

ANTONIO JOSÉ DIAS SILVA

GERALDO MOTTA AZEVEDO JUNIOR

WALLACE NUNES DA SILVA MARQUES

\section{AURELIANO FERNANDES}

Centro Universitário Augusto Motta UNISUAM

Centro Universitário Augusto Motta . UNISUAM

Centro Universitário Augusto Motta UNISUAM

Centro Universitário Augusto Motta . UNISUAM 
Resumo: No atual cenário tecnológico há uma incessante busca pelo aprimoramento das tecnologias utilizadas, este tem sido desenvolvido ligado intimamente à inovação, como uma possível solução surgiu um novo conceito para poder interligar nossas tecnologias ao futuro, uma forma de centralizar o controle e assim aprimorar aspectos do seu funcionamento, o conceito da Internet das Coisas (Internet of Things -IoT) surgiu como um meio de facilitar o controle de informações, mas suas infinitas possibilidades de aplicações demonstram o seu potencial, desde automatização de tarefas para o conforto dos usuários até a análise e transmissão de dados detalhados sobre equipamentos industriais, estes podendo ser realizados a distância a partir de qualquer lugar do mundo apenas com o acesso a internet. Mediante este cenário e vislumbrando as possibilidades de aplicações este trabalho visa apresentar algumas das muitas aplicações já existentes para a IoT, facilitando assim a sua disseminação nos meios acadêmicos para possibilitar o desenvolvimento e aplicações desta tecnologia tão recente.

Palavras-chave: Internet das Coisas. Controle de informações. Automatização de tarefas. 


\section{INTRODUÇÃO}

A Internet das Coisas ou Internet de Tudo, como também é chamada, como o próprio nome sugere é uma tecnologia que tem como princípio a conexão e comunicação entre diversos tipos de equipamentos com diferentes tipos de tecnologia, a partir do princípio da conexão entre computadores pela rede mundial da internet, idealizou-se a ideia de conectar objetos utilizados no dia-a-dia com a mesma, podendo assim promover qualidade de vida para o homem moderno (SILVA, Alan Mônico da, et al, 2015).

Informações transmitidas a partir de dados são a base de muitas tecnologias atuais e com a loT não seria diferente, seu princípio de funcionamento tem como base a leitura, o envio e o recebimento de dados constantes e a adequação do funcionamento mediante a estas. Os pilares desses dados são os sensores, pois através deles podemos obter informações provenientes dos mais diversos tipos no contexto onde estão inseridos (MELO, André, 2017).

Os benefícios provenientes da tecnologia loT são muitos, entre eles o econômico, soluções inteligentes de transporte controladas por análises em tempo real podem melhorar consideravelmente o tráfego e consequentemente a redução do consumo de combustível, assim como um controle eficiente do cronograma de reparos, evitando diversos tipos de acidentes. Sistemas complexos orientados por meio de dados estão sendo implementados para tarefas como monitoramentos, sendo assim implementados na infraestruturas de "cidades inteligentes" (SAS, The power to know, 2019).

\section{DESENVOLVIMENTO}

A fim de compreendermos melhor a tecnologia faremos um breve desenvolvimento sobre o surgimento da internet e do conceito de loT, assim seguiremos com a descrição e o detalhamento das tecnologias construídas com base no sistema da mesma atualmente.

\subsection{SURGIMENTO E CONCEITO DA INTERNET}

A internet é uma rede de computadores espalhados por todo o mundo que comutam dados e informações entre si, por meio de um protocolo em comum (Houaiss, 2001).

A primeira aplicação do sistema de internet de que se tem notícia data de 1969, inicialmente denominada de Arpanet teve como finalidade interligar dois laboratórios de pesquisa nos Estados Unidos para a comunicação entre eles. Como uma iniciativa militar visava manter a comunicação entre os laboratórios de pesquisa mesmo sob possíveis bombardeios durante o período da Guerra Fria, nas 
décadas seguintes o uso da até então Arpanet,se tornou frequente nos meios acadêmicos no país, conforme esta tecnologia foi se expandindo para diversos países, sob influência e aprimoramentos provenientes deste meio acadêmico passou a ser utilizado o termo internet para se referir a rede, tal como o conhecemos até os dias atuais. Somente no final da década de 90 foi liberado o uso comercial, o primeiro passo para o início da popularização da internet, pois se deu início ao surgimento de diversas empresas de provedores, o Laboratório Europeu de Física dePartículas (Cern), desenvolveu a chamada World Wide Web, com a finalidade de disponibilizar informações a qualquer usuário da internet que estivesse interessado (SILVA, Leonardo Werner, 2001).

\subsection{SURGIMENTO E CONCEITO DE IOT}

Internet das Coisas ou loT (Internet of Things), é o termo utilizado para identificar tecnologias que possibilitam a interligação direta entre dispositivos, trocando informações entre si, possibilitando a tomada de decisões de forma autônoma, cumprindo seu objetivo principal de facilitar a vida do seu usuário. O termo foi utilizado pela primeira vez em 1999 através do pesquisador britânico, Kevin Ashton, do Instituto de Tecnologia de Massachusetts, para um etiquetador eletrônico, com o intuito de facilitar a logística desenvolveu um o equipamento que através de radiofrequência identificava os produtos de uma linha de produção. Mediante os resultados obtidos pode-se observar a possibilidade de interligar dispositivos para trabalhos de forma independente de operadores, apesar de ter sido conceituado após este ocorrido a ideia em si já vinha sendo utilizada em pequenas atividades, como a troca de informações com o sistema bancário através de um caixa eletrônico, este por sua vez poderia realizar funções como liberação de dinheiro ou extratos, tudo de forma autônoma (SILVA, Alan Mônico da, et al, 2015).

Dessa forma podemos identificar e conceituar como Internet das Coisas todo tipo de tecnologia que funcione com base na troca de informações e dados através de uma rede, de forma a cumprir sua finalidade sem a necessidade de interferência humana, ou seja, faça a leitura dos dados e tome decisões pré-programadas de forma autônoma. 


\subsection{APLICAÇÕES DE IOT - AUTOMAÇÃO RESIDENCIAL}

Conceitualmente a automatização de espaços como habitações é um conjunto de serviços como os de segurança, comunicação, gestão de energia e principalmente conforto, todos interligados e gerenciados por um sistema tecnológico integrado. Para este contexto residencial não é incomum observarmos o termo "domótica", no entanto um termo mais comumente encontrado é o "home automation". Esta automatização e controle em residências é pré-estabelecida pelo usuário com suas preferências no sistema utilizado, este por sua vez é responsável por manter todos os equipamentos em interação de dados, sendo capazes de seguir as intruções de acordo com os dados obtidos em cada uma das situações, entre os inúmeros benefícios possíveis podemos enfatizar o aumento na qualidade de vida com o bem estar e segurança proporcionados e a racionalização eficiente do consumo de energia elétrica (MURATORI, José Roberto; BÓ, Paulo Henrique Dal, 2011).

Entre a integração dos sistemas tecnológicos residenciais, o sistema controla sistemas de instalação elétrica que compreendem iluminação, cortinas, controle de irrigação e a gestão da energia consumida por exemplo, nos sistemas de segurança o controle integra alarmes desde intrusão a detecção de fumaça e gases, com circuitos de TV e controles de acesso como exemplo, aprimorando assim a segurança em diferentes aspectos de forma independente. A eficiência aliada com a sustentabilidade tornam soluções como essa uma opção tecnológica cada vez mais necessária para a vida do homem moderno.

Abaixo na figura 1 podemos observar que já no início do século houve um grande crescimento na instalação de sistemas de controle e automação em residências construídas, um reflexo dos resultados positivos apresentados pelos primeiros sistemas.

Figura 1 - Evolução da adoção de tecnologias de automação

\begin{tabular}{|c|c|c|c|c|c|}
\hline Fecinatogla & 2003 & 2004 & 2005 & 2006 & 20750 \\
\hline Cabeamento estruturado & $42 \%$ & $61 \%$ & $49 \%$ & $53 \%$ & $80 \%$ \\
\hline Monitoramento de segurança & $18 \%$ & $28 \%$ & $29 \%$ & $32 \%$ & $81 \%$ \\
\hline Multiroom audio & $9 \%$ & $12 \%$ & $15 \%$ & $16 \%$ & $86 \%$ \\
\hline Home Theatur & $9 \%$ & $8 \%$ & $11 \%$ & $12 \%$ & $86 \%$ \\
\hline Controle de iluminaçào & $1 \%$ & $2 \%$ & $6 \%$ & $8 \%$ & $75 \%$ \\
\hline Automaçào integrada & 0 & $2 \%$ & $6 \%$ & $6 \%$ & $70 \%$ \\
\hline Gerenciamento de energia & $1 \%$ & $5 \%$ & $11 \%$ & $11 \%$ & $62 \%$ \\
\hline
\end{tabular}

Fonte: Adaptado de (MURATORI, José Roberto; BÓ, Paulo Henrique Dal, 2011)

A idéia da automação residencial se desenvolveu de tal forma que atualmente encontramos no mercado diversas marcas de produtos para controle de automação via Wi-Fi (Wireless Fidelity), ou 
seja, sistemas para controlar diversas "funções" da casa sem a necessidade de conexão por fios, os equipamentos são acompanhados de instruções de forma que o próprio comprador pode instalar e configurá-los, e todo o acesso é realizado via smartphone por aplicativos que o próprio fabricante disponibiliza, esta tecnologia por sua vez é mais utilizada para controle de sistemas de iluminação, acionamento de ar condicionados, controle de portões, sistemas de irrigação, sistemas que necessitam apenas de ligar e desligar.

Os sistemas de controle mais complexos contam com sensores dos mais diversos instalados em locais estratégicos nos cômodos das residências, oferecendo a todo momento dados precisos sobre as condições daquele ambiente, uma central com inteligência artificial fica responsável pelo controle de tudo o que acontece baseado nas preferências do usuário, que também são "aprendidas" pela central conforme o comportamento dos usuários (Automatic House, 2018).

\subsection{APLICAÇÕES DE IOT - CIDADES INTELIGENTES}

“Cidades inteligentes são compostas por processos sensíveis ao contexto, lidando com um gigantesco volume de dados, redes em nuvem e comunicação entre diversos objetos" (LEMOS, André, p.48, 2013).

A criação das chamadas "Cidades Inteligentes" está prevista na agenda mundial no cronograma para as próximas décadas, obtendo com ela conceitos como a integração de pessoas, mobilidade, governo e meio ambiente, e para tal é necessário o "Big data", uma tecnologia capaz de realizar a análise e a interpretação de dados de grande variedade em grandes volumes (Estúdio ABC, 2013).

As cidades inteligentes são uma versão maior e mais complexa de um sistema de automação residencial, partem do mesmo principio básico de captura e fluxo de informações para tomar decisões. Por exemplo para entender melhor o trânsito de uma cidade, e o comportamento dos passageiros do transporte público através da coleta de dados de eficiência, na cidade do Rio de Janeiro as primeiras etapas para o processo de implementação de um sistema de cidade inteligente foram adotadas com a criação do Centro de Operações do Rio de Janeiro (COR), responsável por monitorar dados de cerca de 30 órgãos públicos, como CET, Guarda Municipal e Light, para apontar locais que requerem qualquer tipo de apoio através de um mapeamento, desde um farol quebrado causando lentidão ou uma árvore caída trazendo riscos à rua (Estúdio ABC, 2013).

Abaixo na figura 2 podemos observar a foto da construção da cidade SmartCity Laguna em andamento. 


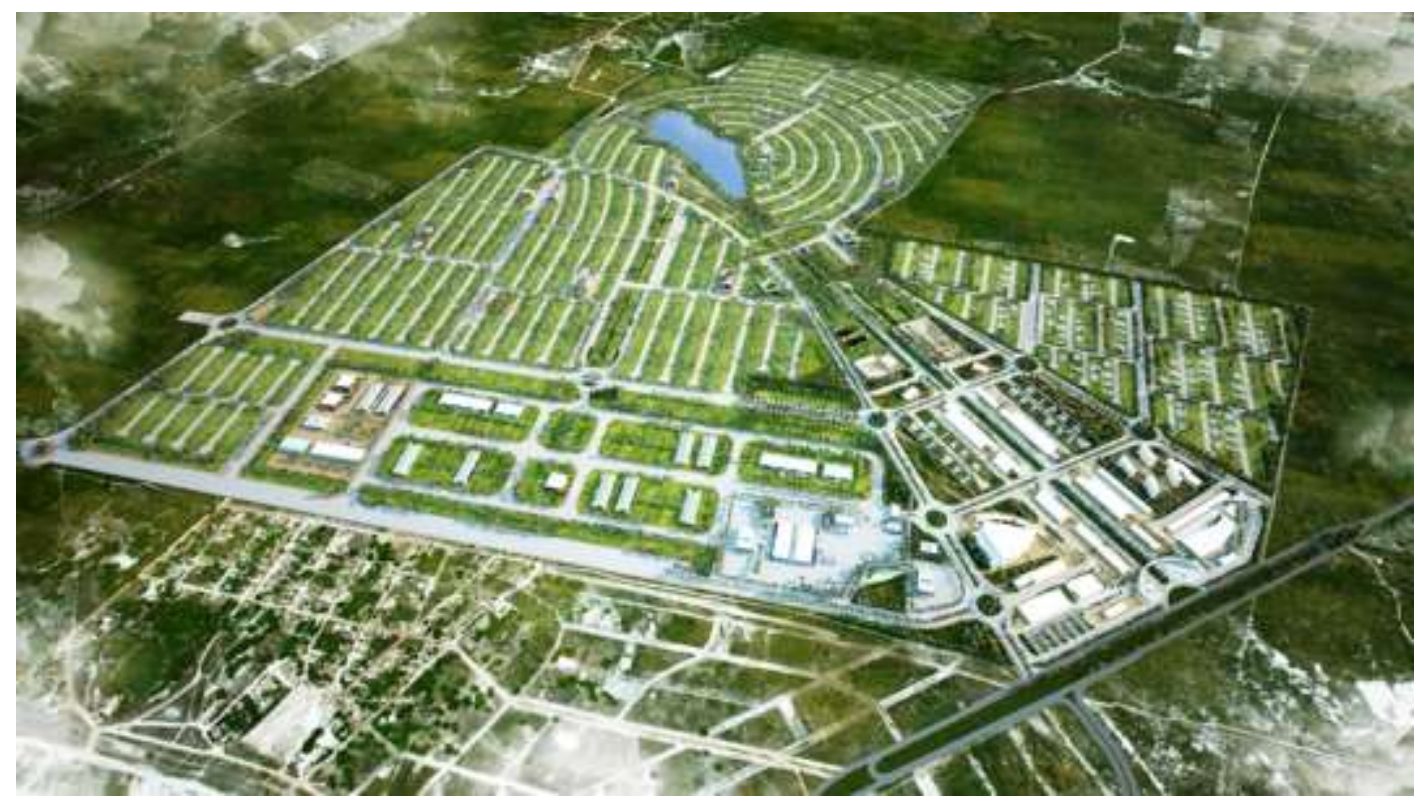

Fonte: https://smartcitylaguna.com.br/wp-content/uploads/2017/12/RELEASE-01.jpg

A primeira cidade inteligente social do mundo está sendo construída no Brasil, no município de São Gonçalo do Amarante, no Ceará, a SmartCity Laguna conta com a seleção de produtos e conceitos inteligentes disponíveis no mundo, em uma área de 330 hectares projetada para cerca de 25.000 habitantes, a implementação do conjunto tecnologias na cidade proporcionará um planejamento urbano sustentável, possibilitando o uso responsável dos recursos e promovendo o consumo consciente de energia e água, reduzindo os níveis de poluição e melhorando a qualidade dos moradores com os serviços prestados (Estúdio ABC, 2013).

\subsection{APLICAÇÕES DE IOT - INDÚSTRIA 4.0}

O termo indústria 4.0 é comumente encontrado na Europa, visto que seu surgimento ocorreu na Alemanha, o mesmo pode também ser referido como "Fábrica Inteligente" ou "Internet Industrial", indicando claramente a sua aplicação como um novo sistema de organização e controle da cadeia de processos industriais, tendo o controle com base nas leituras de dados em tempo real dos equipamentos interconectados na "nuvem", em suma, trata-se da aplicação à indústria do modelo de IoT (Internet of Things), algo que possibilitou uma mudança tão grande no processo, podendo ser definido como a 4a revolução industrial, ocasionada pelo avanço tecnológico digital, particularmente, da ciência da computação e do software (ROMÁN, José Luis Del Val, 2018). 
A indústria 4.0 está apoiada em três pilares, estes oferecem a base necessária para a nova estrutura de funcionamento da indústria, são eles a loT (Internet of Things), Big Data Analytics e a Segurança, está última ainda não foi apresentada até agora. Pela loT temos a conexão em rede de equipamentos, ambientes, veículos e máquinas auxiliados por equipamentos eletrônicos responsáveis pela captação e troca de dados. Com a Big Data são possíveis captação, análise e câmbio de grandes volumes de dados simultaneamente, a tecnologia teve seu conceito de funcionamento nomeado em $6 C^{\prime}$ 's, são eles, Conexão (À rede de computadores), Cloud (Nuvem, acesso em qualquer lugar), Cyber (Modelo e memória), Conteúdo (Dados obtidos), Comunidade (Compartilhamento dos dados) e Customização (Personalização). Por último e com grande relevância temos a segurança, que basicamente é o responsável pelo sucesso de todo o processo, mantendo a robustez do sistema, evitando falhas na transmissão dos dados e na comunicação entre máquinas, qualquer "engasgo" no sistema pode ocasionar grandes transtornos na linha de produção, juntamente com a proteção do know-how da empresa, nos arquivos de controle dos processos (SILVEIRA, Cristiano Bertulucci, 2017).

O quesito segurança vem intimamente ligado em alguns pontos à privacidade, a segurança pode ser definida como um conjunto de mecanismos utilizados para preservar o bem estar social, porém gerase um conflito a partir do momento que soluções motivadas para um bem estar social vão contra a privacidade dos indivíduos, um dos bens mais valiosos para empresas são os dados coletados, provenientes das mais diversas fontes, seu conteúdo pode ser reaproveitado e explorado de incontáveis maneiras, no entanto o seu uso traz ameaças à privacidade que devem ser consideradas, como identificação e rastreamento, para manter a identificação do usuário em segurança a maioria dos dados são armazenados de forma anônima, pois muitas ameaças são facilitadas pela identificação principalmente se tratando de loT (Internet of Things), através dos dados auxiliares, como exemplo temos a utilização de sistemas de segurança para integração de sistemas de detecção facial, ou sistemas de reconhecimento por voz, para preservação dos dados existem os sistemas de criptografia, mas se tratando de loT (Internet of Things), tornam sua utilização bem mais complexa (SILVA, Camila Dias Oliveira da, 2018).

\section{AGRADECIMENTOS}

Nesta seção poderão ser incluídos reconhecimentos de apoios recebidos de pessoas físicas e instituições. Esta seção deve estar localizada entre o fim do corpo do texto e a lista de referências. Digite somente "Agradecimentos" em negrito e itálico e digite o texto na linha seguinte. 


\section{REFERÊNCIAS}

Automatic House. Automação residencial como auxilio as necessidades do lar. Disponível em: https://www.automatichouse.com.br/automacao-residencial/o-que-e-automacao-residencial. 2018. Acesso em: 26 abr. 2019.

Estúdio ABC. Porque as cidades inteligentes precisam do big data. Revista Exame. São Paulo, 2013. Disponível em : https://exame.abril.com.br/tecnologia/por-que-as-cidades-inteligentes-precisam-dobig-data/. Acesso em: 25 abr. 2019.

HOUAISS, Antônio. Dicionário da Língua Portuguesa. Rio de Janeiro. Ed. Objetiva, 2001.

Lemos, André. De que forma as novas tecnologias - como a computação em nuvem, o Big Data e a Internet das Coisas - podem melhorar a condição de vida nos espaços urbanos?. Revista GV Executivo. São Paulo, v. 12, n. 2, 2013.

MELO, André. Sensores, atuadores, dispositivos: É por aí que começa a internet das coisas. Disponível em: http://innovationinsider.com.br/sensores-atuadores-dispositivos-e-por-ai-que-comeca-internetdas-coisas/. 2017. Acesso em: 16 abr. 2019.

MURATORI, José Roberto; BÓ, Paulo Henrique Dal. Automação residencial: histórico, definições e conceitos. Revista O Setor Elétrico, São Paulo, ed. 62, 2011.

ROMÁN, José Luis Del Val. Industria 4.0: la transformación digital de la indústria. Facultad de Ingeniería de La Universidad de Deusto.10p.2018.

SAS The Power to know. Internet das Coisas (IoT) O que é e qual sua importância?. Disponível em: https://www.sas.com/pt_br/insights/big-data/internet-das-coisas.html. Acesso em: 24 abr. 2019.

SILVA, Alan Mônico da, et al. Criatividade e Inovação: Internet das Coisas (loT - Internet of Things). 2015.

SILVA, Camila Dias Oliveira da. O Desafio da Segurança das Informações Digitais na Internet das Coisas. Revista Científica Multidisciplinar Núcleo do Conhecimento. Ano 03, Ed. 05, Vol. 04, pp. 137-157, Maio de 2018. ISSN:2448-0959

SILVA, Leonardo Werner. Internet foi criada em 1969 com o nome de "Arpanet" nos EUA. Folha de São Paulo, São Paulo, 12 ago. 2001. Caderno cotidiano. Disponível em:

https://www1.folha.uol.com.br/folha/cotidiano/ult95u34809.shtml. Acesso em: 23 abr. 2019.

SILVEIRA, Cristiano Bertulucci. O que é a indústria 4.0 e como ela vai impactar o mundo. Disponível em: https://www.citisystems.com.br/industria-4-0/. 2017. Acesso em: 26 abr. 2019.

SmartCity é. Você conhece a primeira cidade inteligente social do mundo em construção no Ceará?. Disponível em:

https://engenhariae.com.br/smart-city-e/voce-conhece-a-primeira-cidade-inteligente-social-domundo-em-construcao-no-ceara. 2019. Acesso em: 25 abr. 2019. 


\section{Capítulo 4}

doi) $10.37423 / 210704448$

FERRAMENTA EDUCACIONAL DESENVOLVIDA NO SCILAB PARA AUXÍLIO NA DISCIPLINA DE SISTEMAS DE CONTROLE DINÂMICO

\section{Lucivando Ribeiro de Araújo}

\section{Vandillberto Pereira Pinto}

Rômulo Nunes de Garvalho Almeida

\section{Muriel Martins Aragão}

Universidade Federal do Ceará Campus Sobral

Universidade Federal do Ceará Campus Sobral

Universidade Federal do Ceará Campus Sobral

UniversidadefFederal do Ceará Campus Sobral 
Resumo - A engenharia de controle apresenta ferramentas para análise de sistemas reais com o intuito de mostrar as características de um sistema em estudo como também compreender cada etapa de um processo e projetar algum dispositivo específico para controlá-lo. Ela possui diversas abordagens que possibilitam adaptar o estudo a cada caso embasado em teoremas e demonstrações ligados a fundamentos matemáticos. Entretanto, com o aumento da complexidade dos sistemas de controle principalmente nas indústrias objetivando aumentar a produtividade e melhorar o desempenho de um dispositivo ou até mesmo do sistema, passa a ser necessária uma análise precisa e rápida a respeito de tal processo. Para facilitar e melhorar o rendimento nesta etapa foi desenvolvido uma ferramenta gráfica que permite utilizar os conceitos de engenharia de controle para agilizar a análise através de uma interface simples e acessivel para os estudantes de engenharia.

Palavras-Chave: Análise de Sistema, scilab, ferramenta gráfica, interface, sistemas de controle 


\section{INTRODUÇÃO}

No geral, a área de controle de sistemas dinâmicos trata da análise, modelagem, simulação e controle de sistemas que possam ser descritas matematicamente, sendo multidisciplinar e presente nos cursos de engenharia. Ela possibilita a realização de avanços na tecnologia atual e desenvolvimento de novas ferramentas aplicadas a processos físicos (mecânicos, elétricos, químicos etc.). Nela há várias técnicas que possibilitam compreender de maneira mais objetiva o comportamento dos processos, mas tornase necessário o conhecimento prévio de matemática superior e conhecimento físico do sistema a controlar para obtenção do modelo matemático. Na modelagem do sistema há a possibilidade da realização do controle com uma ou mais variáveis de entrada e saída. Após a modelagem busca-se encontrar soluções que possam melhorar o rendimento de algum componente ou até mesmo do próprio sistema.

Atualmente há uma quantidade considerável de softwares que auxiliam nas análises de sistemas permitindo um melhor entendimento sobre as características do comportamento do processo em estudo. Dentre estes o SCILAB se destaca pela sua versatilidade e numerosos recursos presentes para análise de sistemas, simulação e programação além de ser uma ferramenta gratuita. Neste trabalho foi utilizado o SCILAB para criação de uma ferramenta que auxilie na análise de sistemas mostrando as características existentes no sistema.

\section{SOBRE O SOFTWARE SCILAB}

O programa SCILAB (ScientificLaboratory) é um programa que permite o desenvolvimento e implementação de algoritmos numéricos nas mais diversas áreas voltadas para aplicações científicas e engenharia. Foi desenvolvido pelos pesquisadores do INRIA (InstitutNational de RechercheenInformatiqueetenAutomatique) e do ENPC( ÉcoleNationaledesPonts et Chaussées) com codificação livre e distribuição gratuita através da internet(http://www.scilab.org) para diversas plataformas como Linux e Windows. Este programa possui recursos de programação similares ao MATLAB possibilitando realizar desde cálculos simples a análise de sistemas mais complexos com o atrativo de ser gratuito sendo assim vantajoso em comparação a este por ser um software comercial e pago.

É possível instalar mais recursos( similares ao toolboxes do MATLAB) no SCILAB caso necessário for a utilização de ferramentas não presentes na versão instalada no computador do usuário. Para isso basta ter acesso a internet e, através de o comando atomsInstall ('nome_do_aplicativo'), digitado no 
prompt do SCILAB esperar o download e instalação do aplicativo desejado. Dentre estes recursos extras foi utilizado o guibuilder fornecido gratuitamente no site da atoms (https://atoms.scilab.org), é um ambiente separado dentro do próprio programa que permite a criação de interfaces gráficas para interação mais intuitiva entre um programa e o usuário.

Neste ambiente foi construída uma interface gráfica para estudo e análise de sistemas de controle que permita explorar e compreender de maneira mais eficiente o comportamento de uma planta generalizada de um sistema.

\section{VANTAGENS DA UTILIZAÇÃO DE SOFTWARES DE SIMULAÇÃO}

O uso destes programas na área de controle propicia o entendimento prévio a respeito das características existentes no sistema em questão, ele permite a análise do comportamento da planta facilitando a tomada de decisões como, entre outras coisas, acrescentar ou retirar algum componente (como um controlador ou compensador) do sistema, verificar a estabilidade do mesmo. As ferramentas interativas virtuais cada vez mais vêm sendo desenvolvidas com a intenção de dar suporte e auxiliar os estudantes no aprendizado de conceitos e princípios sobre os diversos temas científicos (PASSOS apud NASCIMENTO, 2007, p.2). As interfaces gráficas utilizadas atualmente na maioria das aplicaçõestornamo software mais atraente, mais fácil de aprender e mais fácil de utilizar.Para o desenvolvimento destas aplicações, os projetistas utilizam uma série de diretrizes que são essenciais para a criação de um software amigável (PAMBOUKIAN, p.2 e p.3).

Com esse auxilio o tempo de análise de um dado processo pode então ser diminuído e a compreensão pode ser melhorada aumentando assim o desempenho das pessoas envolvidas nesses estudos. BIACHINI(2007) acrescenta que o fato de se trabalhar com o uso de ferramentas de softwares buscando simular situações reais, discutindo na estruturação do modelo a própria realidade em si leva a romper com o isolamento da disciplina e amplia as possibilidades de compreensão e reflexão. É necessário demonstrar como se dá a articulação teoria-prática no processo de organização dos conhecimentos. Não se trata de uma aplicação de conhecimentos teóricos à realidade a ser defrontada pelo profissional. O aluno deverá compreender a forma indissociada e contínua do movimento da relação teoria e prática(NETO,2011,p.4).

Em indústrias esse tipo de ferramenta pode ser bastante útil para aumentar a produtividade de um processo permitindo um melhor planejamento, com as simulações é possível enxergar cenários futuros de uma produção com gastos menores e aproveitamento melhor de matéria prima etc.O uso 
de softwares para criação, análise e simulação de modelos matemáticos se encontra presente nos ambientes de trabalho de forma cada vez mais intensa e generalizada diante da forte presença dos recursos computacionais que a cada dia se tornam mais poderosos em termos de capacidade de processamento e maiores recursos de memória (MATSUMOTO apud BIACHINI, 2007,p.2).O uso de simulação e modelagem propicia o desenvolvimento de uma visão sistêmica, fortalecendo a prática de pensar de forma estratégica, instigando o trabalho em equipe com reflexos no compartilhamento de conhecimentos e da aprendizagem em grupo(BELTHOT apud BIACHINI, 2007,p.2).

\section{DO QUE TRATA A FERRAMENTA}

Segundo OGATA(2010) uma planta seria qualquer objeto físico( um forno, um reator químico, uma espaçonave etc.) a ser controlado, esse objeto tem o objetivo de realizar determinada operação. Ele é descrito matematicamente por uma função transferência que relaciona a saída com a entrada. Essa planta se encontra em um sistema que é definido como uma interconexão de componentes e dispositivos para um fim desejado(DORF, 1998). O sistema pode ser malha aberta (sem retroação ou realimentação) ou malha fechada (com retroação ou realimentação). Essa realimentação serve para comparar o sinal de saída com a entrada de referência para diminuir ao máximo os erros produzidos usando a diferença entre os dois como meio de controle. De acordo com NISE (2002) Um sistema de controle é composto de subsistemas e processos objetivando, de acordo com a entrada fornecida, obter uma saída específica com desempenho desejado.

Na ferramenta criada no ambiente guibuilder do SCILAB é possível entrar com a função transferência da planta a ser analisada, aplicar um sinal degrau, impulso ou rampa nela visualizando os gráficos gerados. Pode-se visualizar o gráfico do lugar das raízes, diagrama de Nyquist, Bode, como também o diagrama de pólos e zeros da função transferência. O diagrama de pólos e zeros mostra o posicionamento dos pólos e zeros no plano complexo permitindo verificar a estabilidade do sistema onde para instabilidade basta ter pelo menos um pólo no semi-plano direito, caso os pólos estejam no semi-plano esquerdo o sistema é estável. O lugar das raízes permite estudar a evolução das raízes de uma equação, quando um parâmetro é variado continuamente possibilitando a determinação deste parâmetro de tal forma que o sistema atinja o comportamento dinâmico desejado (EDVALDO \&MARCELO,2010).

Diagrama de bode apresenta dois gráficos, um do logaritmo do modulo da função transferência em decibel o outro do ângulo de fase em graus, ambos em função da freqüência em escala logarítmica 
(OGATA, 2010). Serve para análise e projeto de sistemas de controle onde o cruzamento de fase e de ganho, margem de ganho e de fase são mais facilmente encontrados do que no diagrama de Nyquist (KUO, 1996), sendo úteis principalmente para estudo de estabilidade de sistemas com função transferência de fase mínima( pelo menos um pólo ou zero no semiplano direito). Diagrama de Nyquist permite investigar tanto a estabilidade absoluta quanto a relativa através do critério da estabilidade de Nyquist de sistemas a malha fechada a partir do conhecimento de suas características de resposta de freqüência a malha aberta (OGATA, 2010).

Pode-se também adicionar um controlador e variar os ganhos proporcional (Kp), integral (Ki) e derivativo $(\mathrm{Kd})$ para verificar suas influências no comportamento do sistema.

\section{DESCRIÇÃO DA FERRAENTA E FUNCIONAMENTO}

Na figura 01 mostra a ferramenta desenvolvida no ambiente guibuilder do SCILAB. Na parte superior desta figura há um desenho que mostra a forma do sistema analisado, neleo sistema está em malha aberta. Na parte logo abaixo encontramos dois painéis:O “G(s)" e o "Controlador Gc(s)". No G(s) temos os campos Numerador e Denominador em que sãoinseridosas equações correspondentes ao numerador e denominador respectivos da função transferência da planta.

A função transferência abaixo será usada para exemplificar a forma de como preencher e gerar os gráficos

$$
G(s)=\frac{1}{s^{2}+3 \cdot s+1}
$$




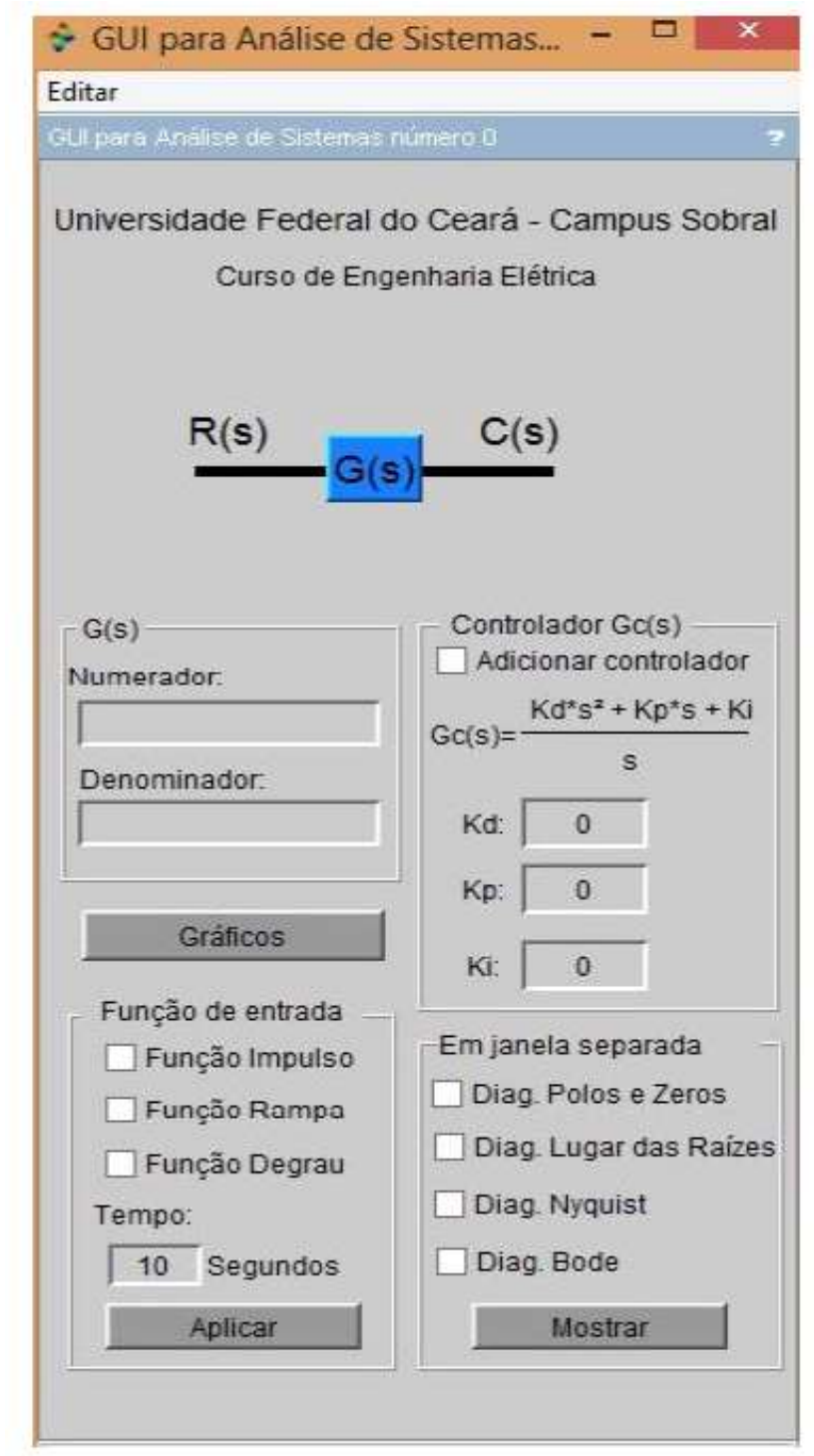

Figura 01 - Interface para análise de sistemas de controle

Algumas observações devem ser levadas em consideração na hora de utilizar a ferramenta:

A função de transferência deve ser usada com a letra „s " em minúsculo como variável;

Ao entrar com a função transferência nos campos numerador e denominador e apertar o botão gráficos ou qualquer outro botão, o SCILAB não reconhece de imediato que estes campos estão preenchidos. Para resolver este problema basta apertar novamente o botão que o software passa a reconhecer os dados;

Ao alterar os dados de entrada e apertar qualquer botão o SCILAB não atualiza imediatamente podendo apresentar gráficos da função de transferência anterior. Como anteriormente dito, basta apertar novamente o botão que ele mostra os gráficos dos dados atuais; 
Função de transferência cujo denominador seja uma função do tipo $s^{2 n} \pm s^{n} \pm a$ ou a equação do denominador sem um ou dois termos desta, em que $a$ é um número

Qualquer e $n$ um número par, apresentará problemas para mostrar o diagrama de Nyquist. Este problema é da própria programação do SCILAB e não da ferramenta desenvolvida.

Usando a fórmula (1), a forma de preencher é mostrada na figura 02:

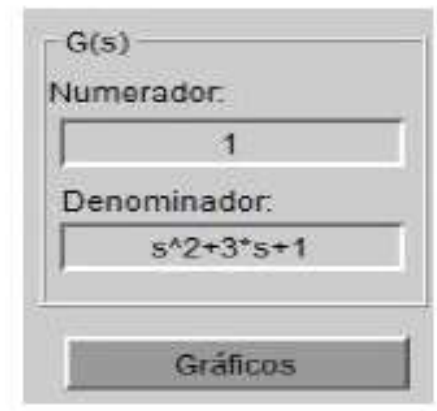

Figura 02 - Campos preenchidos com a função transferência de exemplo

Logo abaixo encontramos o botão Gráficos que, ao ser pressionado, exibe os diagramas de Pólos e Zeros, Lugar da Raízes, Bode e Nyquist da função transferência do sistema em um janela separada da interface sendo apresentada na figura 03.

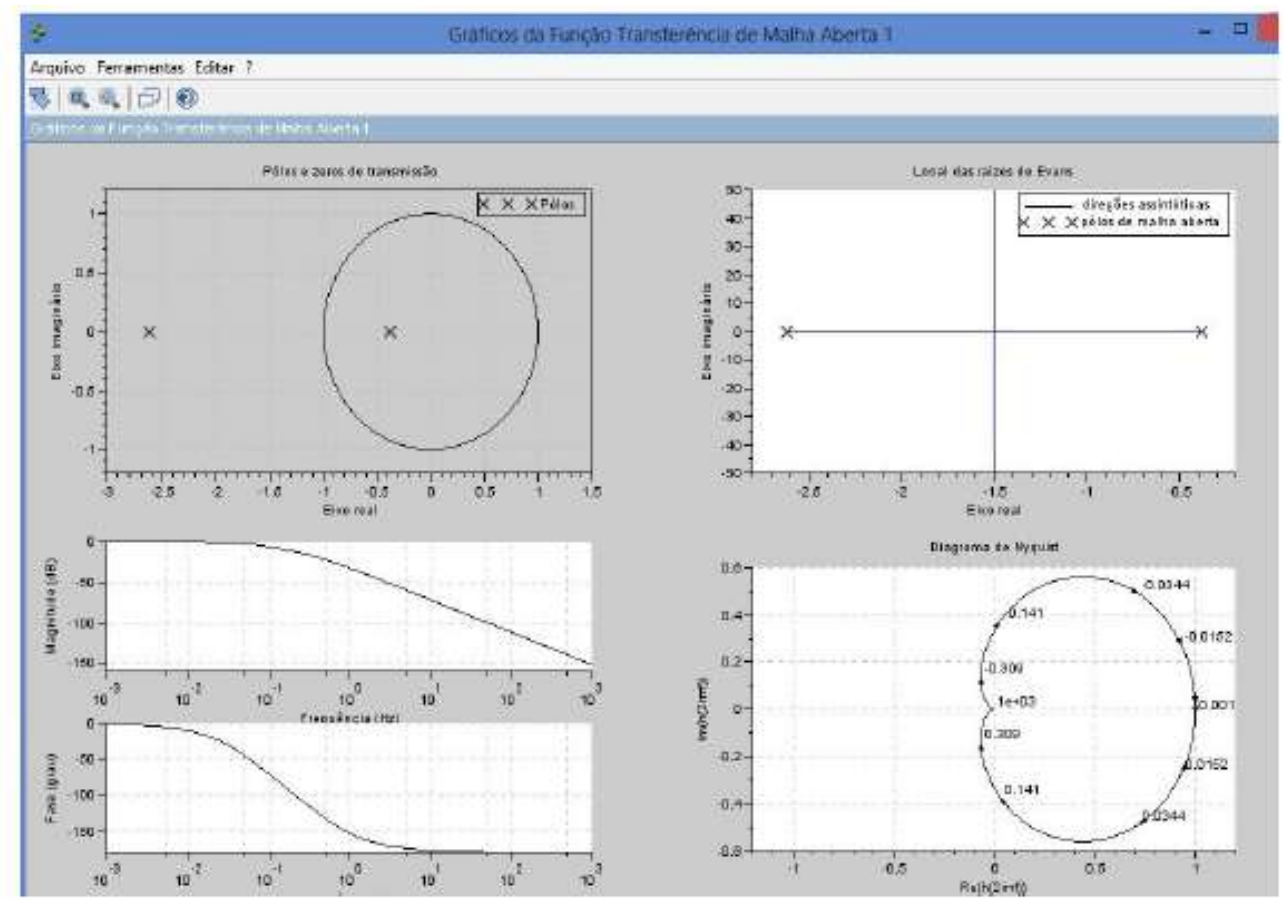

Figura 03 - Janela apresentada ao apertar o botão Gráficos para a função de transferência de entrada 
Abaixo do botão Gráficos tem um painel chamado "Função de entrada" que serve para mostrar a resposta gráfica ao aplicar uma das funções de entrada (escolhida ao marcar a caixa em branco logo ao lado da opção) na função transferência do sistema quando se pressiona o botão Aplicar. O tempo do gráfico em segundos é digitado no campo tempo. A figura 04 mostra esse painel e a figura 05 mostra a resposta a entrada da função degrau.

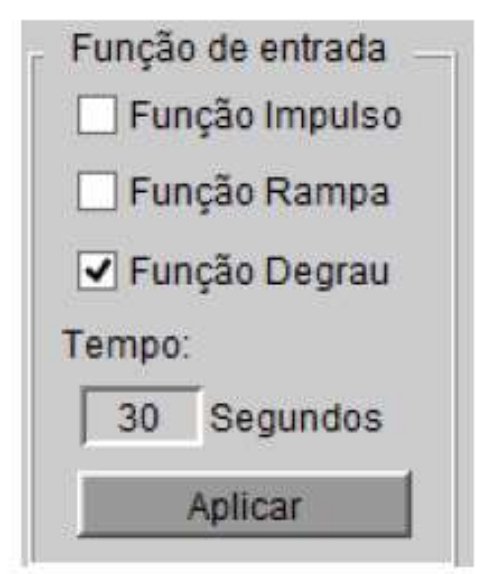

Figura 04 - Aplicação da função degrau a entrada da planta em malha aberta

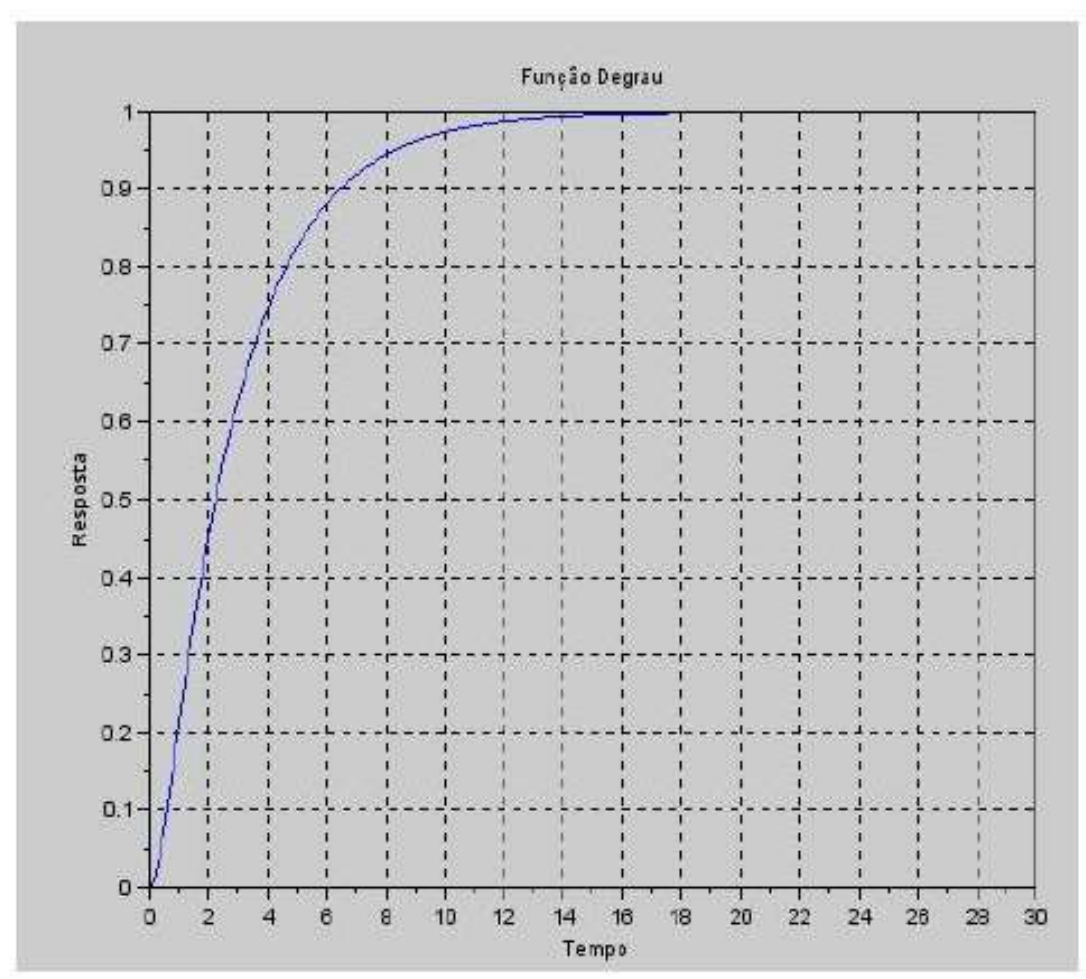

Figura 05 - Gráfico correspondente a aplicação da função degrau a entrada da planta em malha aberta

Ao desejar o acréscimo do controlador no sistema marcamos no painel "Controlador Gc(s)", a caixa Adicionar controlador e em seguida nos campos inferiores altera-se os valores de cada ganho, que inicialmente possuem valor zero, para os valores desejados. Nesse caso o sistema torna-se automaticamente malha fechada, com isso a representação do sistema será alterada para uma figura com o sistema em malha fechada adicionado o controlador.

A representação da função transferência do controlador foi acrescentada nesse painel para facilitar a visualização. Depois basta apertar o botão Gráfico para obter o resultado da atuação do controlador no sistema em malha fechada. Pode-se ver a resposta deste sistema com o controlador e em malha fechada ao escolher a função de entrada e apertar o botão Aplicar. Na figura 06 vemos a inclusão do controlador no sistema com os valores dos ganhos e na figura 07 a função degrau aplicada a esse sistema em malha fechada com o controlador. 
No caso de o usuário desejar ver apenas um dos diagramas em uma janela separada, basta no painel "Em janela separada" marcar a opção desejada e apertar o botão Mostrar que será apresentado a figura do diagrama do sistema em questão.

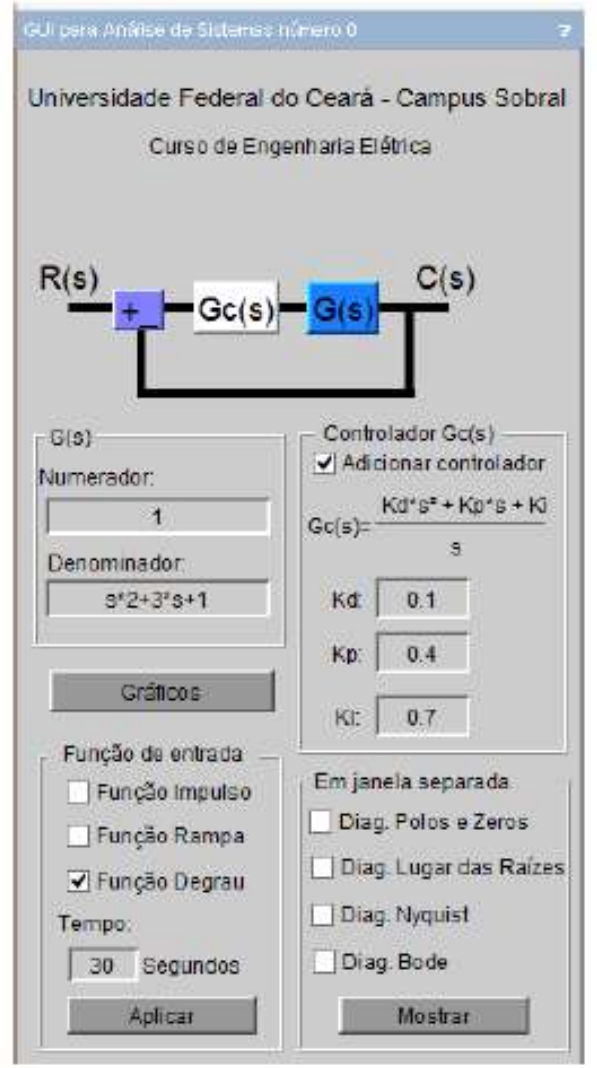

Figura 06 - Aplicação da função degrau a entrada da planta em malha fechada com controlador

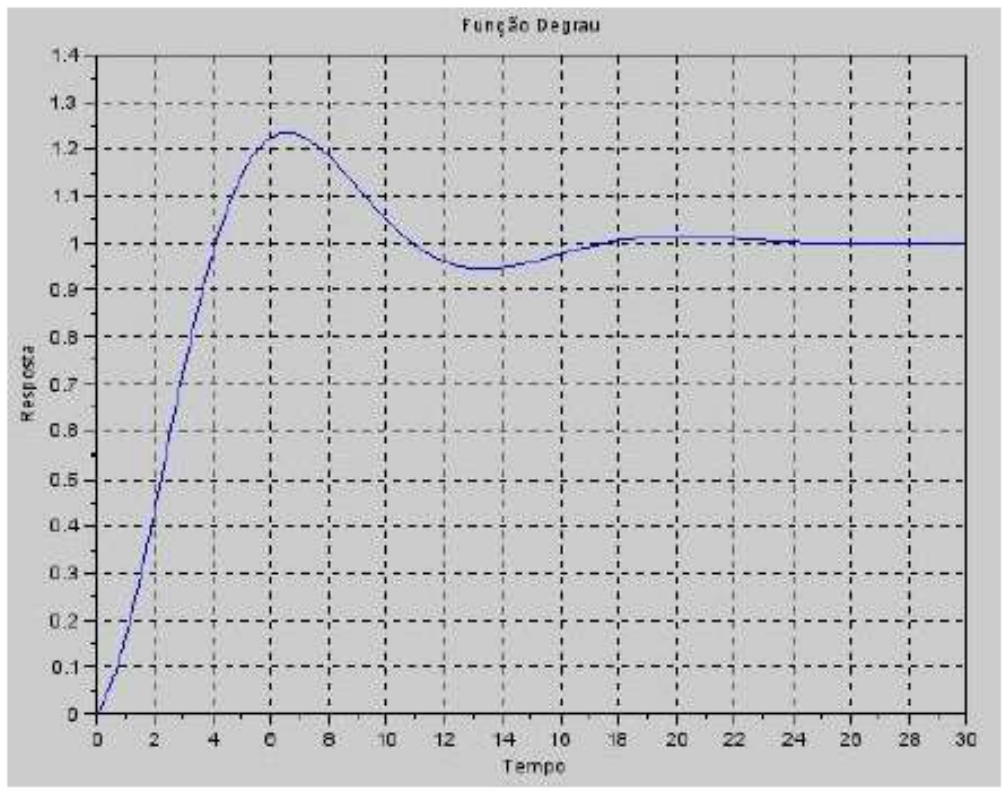

Figura 07 - Gráfico correspondente a aplicação da função degrau a entrada da planta em malha fechada com controlador

\section{CONCLUSÃO}

A interface desenvolvida atendeu ao objetivo que é o de criar um ambiente para análise de sistemas sobre a ótica da teoria contida na área de controle de sistemas se mostrando bastante útil, pois acelera o processo de exame dos vários componentes que o compõe mostrando a interferência na resposta final. É uma ferramenta que pode ser usado a qualquer sistema que possa ser descrito por uma função transferência podendo ou não ser acrescentado um controlador dando atenção as observações feitas. Isso facilita a análise de sistemas reais que possuem maior complexidade melhorando significativamente a compreensão das características do processo. 


\section{REFERÊNCIAS / CITAÇÕES}

BIACHINI D., GOMES F.S.C., A Simulação Como Ferramenta Didática No Ensino De EngenhariaPontifícia Universidade Católica, Faculdade de Engenharia Elétrica -Campinas, São Paulo - 2007

DORF, R. C.; BISHOP, R. H. - Sistemas de Controle Modernos, 8a Edição, LTC, Rio de Janeiro, 1998.

KUO, B.C..Sistemas de Control Automático. 7ạ Edição, Prentice Hall Hispanoamericana,S.A.,1996.

OGATA, K. - Engenharia de Controle Moderno, 5ạ Edição, Pearson Pretice Hall, São Paulo, 2010

MURTA, A.A.P.,PAULA, L.T., BRAGA,M.R.,GUIMARÃES,R., Universidade e Software Livre O uso do SCILAB nas Ciências e Engenharias - Anais do Congresso Nacional Universidade, EAD e Software Livre. Disponível em: http://www.periodicos.letras.ufmg.br/index.php/ueadsl/article/view/2699/2652 acessado dia 04/02/2014

NASCIMENTO W.D., Desenvolvimento De Software Interativo Para Apoiar O Ensino Do Movimento De Água Nos Solos -Departamento de Construções Civis, Universidade Federal de Juiz de Fora - Juiz de Fora Minas Gerais - 2007

NETO,J.C.S.,Caracterização do Curso de Engenharia de Automação Industrial do Cefet-Mg Campus IV Araxá - CEFET-MG-Centro Federal de Educação Tecnológica de Minas Gerais-Campus IV, Araxá - 2011

NISE, N.S. - Engenharia de Sistemas de Controle, 3ạ Edição, LTC, Rio de Janeiro, 2002.

PAMBOUKIAN, S.V.D., CYMROT,R., ZAMBONI, L.C., TSAN HU, O.R., BARROS, E.A.R.. Ensino de Programação em Cursos de Engenharia: Interfaces Console X Interfaces Gráficas - Universidade Presbiteriana Mackenzie, São Paulo - 2010.

SILVA, E.M., CUNHA, J.P.V.S.. SCILAB, SCICOS e RLTOOL: Softwares Livres no Ensino de Engenharia Elétrica - Universidade do Estado do Rio de Janeiro - 2006 


\section{Capítulo 5}

doi) $10.37423 / 210704450$

O MODELO SWAN COMO FERRAMENTA ÚTIL NA PREVISÃO DE ONDA EM RECINTO FECHADO ESTUDO DE CASO NO LAGO DA BARRAGEM DE ILHA SOLTEIRA - S.P

Adriana Silveira Vieira

Geraldo de Freitas Maciel

Conceição Juana Espinosa Morais Fortes

\section{UEMS- Universidade Estadual de Mato Grosso do Sul}

UNESP - Universidade Estadual Paulista

LNEC-Laboratório Nacional de Engenharia Civill Portugal 
Resumo: O reservatório do lago da barragem de Ilha Solteira, que tem uma extensão de 100 km, está localizado no noroeste do estado de São Paulo, Brasil. Devido à sua grande dimensão, ondas geradas por ventos podem causar problemas à segurança de navegação, para a estabilidade das margens do rio, para as infra-estruturas de todo o reservatório, ou mesmo para a segurança pública. Em 2010/2011, uma campanha de dados de campo foi realizada a fim de medir o campo de ventos, de ondas e altura significativa. A batimetria de fundo do lago e a velocidade do vento foram usados no Swan (Simulating Waves Nearshore) para prever a altura significativa das ondas. A partir dos resultados obtidos pode-se dizer que a previsão do modelo numérico apresenta semelhanças com os valores experimentais. 


\section{INTRODUÇÃO}

O Reservatório da barragem de Ilha Solteira, que tem uma extensão de $100 \mathrm{~km}$, está localizado no noroeste do estado de São Paulo, Brasil, (Figura 1). Como a maioria dos reservatórios do Estado de São Paulo, é um aproveitamento de usos múltiplos e faz parte de importante rota de navegação comercial, no caso a Hidrovia Tietê-Paraná.

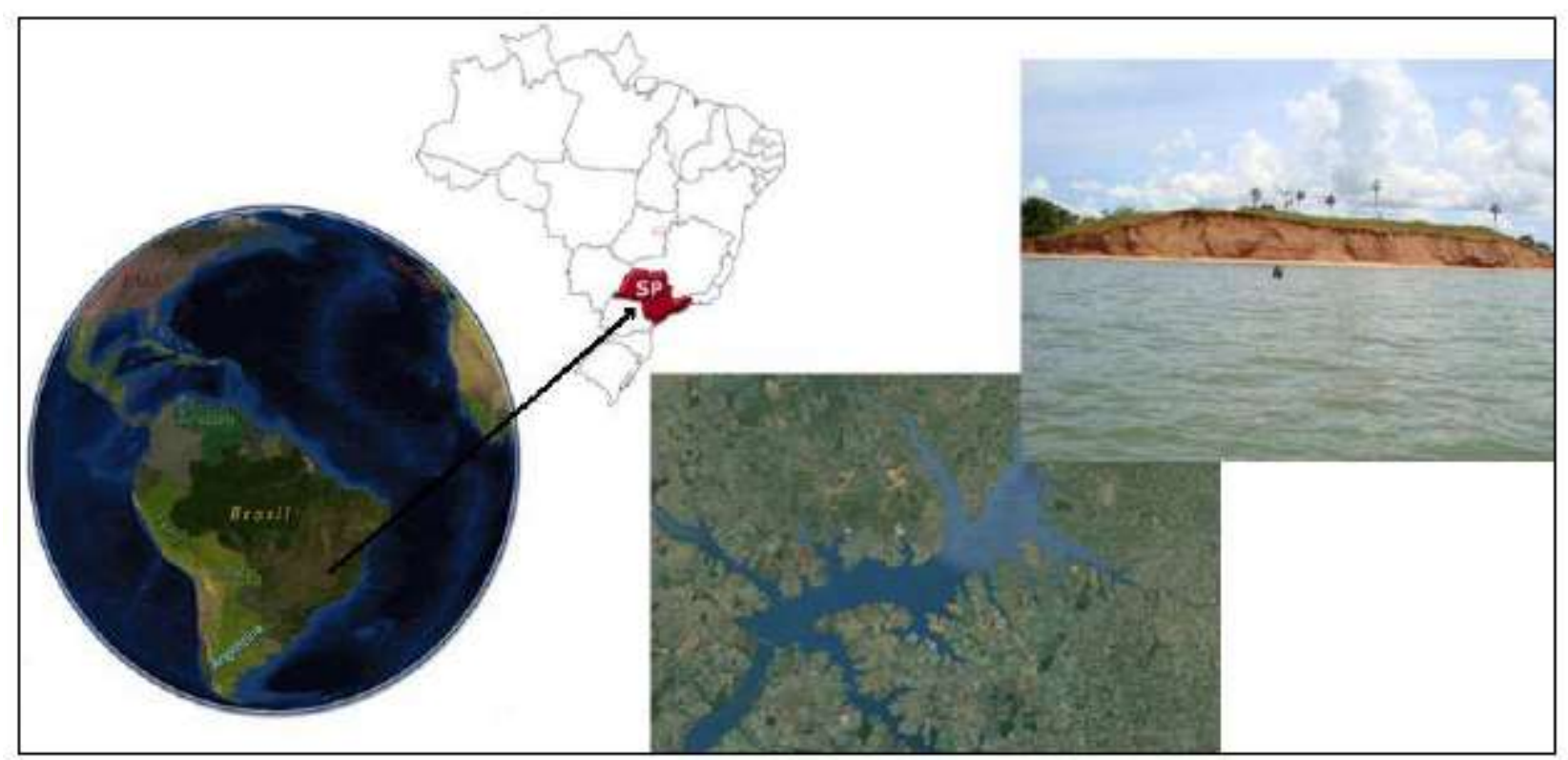

Figura 1. Posição geográfica do lago da barragem de Ilha Solteira.

Devido à grande dimensão do reservatório da barragem de llha Solteira, ondas geradas pelo vento pode causar problemas à segurança de navegação, à estabilidade das margens do rio, às infraestruturas de todo o reservatório, ou mesmo para a segurança pública. Neste contexto, o projeto ONDISA (Ondas no lago de Ilha Solteira), UNESP $(1997,2008)$, ainda em curso, tem como objetivo melhorar a compreensão da hidrodinâmica e morfodinâmica dentro do lago da barragem de Ilha Solteira. Por isso, um aspecto importante é a avaliação dos efeitos de ondas geradas pelo vento sobre as margens de lagos e / ou sobre a segurança de navegação. Assim, aquisição, processamento e modelagem numérica de ondas geradas por vento vêm sendo utilizadas para caracterizar o clima de ondas local.

Uma ampla campanha de dados de campo vem sendo realizada desde janeiro de 2010. Vários instrumentos foram utilizados em diferentes locais no reservatório de Ilha Solteira e em suas margens para medir ondas, correntes e ventos. Apesar de ser muito útil para descrever as características de ondas e correntes locais, essas medidas são de curta duração para caracterizar o clima de ondas de longo prazo. Além disso, a representação espacial das condições de onda fornecidos por estas 
medições é muito restrito, para além do custo elevado do equipamento de instalação, manutenção e monitorização.

A utilização de modelos numéricos para a geração de ondas de vento, a propagação e atenuação pode ser uma alternativa, uma vez que pode caracterizar espacialmente toda a região de estudo e pode ser utilizado para estudos de longo prazo. Particularmente, o uso de espectro não-linear do modelo Swan (Simulating Waves Nearshore, Booij et al., 1999), um modelo numérico que leva em conta a geração de ondas, propagação, fenômenos de atenuação e interações não lineares entre ondas e correntes, é uma boa escolha. De qualquer modo, a aplicação de Swan envolve o estabelecimento de um conjunto de parâmetros que devem ser calibrados para cada caso. Por isso, é interessante aplicar o modelo para situações em que existem dados de modo a se poder avaliar o seu desempenho.

O presente trabalho lida com a aplicação do modelo Swan para o reservatório da barragem de Ilha Solteira, a fim de simular a geração de ondas por vento e sua propagação no lago da barragem. Além disso, apresenta uma análise comparativa do modelo numérico Swan com dados medidos por um dos equipamentos (sensor de pressão) instalado no reservatório de Ilha Solteira, a fim de avaliar o desempenho do modelo e para calibrar alguns de seus parâmetros para esta região. A análise apresentada neste artigo foi feita para os dados medidos no mês de março de 2011.

Este artigo começa com uma breve descrição da aquisição de dados (seção 2). Em seguida, a descrição (seção 3) do modelo numérico utilizado e sua aplicação para a área de estudo é apresentado. Uma discussão sobre os resultados obtidos com ambos os modelos são apresentados na seção 4. Por fim, as conclusões são tiradas na seção 5 .

\section{A COLETA DE DADOS}

\subsection{DESCRIÇÃO GERAL E METODOLOGIA}

Um extenso plano de monitoramento na região está sendo realizado bem como a definição de um sistema de alerta no âmbito do projeto de pesquisa FINEP - ONDISA5. O objetivo é desenvolver modelos preditivos para a geração de ondas de vento para ser incluído em um sistema de alerta para a navegação. Várias campanhas de medição de vento e onda foram realizadas.

Vários equipamentos (sensores de pressão, anemômetros e outros) foram instalados no reservatório de Ilha Solteira para medir continuamente vento e as características de onda (Dall'Aglio Sobrinho et al., 2011). 
Parte desses instrumentos foi instalado em uma árvore dentro do lago, localizado na latitude 20020'49 $.07 "$ e longitude 51018'17 .63", Figura 2, para medir o vento e as características de onda. Em detalhe, o equipamento implantado no interior do lago e perto da árvore consiste em (Figura 2 e Figura 3-A): (1) um ADCP-Waves, que foi implantado a $8 \mathrm{~m}$ de profundidade, a $20 \mathrm{~m}$ de distância da base da árvore e conectados via cabo ao rádio localizado na caixa de instrumentação, (2) um transdutor de pressão (Druck), a qual foi implantado a $1 \mathrm{~m}$ de profundidade e ligado ao conjunto de dataloggers / rádio localizado na caixa de instrumentação, (3 e 4). Anemômetros convencionais do tipo concha, que estão localizados em 0,3 e 0,6 m no topo da estrutura ligada à árvore, (5) um Anemômetro Ultrasônico 2D foi localizado a $1.2 \mathrm{~m}$ de altura, (6) da caixa de instrumentação, que contém dados de rádio, dataloggers baterias, etc; (7) Antenas para transmissão de dados; (8) um sistema de painel solar de energia, 80w, (9) uma câmera de vídeo com baixo consumo de energia e alta resolução, para visualização de onda em tempo real.

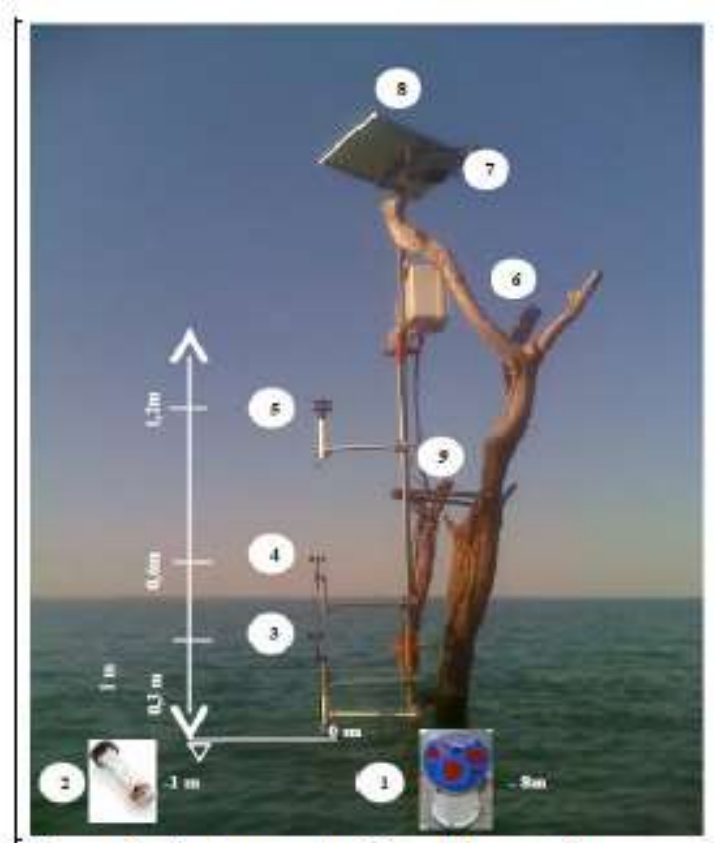

Figura 2. Instrumentação e telemetria.

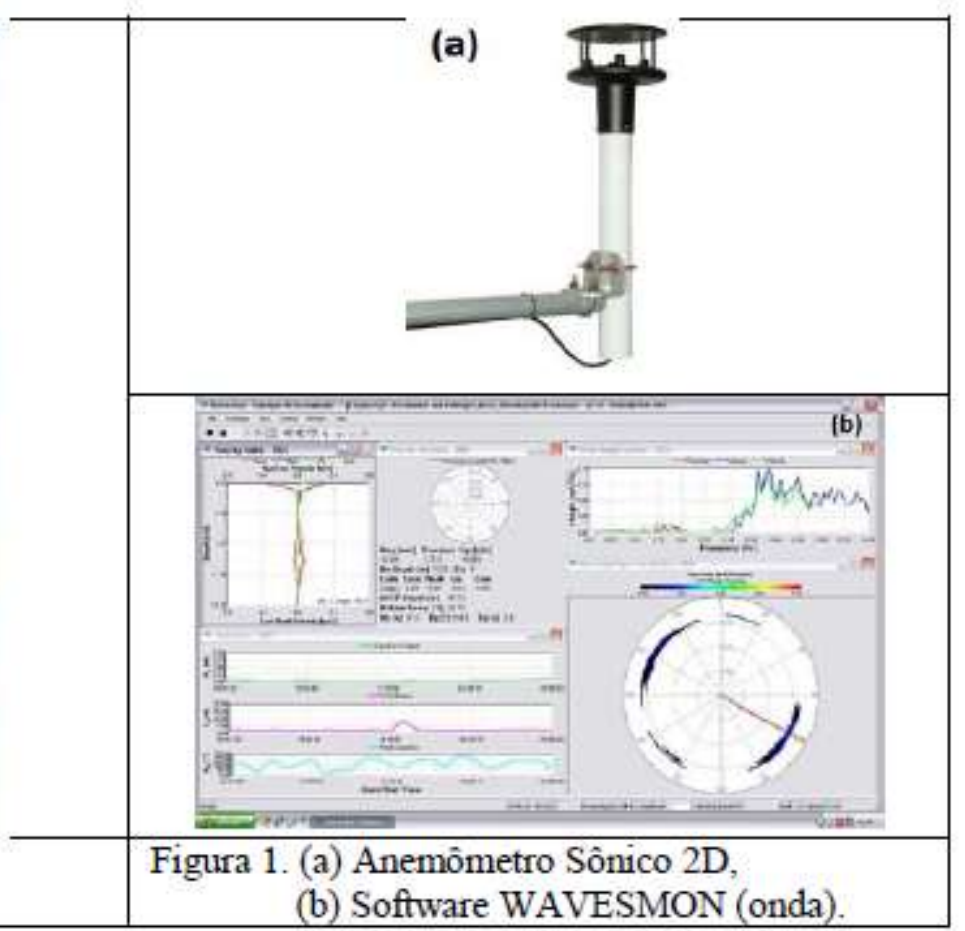

(b) Software WAVESMON (onda).

\subsection{VENTO E MEDIÇÕES DE ONDAS}

Conforme citado, a velocidade do vento é medida por vários anemômetros de tipo concha posicionado em 0,3 e 0,6 m, bem como com um anemômetro sônico 2D posicionado a 1,2 $\mathrm{m}$ acima do nível da água, que também pode medir a direção do vento. O objetivo é traçar o perfil dos dados de vento neste local. Para o presente trabalho apenas os dados do anemômetro sônico 2D é considerado. Esses dados foram registrados em um CR1000 data-logger de Campbell Scientific. 
Em relação às medições de ondas, os dados (altura significativa das ondas e períodos) são determinados a partir dos dados medidos com um sensor de pressão PDCR 1830 Druck.

É importante notar que o elemento principal do sistema de coleta é a frequência de aquisição de dados e sua transmissão por ondas de rádio. Uma vez que a altura das ondas e período não eram conhecidos, foi decidido usar uma amostragem quase contínua, considerando a maior frequência possível. 0 registador de dados tem um programa interno, que verifica a memória disponível e o tempo de transmissão necessário, de modo a não comprometer toda memória. Além disso, considerou-se um tempo adicional, tal como um fator de segurança, a fim de evitar uma eventual perda de dados, devido a problemas de comunicação. Portanto, com base em um teste preliminar, foi assumida uma frequência de $8 \mathrm{~Hz}$ para o sensor de pressão e de 0,2 Hz para a velocidade do vento (Dall'Aglio Sobrinho et al., 2011).

O registador de dados de memória disponível também depende da frequência em que os dados são transmitidos. Em primeiro lugar, a transmissão é feita a cada hora, mas devido a uma eventual falha é necessário diminuir esse tempo de transmissão. Em caso de falha do sistema, o tempo é reduzido pela metade. Então, se a falha persistir, o tempo de transmissão torna-se a cada 10 minutos. E, finalmente, um último recurso é a transmissão em cada minuto.

\section{APLICAÇÕES DO SWAN}

\subsection{DESCRIÇÃO SWAN}

SWAN é um modelo numérico desenvolvido na Universidade de Tecnologia de Delft (TUDelft), na Holanda. Ele é usado para obter a avaliação espectral das ondas em áreas costeiras, como estuários e também em áreas fechadas, como lagos, reservatórios de barragens, como mostrado neste artigo. Ele usa a velocidade do vento, o perfil de fundo, e a velocidade da corrente para simular a altura da onda e é baseado na equação de equilíbrio do espectro de ação (Booji et ai., 1999). O modelo 2D está disponível para qualquer um, pois é de domínio público.

As equações resolvidas no SWAN lidam com geração de ondas, dissipação e interação não-linear em águas profundas. Ele também resolve dissipação devido ao atrito de fundo, a interação não-linear e quebra da onda em águas rasas. Beji e Battjes (1994) mostram que os processos são importantes, quando a onda viaja de condições de água profunda para águas rasas, como pode ser visto na Tabela 1. 
Tabela 1. Processos que são importantes, propagação da onda de águas profundas para rasas. Adaptado de Beji e Battjes (1994)

\begin{tabular}{|l|c|c|c|}
\multicolumn{1}{|c|}{ Processos } & Águas profundas & Intermediárias & Rasas \\
\hline Geração de energia & $\mathrm{xxx}$ & $\mathrm{xxx}$ & $\mathrm{x}$ \\
\hline Interações quádruplas & $\mathrm{xxx}$ & $\mathrm{xxx}$ & $\mathrm{x}$ \\
\hline Interações Triad & $\mathrm{o}$ & $\mathrm{o}$ & $\mathrm{xx}$ \\
\hline Ruptura parcial & $\mathrm{o}$ & $\mathrm{xxx}$ & $\mathrm{x}$ \\
\hline Atrito de fundo & $\mathrm{o}$ & $\mathrm{xx}$ & $\mathrm{xx}$ \\
\hline Refração & $\mathrm{x}$ & $\mathrm{x}$ & $\mathrm{xx}$ \\
\hline Empolamento & $\mathrm{o}$ & $\mathrm{xx}$ & $\mathrm{xxx}$ \\
\hline Quebra & $\mathrm{o}$ & $\mathrm{x}$ & $\mathrm{xxx}$ \\
\hline Reflexão & $\mathrm{o}$ & $\mathrm{o}$ & $\mathrm{x} / \mathrm{xx}$ \\
\hline Difração & $\mathrm{o}$ & $\mathrm{o}$ & $\mathrm{x}$ \\
\hline
\end{tabular}

\begin{tabular}{|c|c|}
\hline Símbolo & Efeito \\
\hline $\mathrm{xxx}$ & Dominante \\
\hline $\mathrm{xx}$ & Significativo \\
\hline $\mathrm{x}$ & Relevante \\
\hline $\mathrm{o}$ & Irrelevante \\
\hline
\end{tabular}

XX Simpósio Brasileiro de Recursos Hídricos 5 A equação de equilíbrio do espectro de ação é uma função da densidade de ação, $N(\sigma, \theta)=E(\sigma, \theta) / \sigma$, onde $\sigma$ é a frequência relativa, $\theta$ é a direção da onda e E é a densidade de energia. Escrito em coordenadas Eulerianas, a equação de equilíbrio do espectro é dada pela Equação 1:

$$
\frac{\partial N}{\partial t}+\frac{\partial c_{g, x} N}{\partial x}+\frac{\partial c_{g, y} N}{\partial y}+\frac{\partial c_{\theta} N}{\partial \theta}+\frac{\partial c_{\sigma} N}{\partial \sigma}=\frac{S(\sigma, \theta)}{\sigma}
$$

O primeiro termo do lado da equação 1 representa a taxa local de variação da densidade de ação no tempo, o segundo e o terceiro termo representam a propagação de ação no plano $x y$, com velocidades de propagação $c g, x$ e $c g, y$ em $x$ e $y$ espacial, respectivamente. O quarto termo representa deslocamento da frequência relativa devido às variações em profundidade e correntes e, por fim, o quinto termo representa a profundidade de refração induzida e corrente induzida. Em resumo, o lado esquerdo da equação 1 representa a parte da equação cinemática enquanto que o lado direito representa o termo fonte.

Os dados necessários para executar o modelo SWAN são a batimetria da região de estudo, o vento, os campos de correntes como condições de contorno, além de um conjunto de parâmetros de cálculo das ondas e, entre os vários resultados produzidos pelo SWAN vale a pena mencionar a altura significativa das ondas, a média e os períodos de pico, direção, o parâmetro de largura de banda e do nível médio da água em qualquer ponto do domínio computacional definido. 
Para uma aplicação sistemática do modelo SWAN para diferentes condições de onda incidente, um pacote de software chamado SOPRO-SWAN, Fortes et al. (2006), foi desenvolvido. A interface do utilizador facilita o armazenamento e manipulação de dados e a execução do modelo de Swan, bem como o pós-processamento, nomeadamente a sua visualização gráfica. O pacote foi construído com um banco de dados da Microsoft Access e Visual Basic para aplicação da linguagem de programação.

\subsection{CONDIÇÕES DE ENTRADA NO SWAN}

A aplicação do modelo Swan para reservatório de Ilha Solteira foi feito para as características do vento medida pelo anemômetro sônico 2D durante o período de 01/03/2011 e 21/03/2011, e a cada 10 min. O modelo computacional Swan foi discretizado por três malhas retangulares, com uma cobertura de toda a área do reservatório, como mostrado na Figura 4. A malha maior (global) tem as dimensões 54 $\mathrm{km} \times 33 \mathrm{~km}$. A segunda grade (aninhada) foi definida com uma resolução de $500 \mathrm{~m}$, cobrindo um retângulo de $26,6 \mathrm{~km} \times 18,4 \mathrm{~km}$. A terceira malha (aninhada) foi definida com uma resolução de 250 m, cobrindo um retângulo de 14,8 km x 14,3 km, como pode ser visto na Tabela 2. É necessário o uso de redes múltiplas para alcançar um desempenho numérico melhor. Um ponto foi definido na terceira grade de onde foram extraídos os resultados pelo Swan, o mesmo onde estava localizado o sensor de pressão.

As condições do campo de vento, que foram baseados nas medições do anemômetro sônico 2D, durante o mês de março de 2011, (Figura 6), foram consideradas constantes no espaço em todas as três malhas.

O espectro direcional foi definido a partir da discretização de um espectro em frequência contendo 21 intervalos, de 0.070 a $2.0 \mathrm{~Hz}$, com distribuição logarítmica, e de uma discretização em direção cobrindo os 360으, dividida em 144 intervalos ( $\Delta=2.5^{\circ}$ ). Setenta e duas corridas foram realizadas pelo Swan no modo de variação no tempo, considerando vento estacionário e sem a presença de correntes. Os fenômenos físicos foram incluídos nas três malhas: refração, difração, empolamento e arrebentação, devido à influência de fundo, whitecapping, tríade e quádruplos interações onda-onda. Todos os parâmetros relevantes foram introduzidos no pacote SOPRO-Swan日 (Fortes, et al. De 2009). 


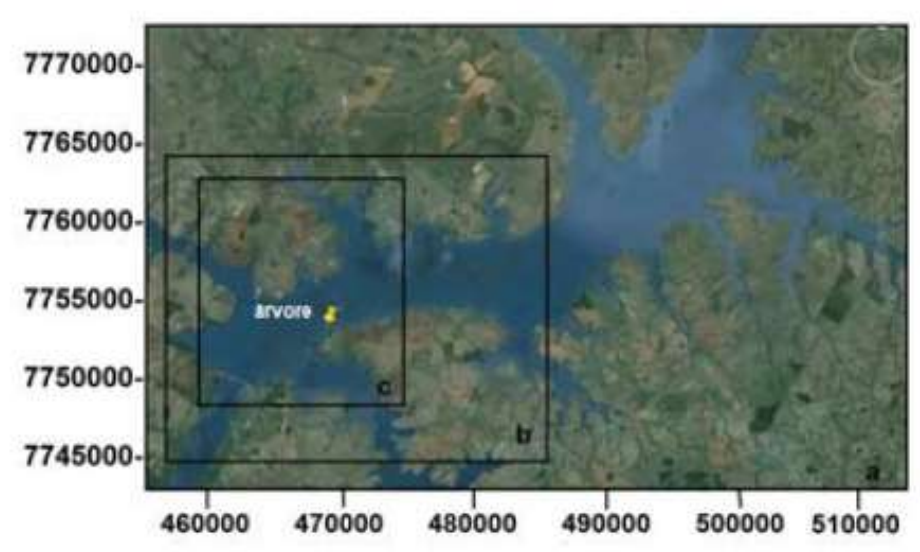

Figura 4. Modelo SWAN: Domínio e malhas.

Tabela 2. Características da malha.

\begin{tabular}{|c|c|c|c|c|c|c|}
\hline Malhas & Inicial X & Inicial Y & $\mathrm{N}^{\circ}$. DX & $\mathrm{N}^{\circ}$. DY & DX (m) & DY (m) \\
\hline 1 & 456680 & 7741700 & 58 & 33 & 1000 & 1000 \\
\hline 2 & 457220 & 7744520 & 53 & 34 & 500 & 500 \\
\hline 3 & 459329 & 7745690 & 58 & 57 & 250 & 250 \\
\hline
\end{tabular}

\section{COMPARAÇÃO ENTRE OS DADOS EXPERIMENTAIS E RESULTADOS NUMÉRICOS}

Para as condições acima referidas, os resultados numéricos ao longo do período de estudo, em termos da altura das ondas e períodos, são obtidos para todo o domínio e a localização do sensor de pressão. Para obter esta posição, os resultados numéricos e dados in situ são comparados.

A Figura 5 apresenta em todo o domínio a altura significativa das ondas e seus respectivos períodos para o dia 01 de março de 2011 às 18:26 h, que teve um vento de intensidade $13.1 \mathrm{~m} / \mathrm{s}$ para uma direção de 75,9 ․

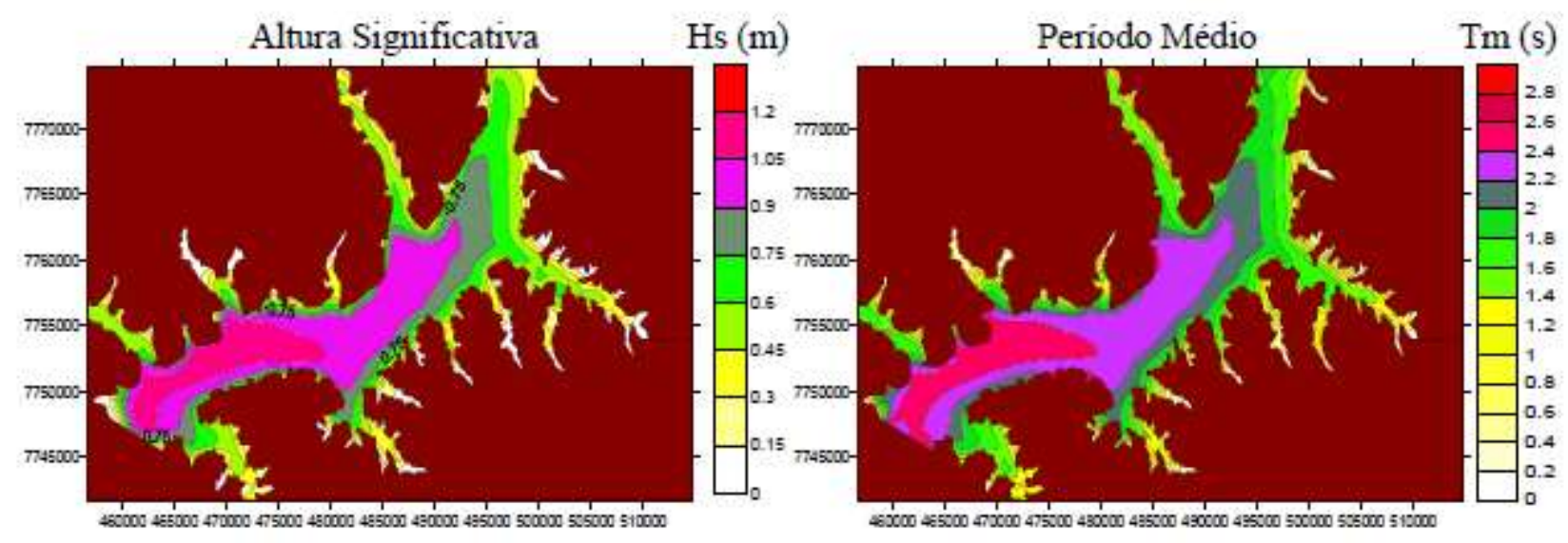

Figura 5. Representação gráfica das alturas significativas e período médio de onda. 
Os resultados mostram que as alturas de onda significativas e períodos variam de 0 a 1,4 m e 0,2 a 3s, respectivamente, sendo os maiores observados no sudeste do reservatório de Ilha Solteira. Observase uma boa concordância espacial entre os parâmetros altura significativa e período médio no lago da barragem, para uma mesma forçante de vento. Isto está de acordo com a direção do vento e velocidade.

A Figura 6 apresenta os resultados numéricos e dados in situ de valores de altura de onda significativa, ao longo do mês de março de 2011.

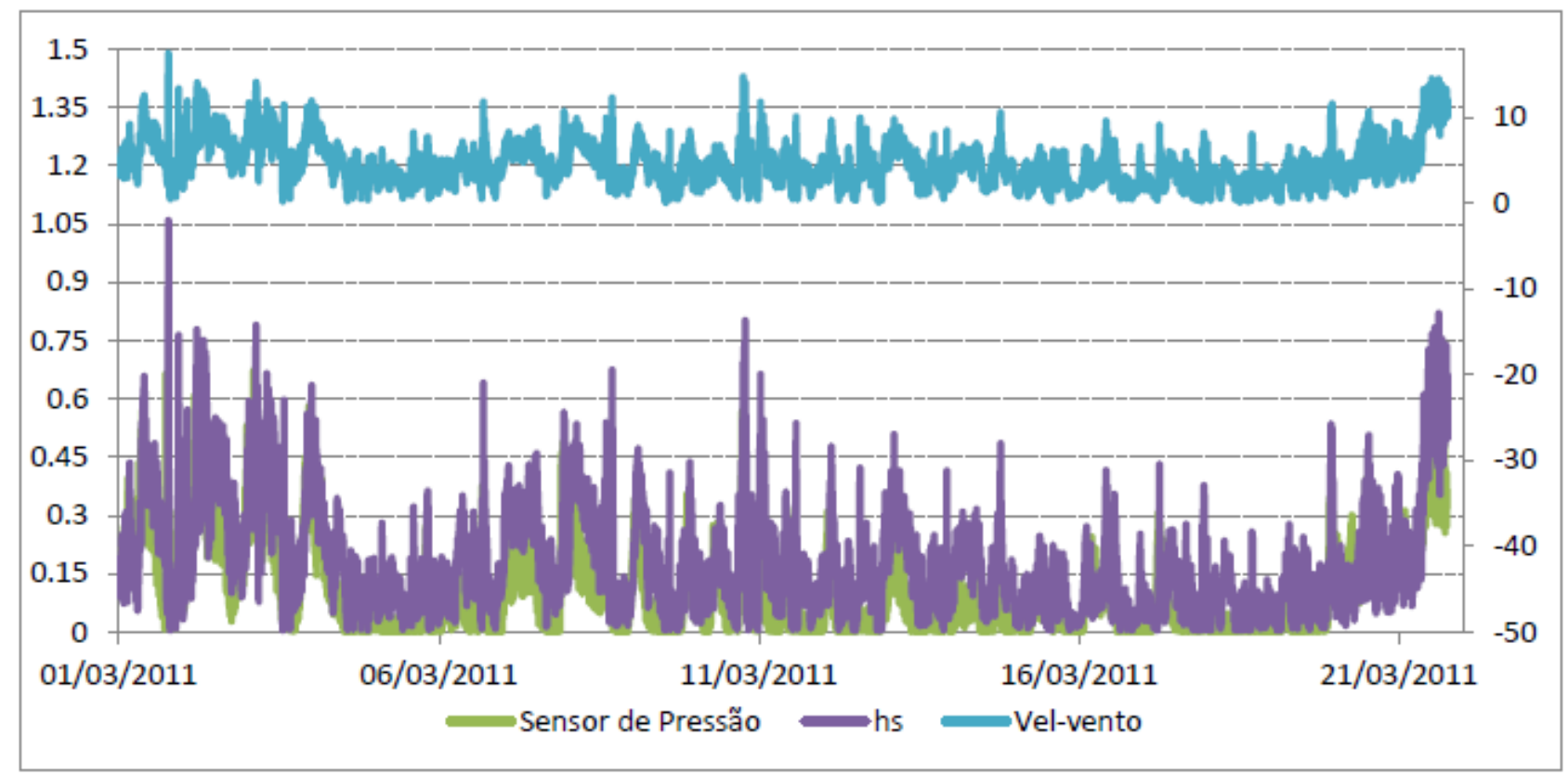

Figura 6. Representação gráfica das alturas significativas de onda de 01-03-2011 a 21-03-2011 usando o SWAN e sensor de pressão. Os dados de vento do período são também mostrados na figura.

A partir da Figura 6, pode-se concluir que o comportamento e a magnitude dos resultados numéricos e experimentais são semelhantes. Além disso, o padrão tanto numérico como o experimental segue a variação dos dados de vento. Mas há algumas diferenças com relação ao fato de que os resultados numéricos não atingem os valores máximos observados, especialmente quando o vento sopra com maior intensidade. Além disso, nas primeiras horas do dia 1 de março, os resultados numéricos de onda são mais elevados do que os observados, enquanto nas últimas horas daquele dia, ocorre o oposto. 


\section{CONCLUSÕES}

Ondas geradas no reservatório de grandes dimensões e uso múltiplos pode ser prejudicial para as operações da usina, trechos da navegação, assim como para a estabilidade de suas margens, em alguns casos. Neste contexto, as ondas são geradas principalmente pelo vento.

Este artigo analisa as alturas significativas de onda no lago da barragem de Ilha Solteira, obtidos a partir de medições de campo nos dias 01 a 21 de março de 2011. A partir da comparação, os resultados do modelo apresentam grandes semelhanças com os resultados experimentais, o que permite indicar o código SWAN como ferramenta promissora para previsão de ondas geradas por ventos em lagos de barragens.

Um trabalho futuro consiste na aplicação do modelo para longos períodos de tempo de registro dos dados de vento e onda, assim como para outros locais na barragem do lago de Ilha Solteira.

\section{AGRADECIMENTOS}

Ao apoio financeiro de doutorado fornecido pelo CNPq e Unesp para o primeiro autor, bem como o apoio técnico do Laboratório de Hidrologia e Hidrometria $\mathrm{LH}^{2}$ da UNESP Ilha Solteira. O apoio financeiro da "Fundação para a Ciência e a Tecnologia", através do projeto de EROS, ref. PTDC/CTEGIX/111230/2009 - Portugal. 


\section{REFERENCIAS}

Beji, S., Battjes, J.A., 1994. Numerical simulation of nonlinear wave propagation over a bar. Coastal Engineering 23, 1-16.

Booij, N., Ris, R. C. and Holthuijsen, L. H., 1999. A third-generation wave model for coastal regions, Part I: Model description and validation. Jornal Geophys. Research, Vol. 104, C4, pp.7649-7666.

Fortes, C. J.; Pinheiro, L.; Santos, J. A.; Neves, M.G.; Capitão, R., 2006. SOPRO - Pacote integrado de modelos de avaliação dos efeitos das ondas em portos. Tecnologias da Água, Edição I, Março 2006, pp. 51-61

Cunha, E. F.; Morais, V. S.; Maciel, G. F., Magina. F., 2009. Sistema de Transmissão de Dados de Vento e Onda, Via Rádio Telemetria, em Lagos de Barragens. Proc. XVIII Simp. Brasileiro de Recursos Hídricos.

Dall'Aglio Sobrinho, M.; Trovati, L.R; Maciel, G.F; Oliveira, J.N de; Albertin, L.L; Oliveira, B.M; Lima, G.B; e Oliveira, E.B. Cunha, E.F, 2011. Monitoramento de ondas com sensor de pressão e comparação com dados de ADCP - Waves. Proc. XIX Simpósio Brasileiro de Recursos Hídricos. Maceió - Alagoas - Brasil.

Morais, V. S.; 2009. Previsão de Ondas Geradas Por Ventos em Águas Interiores e Sua Alteração Devido à Presença de Vegetação Aquática em Margens de Lagos. Dissertação de Mestrado. Unesp - Ilha Solteira- São Paulo- Brasil 


\section{Capítulo 6}

doi) $10.37423 / 210704452$

\section{APLICAÇÃO DA TERMOGRAFIA NA MANUTENÇÃO PREDITIVA}

Antônio Lucas Frazão Santos

Daniela dos Santos da Silva

Roberth Hyther Paulo dos Santos

Eduardo Henrique Castro Mendes
Faculdade de Ensino Internacional do Maranhão

Faculdade de Ensino Internacional do Maranhão

Faculdade de Ensino Internacional do Maranhão

Faculdade de Ensino Internacional do Maranhão 
Resumo: O objetivo deste artigo foi apresentar os benefícios que a termografia traz para manutenção preditiva durante a pandemia e para o "novo" normal. Para tanto, foi empregado a revisão bibliográfica como metodologia de pesquisa. Desta forma, foi possível compreender que este percurso é marcado por uma temática: a celeridade que o atual cenário proporcionou no avanço da Industria 4.0, que reúne altas tecnologias alinhadas a estratégias de produção, confiabilidade e disponibilidade de ativos. O tema foi fundamentado na necessidade de mudança de paradigma com a adoção de métodos cada vez mais preditivos e à distância na indústria, trazendo impactos operacionais significativos e positivos. Findando, assim, com o parecer de como essa mudança de comportamento também permite uma rentabilidade maior, agregando valor a setores que estruturam a indústria e cuidando das pessoas.

Palavras-chave: Termografia, Manutenção, Preditiva, Pandemia. 


\section{INTRODUÇÃO}

A manutenção preditiva é adotada para acompanhar parâmetros, a partir de dados coletados através de inspeções e monitoramentos, avaliando o estado real dos ativos e apontando as necessidades e ações a serem adotadas para conservação, antecipando, também, a visualização de possíveis problemas e atuação antes de uma ocorrência ou paralização não programada.

A termografia é uma dessas forma de inspeção, auxiliando na identificação de falhas ou desvios em componentes, equipamentos, sistemas, processos e até na gestão da manutenção. Possibilitando a prevenção de defeitos, o uso desta tecnologia em conjunto aos planos de manutenção, contribui na confiabilidade do processo produtivo, controle de custo, redução de paradas de produção, manutenções preventivas e corretivas mais pontuais e, consequentemente, lucratividade ao negócio. Considerando o desafio da indústria no cenário mundial atual com a pandemia em se manter rentável e atendendo aos protocolos sanitários necessários, este instrumento colabora com métodos eficazes e bom custo-benefício.

Assim, o objetivo deste trabalho é apresentar a aplicação da termografia na manutenção preditiva considerando as práticas necessárias no período de pandemia e os benefícios para o novo normal, sendo adotado como metodologia a revisão bibliográfica, composto de livros, teses, dissertações e artigos publicados na área de termografia, manutenção preditiva e informativos de protocolos do novo normal.

\section{DESENVOLVIMENTO}

\section{TERMOGRAFIA}

A termografia é definida como uma técnica não intrusiva e não destrutiva que apresenta a temperatura do corpo através de um termograma, obtido por uma câmera capaz de detectar aos raios infravermelhos emitidos pelo corpo. As diferenças de temperatura presentes no objeto analisado formam um contraste visual na imagem sem que seja necessário o aquecimento do objeto e por isso, a análise termográfica é amplamente utilizada, uma vez que permite a observação remota dos corpos. (COSTA, 2010).

As inspeções termográficas têm como base os raios infravermelhos emitidos por qualquer tipo de corpo, produzindo assim imagens que são chamadas de termogramas. Os raios infravermelhos são 
frequências eletromagnéticas emitidas por corpo que variam em proporção de acordo com a temperatura do corpo. (CABRAL, 2010).

Cabral (2010) ainda destaca a facilidade em localizar regiões quentes e frias, com câmara térmica, que podem fornecer termogramas de faixas de $20^{\circ} \mathrm{C}$ a $1500^{\circ} \mathrm{C}$, com imagens de qualidade, op ção de filtros que removem ruídos gerados (como pela presença do sol ou outras fontes de calor no ambiente) e, ainda, tendo um pequeno tamanho, de grande autonomia e leveza, permitindo sua aplicação em lugares de acesso difíceis.

Outro benefício é a identificação de anomalias antes que elas evoluam gerando paradas não programadas. A possibilidade de realizar a inspeção termográfica sem interromper o fornecimento de energia e mantendo a segurança dos colaboradores tornou a técnica difundida no mercado (SILVA, 2020).

Assim, com o objetivo de propiciar informações relativas à condição operacional de um componente, equipamento ou processo, a termografia permite, em qualquer dos sistemas de manutenção considerados: realizar medições sem contato físico com a instalação (segurança); verificar equipamentos em pleno funcionamento (sem interferência na produção); e inspecionar grandes superfícies em pouco tempo (alto rendimento). (LOUVAIN, CABRAL E GOMES, 2010).

\section{TERMOGRAFIA QUALITATIVA E TERMOGRAFIA QUANTITATIVA}

A manutenção de equipamentos, componentes e sistemas são importantes para garantir a eficiência da operação e o controle de custo, com isso a termografia tem duas técnicas de medição: qualitativa e quantitativa. A termografia qualitativa é a análise termográfica meramente visual, geralmente comparativas, em uma inspeção termográfica, sem preocupação com os valores da temperatura apresentaras pelo termovisor, e sim com a distribuição desta temperatura. Visa a busca por regiões de uma superfície, ou componentes de um processo, que destoam visualmente do restante do cenário, e que possam indicar uma condição de funcionamento inadequado (KOMINSKY, LUCKINO E MARTIN, 2006).

A termografia quantitativa diz respeito à uma análise mais criteriosa dos resultados de uma inspeção termográfica. Informações sobre o ambiente onde ocorre a inspeção, como temperatura ambiente e umidade, devem ser registrados, assim como devem der conhecidas algumas características a respeito do objeto, como emissividade e condições gerais da superfície. Todos estes dados são considerados 
com intuito de ser conhecer os detalhes do resultado da medição, o valor da temperatura e sua incerteza, a classificação da seriedade das anomalias, e outros aspectos relevantes. (JÚNIOR, 2017)

\section{MANUTENÇÃO PREDITIVA}

A manutenção preditiva é o acompanhamento periódico dos equipamentos, baseado na análise de dados coletados através de monitoração ou inspeções em campo, sendo uma das formas de análise a inspeção termográfica (termografia). Esse tipo de inspeção auxilia na detecção de falhas em período inicial, proporcionando, assim, a possibilidade de planejar, de melhor forma, um período para a prevenção de defeitos (manutenção preventiva). (LOUVAIN, CABRAL E GOMES, 2010).

Para Santana (2018), o controle preditivo de manutenção se caracteriza pela determinação do ponto ótimo para se executar a manutenção em um equipamento, ou seja, o ponto a partir do qual a probabilidade de o equipamento falhar assume valores indesejáveis. A determinação desse ponto traz como resultado índices ideais na prevenção de falhas, tanto sob o aspecto técnico como pelo aspecto econômico, uma vez que a intervenção no equipamento não é feita durante o período em que ele ainda está em condições uso, nem tão pouco no período em que as suas características operacionais estejam comprometidas. A manutenção preditiva se caracteriza pelo monitoramento das condições de desgaste em um equipamento. Isso se dá através da medição e comparação de parâmetros operacionais com valores pré-estabelecidos para adequada operação de um sistema, e que descrevem a normalidade desse sistema, possibilitando-se a previsão de possíveis avarias ou falhas. Os lados ou parâmetros de operação de um equipamento são coletados e analisados, evidenciando-se as tendências de desempenho e as características dos componentes. Os reparos devem ser feitos conforme a necessidade.

Em complemento, a manutenção preditiva é a atuação realizada com base na modificação de parâmetros de condição ou desempenho, cujo acompanhamento obedece a uma sistemática, tendo como objetivo a prevenção de falhas em equipamentos ou sistemas através do acompanhamento de dados, possibilitando uma vida útil maior e sem apresentar falhas ou paradas não planejadas (KARDEC E NASCIF, 2012).

\section{MÉTODO DA TERMOGRAFIA PREDITIVA}

Os processos e os equipamentos mecânicos que produzem calor também podem se beneficiar da manutenção preditiva por termografia, já que a irradiação é emitida através da variação de 
temperatura dos objetos, que forma imagem térmica e ajudam na identificação de defeitos mitigando interrupções no processo, e gera economia em recursos e mão de obra (VERRATI, 1996).

A capacidade que cada material tem para emitir radiação chama-se emissividade, e essa varia de 0 a 1, o que significa que o material que emite zero, não emite nenhuma radiação (VERRATI, 1996).

\section{TERMOVISOR}

Segundo o fabricante de termovisores são sistemas geradores de imagens dotados de recursos para a análise e medição de distribuições térmicas. São produzidos normalmente com sensibilidade nas faixas espectrais de 3 a 5 microns (sistemas industriais) e de 8 a 12 microns (sistemas militares e de pesquisa). Tal como nos equipamentos fotográficos, os termovisores possuem objetivos intercambiáveis que possibilitam adequar o campo de visão do aparelho às necessidades específicas de cada observação (FLUKE, 2009).

A Figura 1 ilustra o funcionamento do termovisor.

Figura 1 - Funcionamento Termovisor

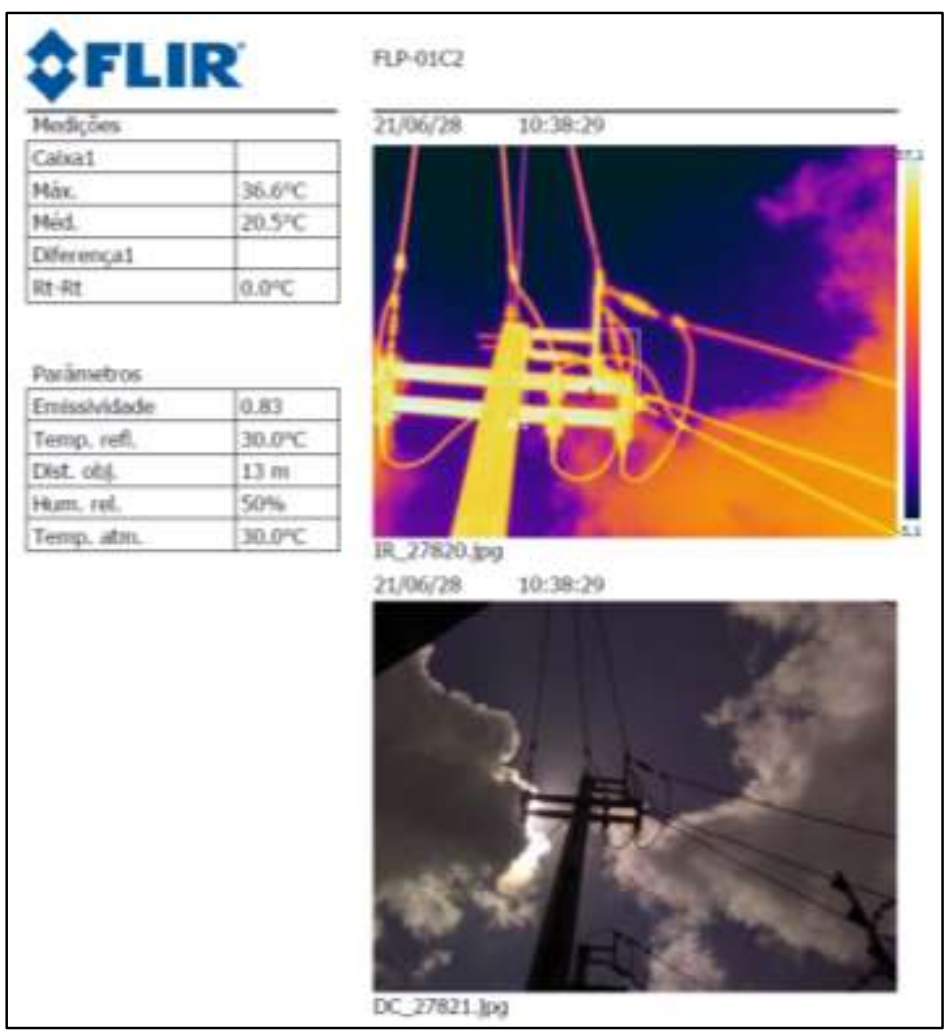

Fonte: Imagem do autor.

O modo como é feito o registro e a partir da geração de imagens em branco e preto, podendo ser convertidas em imagens coloridas pela substituição da escala de cinza por uma escala de cores. 
Atualmente todo o registro das imagens térmicas geradas é digital, com o armazenamento em memórias flash e interfaces que permitem o acoplamento dos sistemas com microcomputadores para posterior processamento da informação (FLUKE, 2009).

\section{APLICAÇÕES}

Na maioria das fábricas atualmente, existem diversos tipos de equipamentos que podem ser inspecionados com eficiência, utilizando a termografia infravermelha. Porém, para os equipamentos mecânicos e elétricos, as técnicas usadas para inspecionar os equipamentos são diretas e com monitoramento objetivo, ou seja, e feito com base em medições utilizando equipamentos e instrumentos especiais, fornecendo assim valores da medição e para comparação com parâmetros principalmente em relação a emissividade, mas outros parâmetros também são levados em conta como o tipo do material, temperatura ambiente, umidade relativa do ar etc (GEBRAN, 2013).

A NP 001 (NP.001.EQTE, 2018) instrui que para tal acompanhamento seja aplicado apresentamos as seguintes considerações:

- Equipe técnica de manutenção que opera os instrumentos sejam treinados e habilitados para realização dos trabalhos no uso do termovisor;

- Calibração dos equipamentos;

- Haja pessoal capacitado para analisar e interpretar os dados coletados e emitir diagnósticos e relatórios para início das ações corretivas;

- Ambiente de medição propício e sem interferências; e

- O conhecimento e a experiência específicos são necessários na maioria dos casos;

\section{A MANUTENÇÃO PREDITIVA DURANTE A PANDEMIA E O NOVO NORMAL}

A pandemia provocada pelo covid-19 reforçou a importância da manutenção preditiva nas indústrias. Com a necessidade de alta produtividade, as paradas de manutenção se tornaram cada vez mais dificultosas e por isso o investimento em processos preditivos e à distância proporcionam maior tranquilidade nessa fase. Destacam, também, que esse processo já vinha crescendo com a indústria 4.0 e o novo cenário mundial acelerou a evolução do segmento de manutenção, com uma crescente por tecnologias com esse propósito nos parques industriais (A VOZ DA INDUSTRIA, 2021). 
A pandemia acelerou diversas mudanças na metodologia de manutenção industrial, pois já existia uma tendencia na diminuição das interações humanas com equipamentos energizados e presença de pessoas em locais como subestações. Sendo importante garantir a segurança das pessoas nesses ambientes e também respeitando os protocolos de distanciamento (A VOZ DA INDUSTRIA, 2021).

O novo normal reflete essas transformações também no cotidiano da equipe de manutenção, na geração de uma nova abordagem sobre os métodos e processos utilizados, buscando agilidade e eficiência para a superação das reduções e paralisações no período pandêmico. Onde através do monitoramento online, é possível identificar falhas potenciais, ou seja, sinais de irregularidades de forma prematura, que justifiquem uma ação preventiva e ainda contribui no combate ao coronavírus, em razão da possibilidade da automação do processo de captura de dados em determinados equipamentos, reduzindo o número de deslocamentos e ações manuais entre os colaboradores, uma vez que os dados são extraídos e disponibilizados através de hardwares e softwares conectados à internet (VIBMASTER, 2020)

De forma rápida, a maioria dos negócios teve que se reinventar e aprender como agir em meio a uma crise nunca vista, setores como a indústria de manufatura se tornam um termômetro sobre como as empresas farão para se adaptar a uma nova economia internacional em um mundo pós-pandemia (ou novo normal) (MARINELLI, 2021).

\section{CONCLUSÃO}

O uso de técnicas de medição de temperatura sem contato em indústrias já existia e seguia em uma crescente, pois contribui para redução de custos, maior qualidade e eficiência operacional e otimização de tempo em manutenção. Com o atual cenário mundial, um novo fator se fez parte integrante do processo produtivo para adequação dos fluxos de trabalho: atender aos protocolos sanitários para reduzir os riscos de contaminação e alastramento do COVID-19 com o menor impacto na cadeia produtiva.

Com isto, observou-se que a aplicação da termografia na manutenção preditiva, que apresentava grandes benefícios à indústria quanto a melhoria de processos, produção, operação e manutenção, agora é fundamental para garantir as atividades operacionais de modo cada vez mais pontual e efetivo, cuidando das pessoas envolvidas na linha de produção e se mantendo de maneira competitiva mesmo em situações adversas, como a pandemia causada pelo novo coronavírus. 
Assim, a manutenção preditiva com inspeções por termografia ganha cada vez mais destaque pela sua contribuição de forma antecipada onde verifica a saúde dos processos - sejam equipamentos, componentes, sistemas - em operação resolvendo situações antes de sua ocorrência efetiva, como também diminuindo, e até evitando, desprogramações, paradas e, agora, aglomerações, além de apoiar significativamente o setor de planejamento, custos não previstos e, consequentemente, rentabilidade. 


\section{REFERÊNCIAS}

A VOZ DA INDUSTRIA. 2021. Pandemia: impactos para a manutenção preditiva e à distância. Disponível em: <Pandemia: impactos para a manutenção preditiva e à distância (avozdaindustria.com.br)> Acesso em 09 de julho de 2021.

COSTA. A. H. 2010. Manutenção preditiva. Universidade Estadual Paulista. UNESP.

FLUKE. 2009. Introdução aos princípios da termografia. Curitiba: Editora ATP. 72 p.

GEBRAN, A. P. 2013. Manutenção e Operação de Equipamentos de Subestações. 1a Ed. Porto Alegre. Editora: Bookman. 246 p.

JÚNIOR, S. C. G. 2017. Sistema Autônomo para Inspeções Visuais e Termográficas em Subestações de Energia Elétrica. Disponível em:

https://repositorio.ufmg.br/bitstream/1843/BUOSAU3HXC/1/disserta_o__final_2017__cd.pdf. Acesso em 28 de junho de 2021.

KARDEC, A. P., NASCIF, J. A. 2018. Manutenção. Função Estratégica. 4ạ Ed. Rio de Janeiro: Qualitymark. $308 \mathrm{p}$.

KOMINSKY, J.; LUCKINO, J. S,; MARTIN, T. F. 2006. Passive infrared thermography - A qualitative method for detecting moisture anomalies in Building envelopes. [S.I.].

MARINELLI, I. 2021. Pandemia acelera adesão de tecnologia no setor industrial. Disponível em: Pandemia acelera adesão de tecnologia no setor industrial - Revista Manutenção (revistamanutencao.com.br). Acesso em 09 de julho de 2021.

NORMA PADRÃO. 2018. NP.001.EQTL: Diretrizes de Manutenção em Linhas de Transmissão. Grupo Equatorial Energia.

SANTANA, Tadeu Silva de. 2018. A Termografia aplicada à Manutenção de Transformadores de Potência a Seco. Disponível em:

<https://pei.ufba.br/sites/pei.ufba.br/files/dissertacao_tadeu_santana_-_versao_final.pdf> Acesso em 29 de junho de 2021.

SILVA, I. Z. 2020. Aplicação da Termografia na Manutenção de instalações elétricas industriais. Disponível em: <http://repositorio.poli.ufrj.br/monografias/monopoli10031777.pdf >. Acesso em 27 de julho de 2021.

VIBMASTER. 2020. Monitoramento Online: o Novo Normal na Manutenção Preditiva. Disponível em: <Monitoramento Online: o Novo Normal na Manutenção Preditiva (vibmaster.com.br)> Acesso em: 10 de Julho de 2021.

VERRATI, A. B. Sistema básico de inspeção termográfica. Disponível em

<https://www.docsity.com/pt/?redirect=\%2Fcontent\%2FABAAAAxCEAE\%2Fprograma-tpm-8-pilaresmanutencao>. Acesso em 28 de junho de 2021. 


\section{Capítulo 7}

doi) $10.37423 / 210704466$

O GUINDASTE: UMA METODOLOGIA ATIVA PARA ASENGENHARIAS COMPATÍVEL COM A INDÚSTRIA 4.0

Daniel Martins Papini Mota

Dayse Nascimento Anselmo

Lucas Silvestre Chaves

Maria Marta Ribeiro da Costa

Silvana Julia da Silveira Diniz
Centro Universitário UNA-MG

Centro Universitário UNA-MG

Centro Universitário UNA-MG

Centro Universitário UNA-MG

Centro Universitário UNA-MG 
Resumo: A mudança do mercado de trabalho é inevitável. Com o surgimento da indústria 4.0 faz-se necessário ajustes dentro da sala de aula para que o aluno se torne protagonista e cocriador do seu conhecimento. Assim, esse aluno obterá uma formação multidisciplinar, flexível com competências emocionais e fácil adaptação a desempenhar trabalhos colaborativos. Dessa forma, esse trabalho apresenta uma atividade realizada nas disciplinas de Mecânica Geral aplicada na Faculdade UNA de Contagem, com o objetivo de proporcionar uma prática coerente com o currículo, a qual promova o progresso e a compreensão dos alunos, através de feedbacks contínuos para o fortalecimento de competências e habilidades que irão auxiliá-los no mercado de trabalho. Nessa prática, os alunos desenvolvem um protótipo de um para participar de um campeonato cujo vencedor será a equipe que possuir um guindaste mais resistente. Pode-se perceber a autonomia, gestão do tempo, planejamento e liderança desenvolvidos nas equipes a partir de critérios avaliativos bem definidos. Conclui-se também, que uma metodologia ativa bem aplicada irá impactar diretamente no aprendizado do aluno, impulsionando-o para o mercado de trabalho.

Palavras-chave: Indústria 4.0. Metodologia Ativa. Habilidade. Competência. Guindaste. 


\section{INTRODUÇÃO}

A quarta revolução industrial, tem impactado a humanidade de forma profunda e exponencial, tendo como característica, tecnologias que permitem a fusão do mundo físico, digital e biológico. Nesse contexto, as indústrias devem assim focar em uma estratégia em que se muda o presente e se constrói o futuro (ABDI, 2019). Segundo Aires (2018), os setores que fazem a diferença no mercado, são os que se preocupam com a gestão do conhecimento e a capacitação para esta nova fase.

Atualmente, o ensino superior tem sido desafiado a contextualizar seu processo de ensino e aprendizagem em virtude dos desafios do mundo atual. As instituições vêm recebendo uma demanda de alunos da geração Y e Z, havendo, portanto, a necessidade de repensar as metodologias e métodos que vem sendo utilizados no aprendizado dos oriundos destas gerações (PERRONE et al, 2016).

O uso de metodologias ativas resulta em mudanças na aprendizagem (SILVA, 2013). A atividade proposta consistiu em construir um guindaste protótipo funcional, confeccionado por palitos de picolé, com uma base que possa sustentar as diversas peças de diferentes pesos. Diante deste contexto, como aprendizagem significativa, na metodologia ativa aplicada ocorre o engajamento do aluno na vivência profissional, aliada ao conceito cientifico, correlacionando o lado humano, social e prático-profissional.

O objetivo geral da metodologia aplicada, foi de proporcionar, a partir de uma prática coerente com o currículo, uma atividade que promova o progresso e a compreensão dos alunos, através de feedbacks contínuos para o fortalecimento de competências e habilidades que irão auxiliá-los no mercado de trabalho. Para tanto se tem como objetivos específicos:

$>$ ensinar o aluno a pesquisar;

> introduzir e aplicar os conceitos de momento fletor, treliças, tensão;

$>$ realizar prática de cálculo de momento fletor, treliças, tensão;

$>$ estudar as propriedades e características dos materiais;

$>$ reconhecer e distinguir materiais;

aprender a gestão do tempo a partir do cumprimento de prazos de tarefas;

aprender a gestão de comunicação a partir do trabalho em grupo; 
gerenciar planejamento e liderança;

$>$ realizar análise crítica dos testes;

$>$ construir um protótipo.

\section{REFERENCIAL TEÓRICO}

Ao longo da história, a humanidade foi marcada por diversas revoluções. A evolução nos métodos industriais de produção impulsiona pesquisas e avanços tecnológicos nas diversas áreas do conhecimento. A robótica, inteligência artificial, realidade aumentada, internet das coisas, dentre outras tecnologias impactam, de sobremaneira, a forma de ver o mundo e de estudar os conteúdos tratados nos cursos de engenharia.

O cenário do mercado de trabalho está em constante mudança. As atividades propostas em sala de aula devem acompanhar tais evoluções, adequando suas metodologias de forma a maximizar os resultados obtidos a partir das práticas propostas. Neste contexto, o trabalho em equipe se mostra como uma poderosa estratégia de crescimento pessoal e acadêmico.

De acordo com Junior (2015), é importante motivar e estimular o aprendizado do graduando. Schwab (2016), ainda reforça que os alunos devem ser capacitados e orientados a reconhecer que ao entrar no mercado de trabalho, eles serão parte de um sistema que requer formas mais colaborativas de interação.

A aprendizagem é um processo, através do qual, adquire-se habilidades, informações, atitudes, valores. Aprende-se quando há contato com outras pessoas, com situações do meio em que vive, com a realidade, com o ambiente em que frequenta. As aprendizagens são geradas quando criados alguns hábitos para poder prestar atenção. $\mathrm{O}$ ato de aprender é uma constante em nossa vida e a aprendizagem é pautada em alguma coisa para aprender. Contudo, para que o aluno aprenda, a metodologia de aprendizagem deve ser eficaz e eficiente (SZLAK, 2007). O uso de práticas docentes com o objetivo de desenvolver além do aspecto profissional, cognitivo, humanista e a capacidade de ultrapassar a sala de aula, fazendo com que a aprendizagem ocorra em qualquer lugar (físico ou digital), torna-se, então, imprescindível.

Ao usar metodologias ativas, o professor tem o papel de mediador da aprendizagem do aluno. Neste momento professor e aluno tornam-se parceiros nas atividades e corresponsáveis pelo processo. 0 sucesso da metodologia é sua adequação a uma atividade pertinente ao graduando, podendo ser de 
forma interdisciplinar ou multidisciplinar, deixando bem claro os propósitos aos quais ela se destina, alinhando assim os objetivos de aprendizagem (MASETTO, 2011).

Especialistas da Dell Technologies apontam que nos próximos 10 anos, "todas as organizações e os negócios serão baseados em tecnologia, exigindo que as empresas repensem os modelos atuais de infraestrutura e formas de trabalho". O IFTF (Institute for the Future) com o avanço tecnológico, até 2030, 85\% das profissões de 2030 serão novas, ou seja, ainda não foram inventadas. Contudo, de acordo com a pesquisa do IFTF, a tecnologia não irá necessariamente substituir os profissionais, mas vai impactar, principalmente, a forma de buscar um trabalho. Sendo assim, as empresas irão procurar cada vez mais colaboradores para executar tarefas específicas e não mais ocuparem uma posição (INFOR CHANNEL,2019).

Segundo Nunes (2018), o profissional 4.0 deverá ter uma formação multidisciplinar, ser flexível, possuir domínio de novas ferramentas, competências emocionais, fácil adaptação e desempenhar trabalhos colaborativos. Acrescenta-se a esse profissional, a habilidade de pró-ativismo e a capacidade de discernimento das informações disponíveis na rede mundial de computadores.

A educação para atender ao mercado de trabalho do futuro próximo, deve então ultrapassar a sala de aula, oferecendo aos alunos mais do que fazer um curso superior e um diploma. A estratégia é ser competitiva, desenvolvendo um aprendizado que ultrapasse a sala de aula e não apenas par desenvolver profissionais, mas também indivíduos e cidadãos. Esse aprendizado deve vir a partir de práticas inovadoras ficando assim em sintonia com o século XXI

\section{METODOLOGIA}

No curso de Engenharia Mecânica, a disciplina Mecânica Geral aborda conceitos de momento, centro de massa, momento de inércia, equilíbrio e o aluno constrói habilidades preparando-se para a disciplina resistência dos materiais. Foi proposta aos alunos desta disciplina de Mecânica Geral, a atividade denominada "O Guindaste". Sendo assim, o aluno será capaz de agrupar as habilidades construídas e colocá-las em prática.

A metodologia ativa "O Guindaste", é um trabalho em grupo no qual os alunos devem construir uma grua de palito de picolé e colocá-la para suportar diferentes cargas. Trata-se de uma gamificação cujo ganhador é o guindaste que suportar maior carga, isto é, o grupo que construir o guindaste mais resistente ganhará a competição. 
A dinâmica da metodologia ativa utilizada, consiste em enviar aos alunos por meio da plataforma digital, um edital explicativo sobre o que precisam fazer. Para melhor entendimento, a atividade é dividida em três partes:

> primeira parte (pesquisa): é destinada à pesquisa. O aluno deverá procurar na bibliografia, assuntos relevantes sobre o funcionamento dos guindastes, tipo grua. Após a pesquisa eles serão capazes de reconhecer algumas competências que irão necessitar para a construção do guindaste de picolé. É fornecido ao aluno um modelo de grua a ser confeccionado por ele, conforme Figura 1, e, alguns parâmetros a serem seguidos, como a altura permitida, o tipo de cola a ser utilizado, a fixação da base do guindaste, a não automatização do içamento de cargas.

Figura 1: Croqui do guindaste

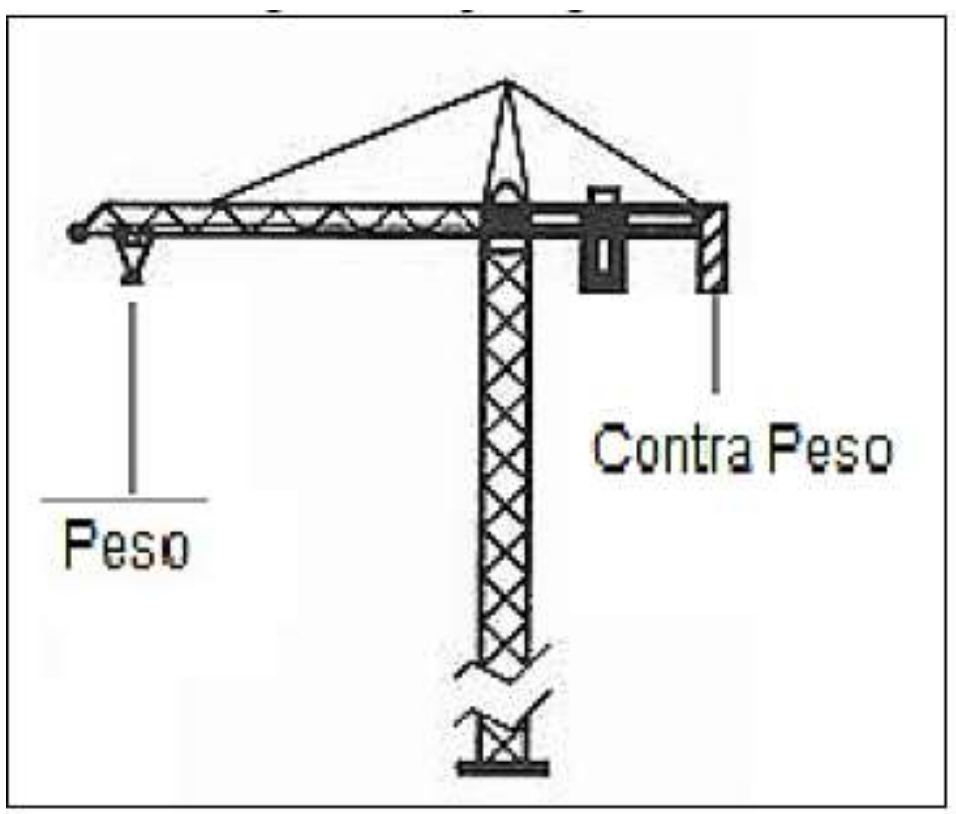

Fonte: Adaptada de PINTEREST; 2019

> segunda parte (compreensão): é orientado aos alunos que visitem sites que apresentam algumas competições já realizadas. Porém ao verificarem os sites, os alunos percebem que há uma grande diferença do projeto que eles visualizam em relação ao que irão construir. Nessa fase, os alunos realizam questionamentos envolvendo os principais conceitos aprendidos em sala.

terceira parte (concepção): nessa fase o aluno começa o projeto, isto é, ele coloca em prática o que realmente aprendeu em sala, através de cálculos envolvendo equilíbrio, momento de inércia e momento, afim de projetar um guindaste resistente suportar as cargas que serão testadas (mão na massa). 
quarta parte (orientação): os alunos são orientados a procurar o professor durante o semestre para receberem orientações e feedbacks referente ao desenvolvimento.

Durante o semestre o professor acompanha os alunos, através de encontros mensais onde são discutidas as dúvidas, sugestões de melhoria e tarefas para o próximo encontro. Nestes encontros, o professor coleta informações relacionado aos objetivos específicos da atividade, para relacioná-los aos critérios de avaliação.

No início da atividade, discutiu-se com os alunos os critérios de avaliação para organizá-los e mensurar o alcance dos objetivos das atividades em cada encontros mensais, conforme Quadro 1 a seguir.

\section{Quadro 1: Critérios de Avaliação}

\begin{tabular}{|c|c|c|c|c|}
\hline Critérios & $1 d$ & $\frac{1}{\text { Peso }}$ & $\frac{1}{\text { Paso }}$ & contrapeso \\
\hline & $50 \%<\mathrm{D}<65 \%$ & $65 \%<C<75 \%$ & $75 \%<B<85 \%$ & $A \geq 85 \%$ \\
\hline Autonomia & $\begin{array}{l}\text { A equipe apresentou } \\
\text { dependència do professor e } \\
\text { dos outros grupos }\end{array}$ & $\begin{array}{c}\text { Parte da equipe desenvolveu } \\
\text { sua autonomia e parte da } \\
\text { equipe apresentava-se } \\
\text { dispersa com pouca } \\
\text { concentração na atividade } \\
\text { proposta }\end{array}$ & $\begin{array}{c}\text { A equipe conseguiu } \\
\text { desenvolver sua } \\
\text { autonomia, discutindo o } \\
\text { tema entre os próprios } \\
\text { componentes porém, } \\
\text { houve algum momento em } \\
\text { que precisaram de um } \\
\text { apoio do professor }\end{array}$ & $\begin{array}{c}\text { A equipe conseguiu } \\
\text { desenvolver sua } \\
\text { autonomia, discutindo } \\
\text { entre os proprios } \\
\text { componentes os assuntos } \\
\text { e tirando as suas próprias } \\
\text { conclusōes de forma } \\
\text { assertiva. }\end{array}$ \\
\hline $\begin{array}{l}\text { Gestão de } \\
\text { tempo }\end{array}$ & $\begin{array}{c}\text { Todos os prazos foram } \\
\text { transgredidos e a equipe nāo } \\
\text { conseguiu concluir a } \\
\text { atividade prevista para o } \\
\text { próximo encontro }\end{array}$ & $\begin{array}{c}\text { Parte dos prazos foram } \\
\text { transgredidos e parte dos } \\
\text { prazos foram cumpridos. As } \\
\text { atividades foram entregues } \\
\text { com atraso }\end{array}$ & $\begin{array}{l}\text { Os prazos foram } \\
\text { cumpridos e as atividades } \\
\text { foram entregues no } \\
\text { momento certo. }\end{array}$ & $\begin{array}{l}\text { As atividades foram } \\
\text { cumpridas com Exito antes } \\
\text { dos prazos estabelecidos }\end{array}$ \\
\hline Planejamento & $\begin{array}{c}\text { A equipe trabalhou de forma } \\
\text { desorganizada. Sem } \\
\text { objetivo. Sem } \\
\text { comprometimento com o } \\
\text { aprendizado e com os } \\
\text { demais componentes }\end{array}$ & $\begin{array}{l}\text { Apenas parte dos } \\
\text { componentes trabalharam } \\
\text { de forma plancjada }\end{array}$ & $\begin{array}{c}\text { A equipe se planejou, } \\
\text { atribuiu as funçōes e } \\
\text { tarefas de forma a atingir } \\
\text { os resultados }\end{array}$ & $\begin{array}{l}\text { A equipe se planejou, } \\
\text { dividiu as funçöes e } \\
\text { tarefas de forma a atingir } \\
\text { os resultados acima do } \\
\text { esperado. }\end{array}$ \\
\hline Liderança & $\begin{array}{c}\text { A minoria dos componentes } \\
\text { da equipe trabalharam em } \\
\text { prol de desafio }\end{array}$ & $\begin{array}{l}\text { Apenas parte dos } \\
\text { componentes participaram } \\
\text { da construção do desafio }\end{array}$ & $\begin{array}{l}\text { Toda a equipe participou. } \\
\text { O desafio foi realizado. }\end{array}$ & $\begin{array}{c}\text { Toda a equipe traballou e } \\
\text { os resultados foram acima } \\
\text { do esperado }\end{array}$ \\
\hline
\end{tabular}

Fonte: Autores; 2018 


\section{RESULTADOS}

Ao decorrer dos encontros, verificou-se a aplicação da teoria da disciplina no desenvolvimento do protótipo através de memórias de cálculos realizadas pelos próprios alunos. E, o acompanhamento das partes apresentadas na metodologia utilizando os critérios, o que possibilitou a percepção de evolução do grupo ao decorrer do semestre.

\subsection{DIA DA COMPETIÇÃO}

No dia da competição cada grupo foi convidado a ir ao centro do evento e explicar ao público, como realizaram as etapas de construção do seu protótipo, utilizando termos técnicos aprendidos durante o curso. Iniciou-se a competição com o corpo de teste com a carga mais baixa afim de que todos os participantes tenham a oportunidade de explicar os cálculos realizados.

Após a explicação, inicia-se o momento do içamento dos corpos teste, como pode ser visto nas Figuras 1 e 2 a seguir.

As Figuras 3 e 4 mostram o momento em que os alunos, após a explicação sobre o protótipo construído pelo grupo, verificam a resistência do guindaste. 


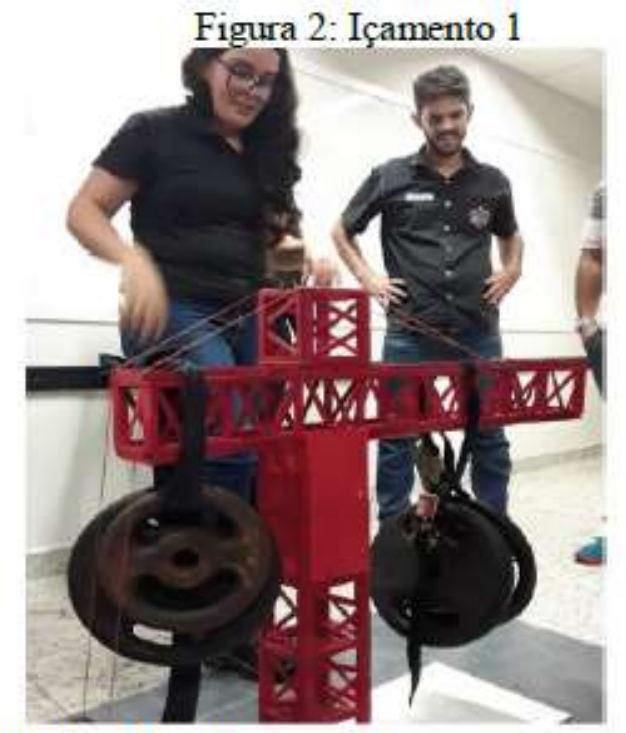

Fontes: Os autores; 2017

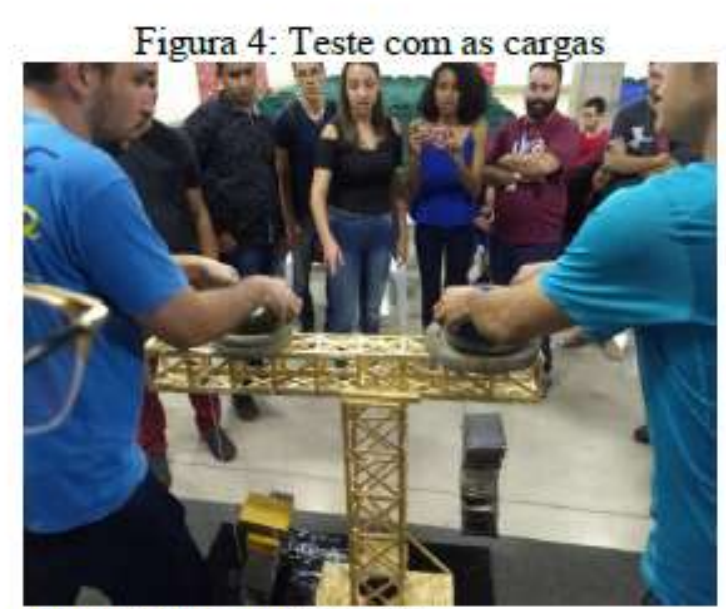

Fontes: Os autores; 2017

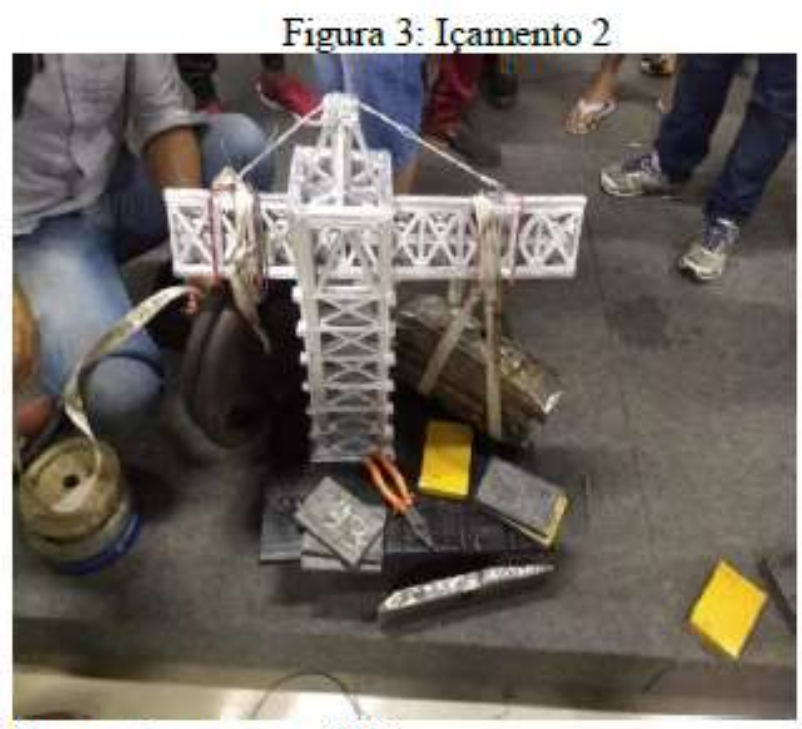

Fontes: Os autores; 2018

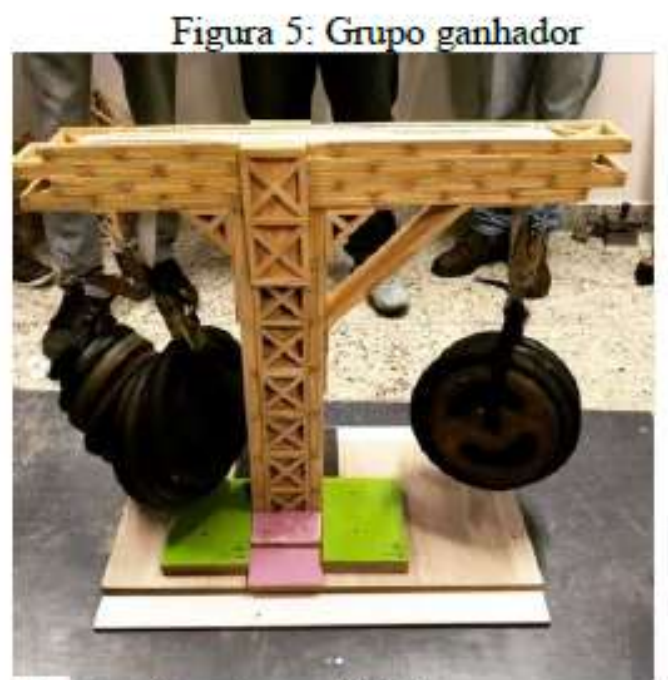

Fontes: Os autores; 2017

\section{CONSIDERAÇÕES FINAIS}

De acordo com a evolução da indústria atual, o profissional da indústria 4.0 necessita desenvolver competências e uma visão multidisciplinar para atuar no mercado. Em um cargo de liderança, ele não exercerá apenas uma posição direcionada, mas sim, uma posição mais complexa e criativa, tornandoo responsável por todo o processo produtivo. Ao trabalhar em equipe o aluno desenvolve a autonomia, sendo corresponsável do seu próprio aprendizado, desenvolvendo uma visão multidisciplinar, colaborativa e crítica, com capacidade de se adaptar às mudanças e às novas funções. 
Os encontros com o professor são importantes pois desenvolvem a capacidade analítica do aluno de cruzar dados e tomar decisões a partir dos feedbacks apresentados. È a partir deles que se consegue mensurar o desenvolvimento do aluno.

Pode-se concluir que com o planejamento, a gestão do tempo, liderança controlados, os alunos foram capazes de:

pesquisar e apresentar aplicações dos conceitos dos conteúdos envolvidos na disciplina Mecânica Geral;

$>$ realizar cálculos referentes ao conteúdo;

estudar as propriedades características dos materiais;

apresentar senso crítico de acordo com os testes;

construir o protótipo dentro das especificações recomendadas.

Para constatação do sucesso da atividade, coletou-se as opiniões de vários alunos que participaram da atividade. Abaixo, segue algumas opiniões:

para o aluno R.M.M:

“O guindaste foi a melhor experiência que eu tive em relação prática sobre projetos no curso de engenharia, junto com o projeto de solenóides feito num trabalho de física. Sem qualquer dúvida contribui na minha formação e na verdade a forma de enxergar o dia a dia na engenharia, em serviços gerais que tem estruturas treliçadas como as unidades de tratamento de minério. (...)Foi demais, de verdade. Sem puxação de saco, foi divertido e trabalhoso. Mas ver tudo funcionando foi sensacional."

para o aluno L.H.O:

"Achei muito bom. E com certeza contribui com minha formação, pois o que gera mais experiência são as práticas em cima das teorias aprendidas.Vou citar o principal ponto que assemelha ao mercado na minha opinião: Gestão de projeto (organização, planejamento, divisão de tarefas, trabalho coletivo)"

para o aluno G.M.R:

"Gerência do tempo foi essencial, mas por falta de experiência com esse tipo de montagem, quase não foi o suficiente. A liderança foi fundamental, não no quesito de designar tarefas, mas no quesito tomar a frente e começar o trabalho, dar um rumo no trabalho mesmo que as vezes quase sozinho. Sim pode contribuir, pois com atividades como essa podemos alinhar nosso aprendizado teóricos à prática." 
para o aluno L.C.R:

\begin{abstract}
"Para mim foi de grande contribuição para minha formação sim, pretendo trabalhar com cálculos mecânico e estrutural e foi uma experiência em ver a estrutura que fizemos eu e meus colegas suportando toda aquela carga. Dependendo do tipo de montagem que você faz na estrutura das vigas você consegue maior resistência, fizemos também o cálculo da carga de suportação e também do contra-peso para o equilíbrio, e esse tipo de conceito é amplamente utilizado em construções estruturais em geral. (...) o tempo foi suficiente para fazer um trabalho de qualidade tendo em vista que foi falado com a turma no início do semestre. Com relação a liderança, nós no nosso grupo fomos tranquilos com isso, não foi necessário eleger um líder, todos nos comprometemos na medida do possível. Com relação a autonomia, todos do grupo fizeram o que ficou decidido que faria, sem ter problema, em outras palavras, cada um fez o que se comprometeu a fazer."
\end{abstract}

A metodologia em questão demonstrou-se alinhada a necessidade de adaptação do ensino superior com a nova realidade, em que o aluno deve ser o verdadeiro protagonista de seu próprio aprendizado. 


\section{REFERÊNCIAS}

ABDI . Agenda Brasileira para a Indústria 4.0: O Brasil Preparado para os Desfios do Futuro.

< http://www.industria40.gov.br/>. Acesso em: 31 de março de 2019.

AIRES, Regina W. A.A.; MOREIRA Fernanda K.; FREIRE, Patricia S. Indústria 4.0: Desafios e Tendências para a Gestão do Conhecimento. Anais do I SUCEG - Florianópolis - SC - Brasil - 07 e 08/12/2017.

INFOR CHANNEL. 85\% das profissões que existirão em 2030 ainda não foram inventadas. <https://inforchannel.com.br/2017/07/27/85-das-profissoes-que-existirao-em-2030-ainda-naoforam-inventadas/> Acesso em: 04 de abril de 2019

JUNIOR, W.C. da. Alunos do século 21: novos caminhos para o ensino superior. Jornal do Brasil. nov. 2015. <http://www.jb.com.br/sociedade-aberta/noticias/2015/09/12/alunos-do-seculo-21-novoscaminhos-para-o-ensino-superior/> . Acesso em: 31 de março de 2019.

SCHWAB, K. A Quarta Revolução Industrial. São Paulo: Edipro, 2016.

NUNES, A. Quais Competências o Profissional da Indústria 4.0 deve ter? Computerworld. Jul. 2018.

PERRONE C; GONÇALVES J; COMAZZETTO L; VASCONCELLOS S. A Geração Y no Mercado de Trabalho: um Estudo Comparativo entre Gerações. Psicol. cienc. prof. [online]. 2016, vol.36, n.1, pp.145-157. ISSN 1414-9893.

SILVA, Salete. Aprendizagem ativa. Revista Ensino. Editora Segmento. Edição 257. Jul.2013. SZLAK, David Carlos. Como as pessoas aprendem: cerebro, mente, experiencia e escola. Câmara Brasileira do Livro. ed. Senac Sao Paulo. 2007. Brasil. 


\title{
Capítulo 8
}

doi) $10.37423 / 210704468$

\begin{abstract}
AVALIAÇÃO ERGONÔMICA DO AMBIENTE CONSTRUIDO: ESTUDO NA CENTRAL DE MATERIAIS E ESTERILIZAÇÃO DE UM HOSPITAL UNIVERSITÁRIO
\end{abstract}


Resumo: Este artigo relata uma avaliação ergonômica do ambiente construído na Central de Materiais e Esterilização de um Hospital Universitário em Recife, foi aplicada a Metodologia Ergonômica para o Ambiente Construído (MEAC), proposta por Villarouco (2008). Após análise dos dados, foi possível identificar alguns problemas e as recomendações foram sugeridas.

Palavras-chave: Ergonomia, Central de Materiais e Esterilização, Ergonomia do Ambiente Construído. 


\section{INTRODUÇÃO}

A Central de Materiais e Esterilização (CME) é definida pelo Ministério da Saúde (1987), como "conjunto de elementos destinados à recepção e expurgo, preparo, esterilização, guarda e distribuição do material não caracterizado como uso único para as unidades de estabelecimento de saúde".

A Resolução RDC no. 307, de 14 de novembro de 2002, considera a CME uma unidade de apoio técnico, que tem como finalidade o fornecimento de materiais médico-hospitalares adequadamente processados, proporcionando assim, condições para o atendimento direto e a assistência à saúde dos indivíduos enfermos e sadios.

Assim, o estudo da ergonomia visa melhorar a adaptação do trabalho ao homem, sendo este multidisciplinar, envolve aspectos físicos e organizacionais. O trabalho diário realizado em condições inadequadas pode levar ao surgimento de problemas de saúde (IIDA, 2005).

Portanto, o presente estudo foi realizado com o objetivo de avaliar o ambiente da CME de um Hospital Universitário sob o foco ergonômico, a partir da Metodologia Ergonômica para o Ambiente Construído (MEAC), proposta por Villarouco (2008).

\section{METODOLOGIA}

Trata-se de uma pesquisa exploratória e qualitativa, de cunho descritivo. A população estudada foi de 19 profissionais de enfermagem, de um universo de 49, de ambos os sexos. A pesquisa foi realizada de outubro a novembro de 2016. Para a realização da análise, optou-se pela MEAC.

Desse modo, a MEAC é constituída por 2 (duas) fases; uma de ordem física e outra perceptiva, com geração de recomendações ergonômicas projetuais ou atitudinais para o ambiente. A primeira fase se divide em 3 (três) etapas: (i) Análise Global do Ambiente, (ii) Configuração Ambiental, (iii) Avaliação do Ambiente em Uso, com objetivo de entender e avaliar o sistema homem-atividade-ambiente, com a identificação de elementos facilitadores e inibidores das atividades. Para entender de que maneira o usuário percebe sua interação com o ambiente, a fase de ordem perceptiva utiliza técnicas da Psicologia Ambiental, tais como Mapa Mental ou Cognitivo, Constelação de Atributos, Poema dos Desejos, questionário, entre outros (PAIVA et al, 2016). 


\section{ANÁLISE ERGONÔMICA}

\subsection{ANÁLISE GLOBAL DO AMBIENTE}

A CME está situada no 3o pavimento do hospital, numa área construída de $346 \mathrm{~m}^{2}, 11$ ambientes, 16 postos de trabalho, é um setor fechado e o acesso é limitado.

A equipe é de 49 trabalhadores (enfermeiros, técnicos e auxiliares de enfermagem, auxiliar administrativo e auxiliares de serviços gerais).

O ambiente é limpo, apresenta má conservação dos equipamentos e mobiliários, a iluminação é deficiente, a acústica é aceitável e a temperatura é inconstante, mudando conforme o posto de trabalho.

A NR 32, a RDC 50 de 2002 da ANVISA, e o Ministério da Saúde são diretrizes regulamentadoras de Normas Específicas para o funcionamento da CME.

\subsection{IDENTIFICAÇÃO DA CONFIGURAÇÃO AMBIENTAL}

A edificação é de $346 \mathrm{~m}^{2}$ de área construída, piso em placa de vinílico de cor clara, paredes com azulejos e pintura acrílica semi-brilho de cor clara e teto com forro removível branco. Possui 11 (onze) ambientes, sendo: entrada/recepção, expurgo, área de preparo e esterilização, sala de depósito, sala de repouso, sala administrativa, copa, vestiário e WC masculino, vestiário e WC feminino, área de armazenamento e distribuição e o hall (entrega de materiais).

Consideramos para análise apenas um ambiente: o expurgo. Nele existe um elevador (monta carga) para recebimento de artigos sujos, um condicionador de ar Split, um balcão de inox duplo e centralizado, com armário inferior ao mesmo, três cadeiras giratórias desgastadas, um armário de parede, dois balcões com cubas em inox lateralizados, uma pia para limpeza de materiais de serviços gerais, e um balcão em inox fixo para liberação dos artigos limpos, uma máquina termodesinfectadora e uma lavadora ultrassônica (quebradas).

$\mathrm{Na}$ área de preparo e esterilização tem um condicionador de ar Split, seis mesas dispostas paralelamente para secagem, preparo e embalagem dos artigos, uma pistola de ar comprimido para secagem dos canulados, três seladoras para papel grau cirúrgico, uma incubadora para testes biológicos, uma mesa em fórmica para preparo dos artigos de produção e uma mesa grande em fórmica para apoio à esterilização e armários para guarda de materiais de consumo. Três autoclaves de barreira (duas quebradas) apenas uma funcionando. Um dispensador de álcool gel. 
Na sala administrativa tem três mesas com computadores e um balcão de fórmica lateralizado ao longo da sala, um condicionador de ar Split e dois armários para guarda de documentos.

$\mathrm{Na}$ área de armazenamento e distribuição existe uma pia para higienização das mãos, estantes paralelas para guarda de artigos, um elevador (monta carga) para distribuição de artigos para os blocos cirúrgicos, um balcão com gavetas e uma janela acima do balcão para distribuição dos artigos para os demais setores.

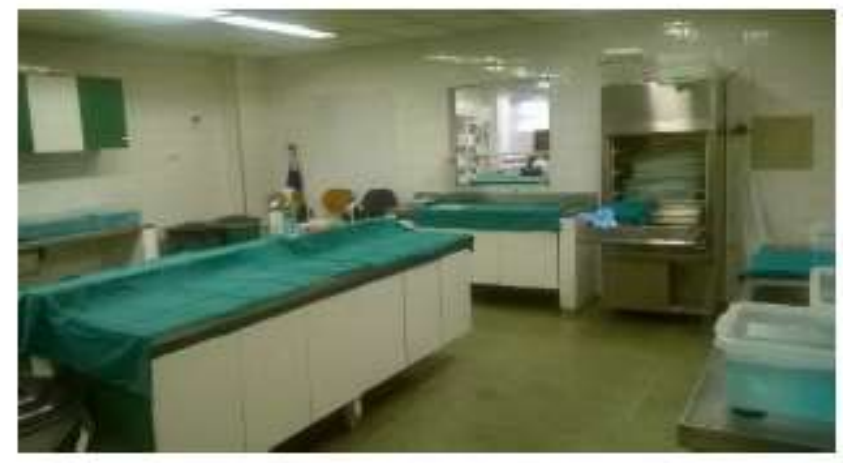

Figura 1. Ambiente analisado: Expurgo

Fonte: Arquivo dos pesquisadores

PLANTA BAIXA DO CME

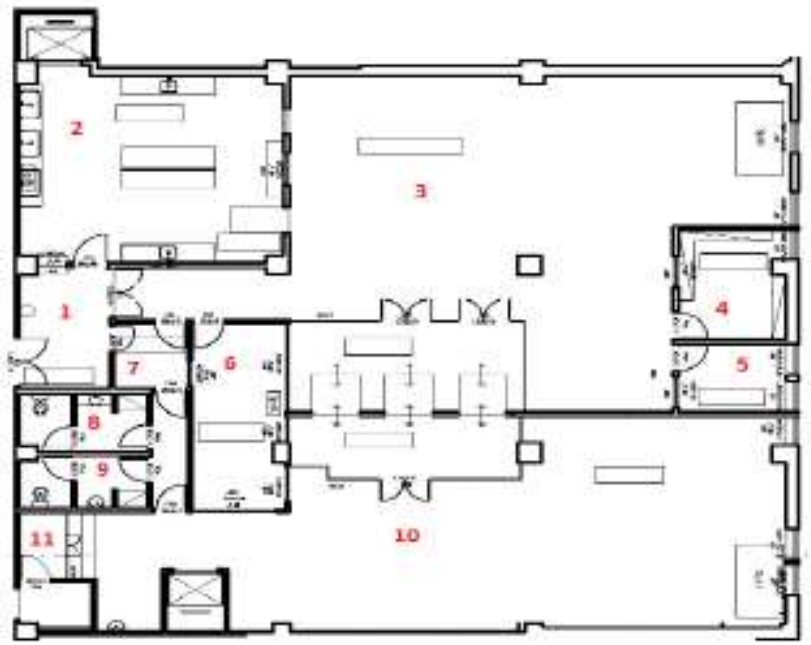

Figura 2. Planta baixa do $\mathrm{CME}$

Fonte: Arquivo dos pesquisadores

1-Entrada/recepção; 2-expurgo; 3-área preparo/esterilização; 4-sala depósito; 5-sala repouso; 6-sala administrativa; 7-copa; 8-vestiário/WC feminino; 9-vestiário/WC masculino; 10-sala de armazenamento e distribuição; 11-hall (entrega de materiais). 
A Norma Técnica utilizada para o parâmetro de avaliação dos aspectos de acessibilidade foi NBR 9050/2015 agregando aspectos de segurança, não tem rota de fuga e os extintores de incêndio estão sem sinalização e em locais inacessíveis e faltando alguns. O acesso a CME pode ser por escadas ou elevadores com sinalização visual e sonora.
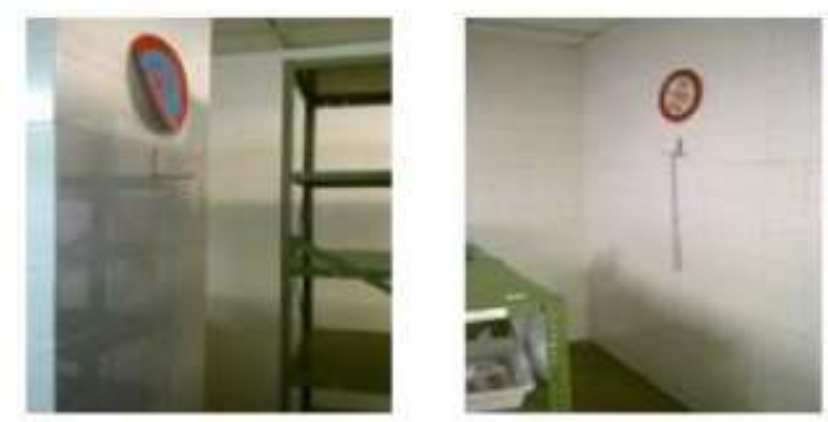

Figura 3. Local dos extintores na área de armazenamento e distribuição

Fonte: Arquivo dos pesquisadores

\section{AVALIAÇÃO DO CONFORTO LUMÍNICO}

A iluminação é composta por luminárias fluorescentes de 40W. Utilizamos o aplicativo Lux Meter, para celular, a fim de medir o nível de iluminância, os dados são apresentados no quadro a seguir e comparados com os níveis indicados pela NBR 5413/1992.

\begin{tabular}{|c|c|c|c|c|}
\hline \multirow[b]{2}{*}{ AMBIENTE } & \multirow[b]{2}{*}{ PONTO } & $\begin{array}{c}\text { MED } \\
\text { (lux) }\end{array}$ & $\begin{array}{c}\text { MED } \\
(\mathrm{lux})\end{array}$ & \multirow{2}{*}{$\begin{array}{l}\text { NBR } \\
5413 \\
\text { (lux) }\end{array}$} \\
\hline & & $08: 00 \mathrm{~h}$ & $16: 00 \mathrm{~h}$ & \\
\hline Expurgo & 2 & 125,1 & 125,1 & 150 \\
\hline
\end{tabular}

Quadro 1. Dados para medição do conforto lumínico

No ambiente escolhido para o estudo (Expurgo), o nível de iluminância estava não conforme com a norma.

\section{AVALIAÇÃO DO CONFORTO ACÚSTICO}

Realizamos medições do ruído interno para analisar o conforto acústico e verificar se os resultados estariam em conformidade com a NBR 10152 da ABNT, 2000. O nível de ruído foi medido com o aplicativo Sound Meter, para celular. 


\begin{tabular}{|c|c|c|c|c|}
\hline \multirow[b]{2}{*}{ AMBIENTE } & \multirow[b]{2}{*}{ PONTO } & $\begin{array}{l}\text { MED } \\
(\mathrm{dB})\end{array}$ & $\begin{array}{l}\text { MED } \\
(\mathrm{dB})\end{array}$ & \multirow{2}{*}{$\begin{array}{c}\text { NBR } \\
10152 \\
\text { (dB) }\end{array}$} \\
\hline & & $08: 00 \mathrm{~h}$ & $16: 00 \mathrm{~h}$ & \\
\hline Expurgo & 2 & 72,9 & 64,1 & $\begin{array}{c}45 \text { a } \\
55\end{array}$ \\
\hline
\end{tabular}

Quadro 2. Dados para medição do conforto acústico

No ambiente analisado, a acústica estava não conforme com a norma, bem acima do limite, devido ao fluxo de pessoas circulando e equipamentos em funcionamento.

\section{AVALIAÇÃO DO CONFORTO TÉRMICO}

O expurgo possui um split de 1.800 BTUs. Utilizamos o aplicativo thermometer, para celular, para verificação do nível de temperatura do ambiente em estudo.

\begin{tabular}{|l|c|c|c|c|}
\hline & & $\begin{array}{c}\text { MED } \\
\left({ }^{\circ} \mathrm{C}\right)\end{array}$ & $\begin{array}{c}\text { MED } \\
\left({ }^{\circ} \mathrm{C}\right)\end{array}$ & \multirow{2}{*}{ NR 17 } \\
\cline { 3 - 4 } AMBIENTE & PONTO & $08: 00 \mathrm{~h}$ & $16: 00 \mathrm{~h}$ & \\
\hline Expurgo & 2 & 28,3 & 28,3 & $20-23^{\circ} \mathrm{C}$ \\
\hline
\end{tabular}

Quadro 3. Dados para medição do conforto térmico

O ambiente está não conforme com a norma. As janelas internas (de recebimento e de entrega de materiais) ficam abertas, favorecendo a não conformidade.

\subsection{AVALIAÇÃO DO AMBIENTE EM USO}

\section{AVALIAÇÃO DO AMBIENTE EM USO NO DESEMPENHO DE SUAS ATIVIDADES:}

\section{FLUXOGRAMA}

O fluxo de uma CME deve ser contínuo e unidirecional, evitando o cruzamento de artigos sujos, limpos e esterilizados, bem como evitar que o trabalhador da área contaminada transite pelas áreas limpas e vice-versa. 


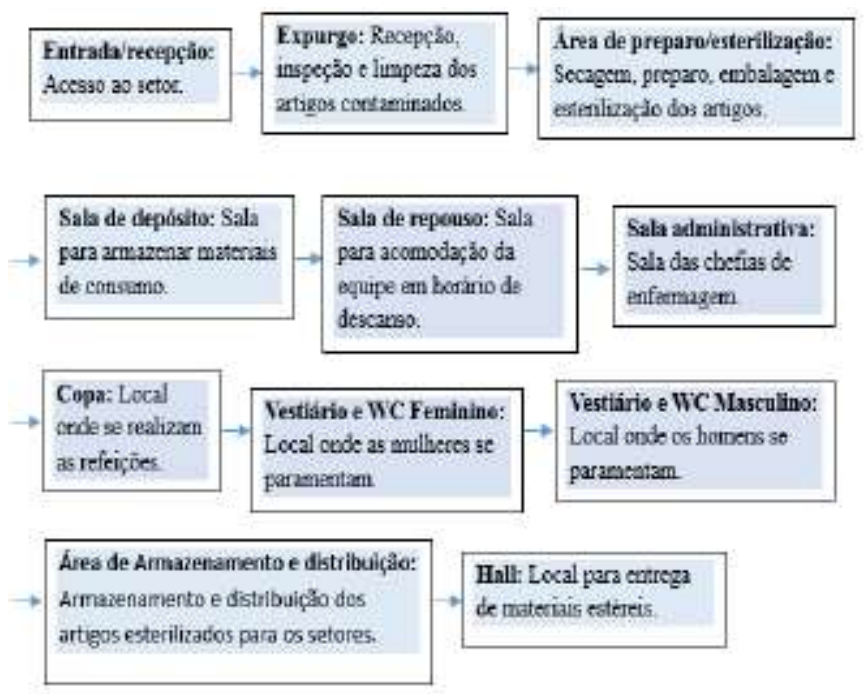

Figura 4. Fluxograma da CME

Através da recepção são entregues os artigos contaminados para serem conferidos e iniciar o processo de lavagem no expurgo, em seguida seguem para a área de preparo, onde são inspecionados novamente, secos e preparados com embalagens para esterilização, depois seguem para esterilização, ao término, são armazenados para posterior distribuição aos setores de origem.

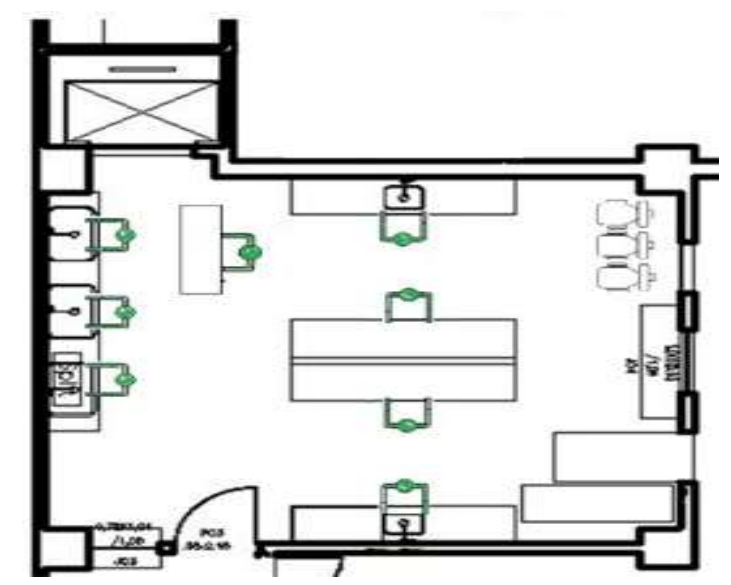

Figura 5. Avaliação antropométrica do expurgo

No layout do Expurgo, a circulação é bem favorecida, porém, deveria estar melhor disposto em relação ao design do mobiliário. Os balcões são altos, os usuários têm que trabalhar em pé, e conforme as variáveis antropométricas dos profissionais, eles ficam em desconforto.

Observamos desconforto aos profissionais no recebimento dos materiais através do monta carga, (a última prateleira é muito alta). 
Como também, a falta de mesas com rodízios para transportar materiais pesados, causam desconforto aos profissionais.

Outra não conformidade, foram as máquinas que sempre estão quebradas e a lavagem é apenas manual, sobrecarregando os profissionais.

Observamos também a falta de cadeiras para os profissionais quando necessitam de uma pausa.

\subsection{PERCEPÇÃO AMBIENTAL DO USUÁRIO}

Para percepção ambiental, o usuário é considerado único, pois experimenta sensações variadas e as compreende conforme seus sentidos e suas condições a nível fisiológico, psicológico e físico (FLORES e ULBRICHT, 2008).

Dessa forma, foi aplicada a Constelação de Atributos idealizada por Moles (1968), ferramenta que possui vantagens como método de coleta simples, rápida e descentralizada; maior liberdade de expressão dos usuários; representação gráfica e legível; respostas a duas perguntas abertas e distintas (uma de caráter imaginário e outra de caráter real) (TAVARES et al, 2016).

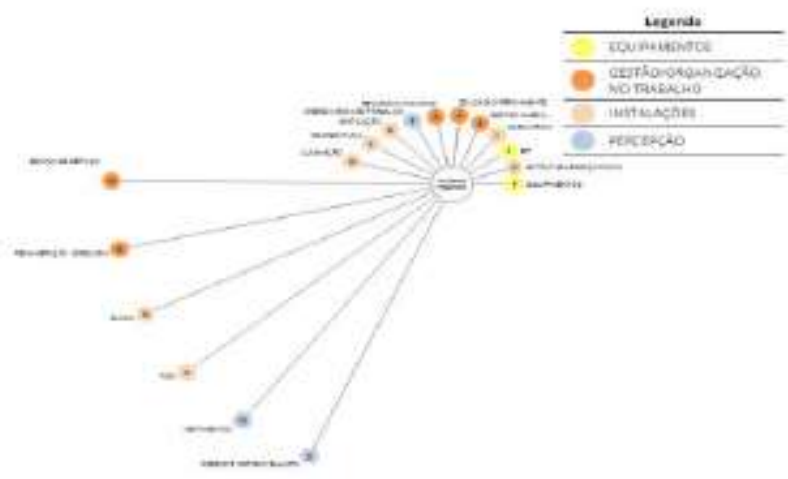

Figura 6. Constelação de atributos "Ideal”

Na figura acima, avaliamos a imagem simbólica do indivíduo frente ao ambiente Ideal, através da pergunta Quando você pensa em uma "Central de Materiais e Esterilização" que idéias ou imagens vem à mente? As respostas evidenciaram a percepção de um ambiente ideal bem estruturado e organizado, com equipamentos de proteção individuais adequados, mobiliários ergonomicamente adaptados, uma gestão moderna, educação permanente presente, RH suficiente evitando a sobre carga de trabalho, temperatura, ruído, iluminação conforme as Normas Regulamentadoras e uma remuneração que satisfaça a classe, como uma escala de serviço mais humanizada que reflete em um melhor atendimento ao usuário no que diz respeito a realização das tarefas. 


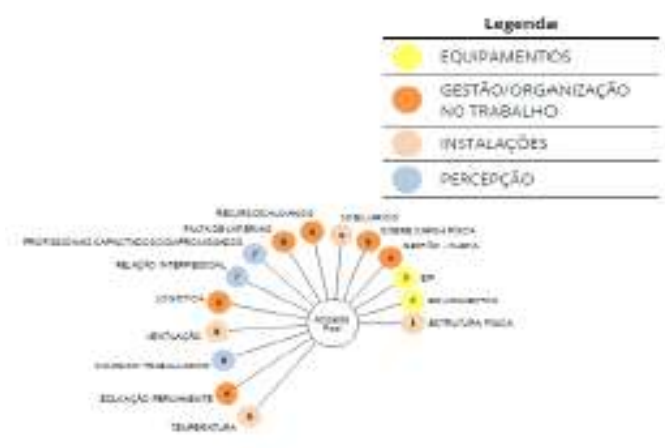

Figura 7. Constelação de Atributos "Real"

Foi avaliada a imagem real do indivíduo frente ao ambiente Real, através da pergunta "Quando você pensa nesta "Central de Materiais e Esterilização" que idéias ou imagens vem à mente? Ao analisarmos as respostas, verificamos que os funcionários são compromissados e capacitados, solicitam uma melhoria na estrutura física, aquisição de equipamentos e mobiliários, uma chefia com gestão humanizada e melhora na relação interpessoal, percebem que a logística precisa ser melhorada, existe sobrecarga física de trabalho, o recurso humano é insuficiente e falta materiais, o que contribui negativamente para a realização de suas atividades.

\subsection{DIAGNÓSTICO ERGONÔMICO DO AMBIENTE E RECOMENDAÇÕES}

\begin{tabular}{|c|c|}
\hline DLAGNOSTICOS & RFCONIFNDAÇOES \\
\hline $\begin{array}{l}\text { Fitintores som } \\
\text { sinalizaçäo, em falta a } \\
\text { com acoseo obstruido. }\end{array}$ & $\begin{array}{l}\text { Providenciar oe esctintores } \\
\text { que faltam, sinalizar } \\
\text { adequadamente e liberar o } \\
\text { acesao aos meamor. }\end{array}$ \\
\hline $\begin{array}{l}\text { Expurgo o fraa do } \\
\text { proparo som pia. }\end{array}$ & $\begin{array}{l}\text { Inatalapio de uma pia para } \\
\text { higionieaçio das mîoa no } \\
\text { expurgo o na jroa de preparo. }\end{array}$ \\
\hline $\begin{array}{l}\text { Mobiliários o } \\
\text { oquipamontos entigos } \\
\text { o ultrapasnados. }\end{array}$ & $\begin{array}{l}\text { Aquinipio de mobilifrios a } \\
\text { squipamentos adequados. }\end{array}$ \\
\hline RH inauficionte. & Redimenaionamento da RH. \\
\hline $\begin{array}{l}\text { Educapio permanente } \\
\text { deficiente. }\end{array}$ & $\begin{array}{l}\text { Promover cursos e } \\
\text { treinnementos aos } \\
\text { traballhadores. }\end{array}$ \\
\hline $\begin{array}{l}\text { Ambientes com } \\
\text { lampadas queimadas } \\
\text { ou danificadas. }\end{array}$ & $\begin{array}{l}\text { Providenciar reposiçio das } \\
\text { larmpadas. }\end{array}$ \\
\hline $\begin{array}{l}\text { Ambiente com } \\
\text { ternperatura fora das } \\
\text { Normas } \\
\text { Regulamentadoras. }\end{array}$ & $\begin{array}{l}\text { Providenciar clirmatizaçio } \\
\text { adequeda para as ambientes } \\
\text { ern questão. }\end{array}$ \\
\hline
\end{tabular}

Quadro 4. Diagnósticos e recomendaçöes 
A CME atende as necessidades a que se propõe, por sua dimensão, teria um potencial para uma maior produtividade se fossem feitos os ajustes necessários. O expurgo foi considerado bem estruturado e respeita ao preconizado para as variáveis ambientais e de conforto, necessita de modernização, revisão dos mobiliários existentes e aquisição de equipamentos. Apresenta pontos críticos, em alguns ambientes a norma não é atendida. Com intuito de eliminar ou diminuir os problemas identificados, e portanto melhorar o layout, o desenvolvimento das atividades e a satisfação dos usuários, construiuse, a partir dos problemas identificados pela percepção dos pesquisadores e dos dados levantados pelas entrevistas e questionários o quadro acima com os respectivos problemas e as recomendações.

\section{CONCLUSÃO}

Os resultados apontam que a ergonomia, área de conhecimento multidisciplinar, pode contribuir de forma positiva para a melhoria da qualidade de vida dos trabalhadores e usuários de serviços, apontando soluções ou minimizando e prevenindo danos à saúde dos profissionais.

Espera-se que os resultados alcançados com esta pesquisa possam colaborar para um olhar atento às necessidades da CME, ressaltando a importância de proporcionar recursos a fim de transformá-la em um ambiente de trabalho adequado. 


\section{REFERÊNCIAS}

ASSOCIAÇÃO BRASILEIRA DE NORMAS TÉCNICAS. NBR 9050: Acessibilidade a edificações, mobiliário espaços e equipamento urbanos. Rio de Janeiro, 2015.

ASSOCIAÇÃO BRASILEIRA DE NORMAS TÉCNICAS. NBR 10152: níveis de ruído para conforto acústico. Rio de Janeiro, $2002.4 \mathrm{p}$.

ASSOCIAÇÃO BRASILEIRA DE NORMAS TÉCNICAS. NBR 5413: iluminância de interiores. Rio de Janeiro, 1992. $13 \mathrm{p}$.

BRASIL. Ministério do Trabalho e Emprego. NR 32 - Ergonomia. Brasília: 2007.

FLORES, A. R. B.; ULBRICHT, V. R.; ZANCHETT, P. S. Terceira idade e moradia. In: Anais do XV Congresso Brasileiro de Ergonomia-ABERGO. Porto Seguro-Bahia, 2008.

IIDA, Itiro. Ergonomia: Projeto e produção. 2a ed. Rev. e ampl. São Paulo: Edgar Blucher, 2005.

PAIVA, M. M.; TAVARES, A. S.; OLIVEIRA, M.; VILLAROUCO, V. Análise Comparativa da Acessibilidade em ILPI's. Anais do I CONAERG. Recife, 2016.

TAVARES, A. S.; AlBuquerque, L. W. N.; BARBOSA, A. H.; VILLAROUCO, V. Percepção ambiental: A importância da opinião dos usuários na geração de recomendação para projetos de ambientes construídos. Anais do X Encontro Nacional de Ergonomia do Ambiente Construído, VII Seminário Brasileiro de Acessibilidade Integral. Recife, 2016.

VILLAROUCO, Vilma. O ambiente está adequado? In: Anais do I Encontro Nacional de Ergonomia do Ambiente Construído, II Seminário Brasileiro de Acessibilidade Integral. Recife, 2008. 


\section{Capítulo 9}

doi $10.37423 / 210704469$

\section{INOVAÇÃO, EMPREENDEDORISMO E FORMAÇÃO DO ENGENHEIRO}


Resumo: O presente artigo relata uma experiência concreta onde a interação de atores que compõem o Sistema Nacional de Inovação (SNI) é suficiente por si só para produzir diálogos públicos e privados capazes de influenciar não apenas na formação de engenheiros comprometidos com a busca da capacidade competitiva nacional como, ao mesmo tempo, produzir soluções empreendedoras que venham ao encontro das necessidades particularmente das micro e pequenas empresas brasileiras. Mostra, por outro lado, que se a interação própria do SNI é uma condição necessária para produzir proximidades cognitivas, a adoção da perspectiva do território é um componente poderoso para articular as dimensões de desenvolvimento e de educação, produzindo desenvolvimento político e social. Para compreender o fenômeno os autores vão buscar elementos teóricos e conceituais na literatura técnica relativa à economia e gestão da inovação, na história do sistema de CT\&I no Brasil, na legislação e em programas governamentais. Como as ações em questão envolviam atores típicos do SNI (UFF, SEBRAE e REDETEC), o trabalho partiu da premissa de que os resultados refletiriam o conjunto de políticas públicas e privadas já em curso no Brasil e que têm como meta preparar a economia brasileira para seu novo protagonismo no cenário da competição global, cuidando dos seus impactos sobre o perfil de aptidões da força de trabalho, sobre novas estruturas administrativas e de organização do trabalho, sobre o padrão de relações industriais e o padrão de regulação institucional nacional e internacional.

Palavras-Chave: Conhecimento, Empreendedorismo, Inovação, Capacitação 


\section{INTRODUÇÃO}

Em entrevista ao Le Monde Diplomatique Brasil de julho de 2010, Federico Burone, Diretor Regional América Latina do IDRC (International Development Research Centre), agência de cooperação canadense que opera em parceria com organizações e instituições ligadas à questão do desenvolvimento local, falando sobre "inovação, meio ambiente e mudanças demográficas", dizia que com relação à inovação era necessário colocarem-se algumas perguntas fundamentais e estruturantes. Burone listava questões objetivas que compõem em grande medida a agenda de inúmeras organizações e instituições envolvidas na temática da "inovação" no Brasil e no mundo: Quais são os resultados? Quais são as metas? Quais são as conquistas sociais ligadas às novas tecnologias e oportunidades que surgem para determinar um papel de maior destaque da economia latino-americana? Quais são os investimentos necessários para propiciar diálogos públicos e privados bem-sucedidos? Quais são os processos para avaliar as inovações sociais combinadas com as inovações tecnológicas?

Olhando a agenda de eventos e de programas do MCT, FINEP, CNPq e outros órgãos e ministérios ligados ao desenvolvimento, acompanhando o sítio eletrônico das agências de inovação, das universidades, das federações de indústria ou de inúmeras outras organizações não governamentais, participando de seminários, workshops e encontros de empresas públicas ou privadas, enfim, seguindo os atores envolvidos e interessados na temática da "inovação" e do desenvolvimento, constata-se a relevância, a abrangência e a atualidade que o tema assumiu no país. Afinal de contas, para usar a metáfora do futebol, para um país que passa da segunda para a primeira divisão no campeonato da competitividade internacional, ciência, tecnologia e inovação se tornam tão estratégicos quanto infraestrutura e energia.

Na abertura da IV Conferência Nacional de Ciência, Tecnologia e Inovação, ocorrida em Brasília entre os dias 26 e 28 de maio de 2010, ao anunciar o aumento do orçamento do MCT, o Presidente Lula afirmou que o Brasil precisa passar a exportar "conhecimento". Em qualquer latitude que se examine a afirmação, essa é a linguagem e a expressão mais atual e esclarecida da inovação: conhecimento que se vende ou ao menos se torna vendável.

O presente trabalho, examinando atores locais que se movem em busca de resultados, buscará compreender por que, em que momento e com que motivação, sujeitos de diferentes filiações institucionais se colocam a caminho para formular, propor e implantar ações conjuntas que vêm a 
compor, como parte, o mosaico de um novo paradigma de articulação institucional cujo leitmotiv é inovação e empreendedorismo. Examinará ainda como, por essa via, acabam por produzir uma "ação" a qual, considerando a definição de DAVENPORT (1998) do "conhecimento como uma capacidade de agir", constitui-se em última análise em produzir "conhecimento". A história tem dois pontos de partida síncronos, porém sem relação explícita de causa e efeito. Por um lado trata-se da criação de uma disciplina optativa em Curso de Graduação em Engenharia de Produção de uma Universidade Pública e, por outro lado, do início de um projeto envolvendo duas instituições ligadas ao complexo de ações de capacitação, consultoria, apoio a pequenas e microempresas e articulação entre oferta e demanda por tecnologia. O fato gerador do encontro foi o desenvolvimento de um projeto cujo objetivo era estruturar métodos de fortalecimento do capital inovativo em territórios selecionados. Os métodos deveriam contribuir para promover desenvolvimento tecnológico e estímulo à inovação nos referidos territórios e, por conseguinte, nas pequenas empresas localizadas nos mesmos.

\section{A INOVAÇÃO COMO FIO CONDUTOR DAS ESTRATÉGIAS DE DESENVOLVIMENTO}

Se na comunidade dos economistas desde os anos 50, Schumpeter e em seguida gerações de seguidores e neo-seguidores já falavam do papel da inovação e da destruição criadora na construção da dinâmica da competição, só bem mais recentemente o assunto sai da esfera de especialistas transformando-se em políticas públicas e privadas que organizam não mais apenas o "modus pensandi", mas agora também o "modus operandi". Constata-se empiricamente o insight poético e profético atribuído ao escritor Victor Hugo segundo o qual "nada é tão irresistível quanto a força de uma idéia cujo tempo chegou". Dentre as reflexões especializadas sobre este fenômeno é um marco o livro organizado por GIBBONS et al

(1994) onde se recupera o conceito marxista de "modo de produção" adaptando-o de forma criativa para propor o "modo 2 da produção do conhecimento", caracterizado, entre outras coisas, pelo fato de se tratar de um conhecimento desenvolvido no contexto da sua aplicação.

A transição para essa fase de uma verdadeira explosão no uso e difusão da inovação na cultura cotidiana do fazer científico, tecnológico e produtivo no Brasil, cuja síntese mais acabada é a introdução e consolidação da perspectiva da "inovação" como leitmotiv dos investimentos em C\&T, não se fez sem o enfrentamento de um componente ideológico forte, o que fica de certa forma explicitado no próprio nome que foi atribuído à Lei 11.196 de 21 de novembro de 2005 de Lei do Bem, 
deixando refletir um certo componente moral que desse respaldo e legitimidade a essa nova forma de alocar recursos e viabilizar o financiamento público para a P\&D pública e privada.

Por mais que houvesse de fato reconhecida necessidade de regulação do sistema e de consolidação dos incentivos fiscais para que as empresas investissem em pesquisa tecnológica e desenvolvimento de inovação, era necessário produzir e acumular reflexões, discussões, teorias e políticas que permitissem compreender as mudanças que se faziam necessárias para dar o salto qualitativo que a produção do conhecimento e a sua incorporação na produção estava a exigir. Um sistema nacional de C\&T que havia se constituído e consolidado em cima do bem sucedido FNDCT (Fundo Nacional de Desenvolvimento Científico e Tecnológico) precisava produzir o próximo passo e este deveria ser necessariamente na direção da inovação.

LONGO (2009), além de autor um dos atores envolvidos na história recente da consolidação do sistema nacional de C\&T propõe um modelo para compreender os estágios de evolução dos sistemas nacionais de ciência e tecnologia. Neste modelo são apresentados quatro estágios com características mais ou menos homogêneas, conforme a Tabela 1 .

Tabela 1 - Estágios de sistema de C\&T.

\begin{tabular}{l|l} 
Estágio & \multicolumn{1}{c}{ Caracteristicas } \\
& Não existência de políticas e estratégias governamentais \\
Nucleação aleatória de competências \\
Órgãos de pesquisa e de serviços técnicos e científicos criados pelo governo, sem visão sistêmica \\
Atendimento de peculiaridades nacionais e emergências conjunturais, principalmente em saúde, \\
agricultura, saneamento e defesa \\
Poucos pesquisadores formados e, quando no exterior, geralmente por iniciativa própria \\
Nucleação programada atendendo à uma disposição política governamental \\
Criados os componentes necessários à formação de um sistema de C\&T \\
Estratégia de povoar o sistema mediante a formação de recursos humanos de alta qualificação \\
Implantação de infra-estrutura física (estatal e privada) \\
Criação de instituiçães de fomento e de fundos públicos para financiar pesquisas \\
Organização dos pesquisadores em associações cientificas \\
Criação de revistas e realização de congressos \\
Os segmentos de governo, educação, empresas e comunidade científica são providos de meios de \\
atuação \\
Crescimento e interação mútua dos componentes do sistema \\
Adequação e aperfeiçoamento das políticas \\
Fortalecimento e expansão dos integrantes do sistema \\
Criação de incentivos creditícios, fiscais, não-fiscais e de mercado \\
Amadurecimento do sistema \\
Sistematização da formulação de políticas e estratégias de C\&T articuladas com as políticas \\
industrial, agrícola, de relações exteriores e de defesa etc \\
Demanda nacional por tecnologia e serviços correlatos crescentemente atendida por soluções e
\end{tabular}


entidades nacionais, que inclusive são exportadas

Estratégias formuladas para o aperfeiçoamento contínuo do sistema, tendo como foco a produção científica de vanguarda e a geração de inovações em produtos, processos e serviços

Intensificação do relacionamento internacional na área

Fonte: adaptado de Longo (2009)

Indiscutível a importância de esquematizações como a proposta por LONGO (2009), que se inscrevem de certa forma na categoria de estudos de maturidade de sistemas e processos produtivos e que dão uma ideia de evolução dinâmica da área, além de possuírem caráter didático importante. Ocorre que tais esquemas falam muito mais do passado do que do futuro, são uma espécie de fotografia ou de contabilidade do que passou. Quando usados para prever ou para construir políticas costumam ter baixo poder explicativo gerando descrições ad hoc que quase sempre remetem para questões como falta de confiança entre os parceiros, ausência de visão estratégica etc.

Uma alternativa aos esquemas anteriores, tipo ciclo de vida, tem sido a adoção da perspectiva do território como fio condutor capaz de tecer e fixar capacidades, competências e estruturas de forma mais permanente. É no território que as clivagens culturais e sociais, dadas pela geografia e pela história, se estabelecem e se reproduzem, influenciando e materializando de certa forma, como uma espécie de plataforma, o conjunto de possibilidades competitivas. A perspectiva do território no entanto deve ser complementada com o conceito apresentado no Plano de Desenvolvimento da Educação de "enlaces conceituais" que, no caso do PDE são construídos entre "educação e território" por um lado e entre "educação e desenvolvimento econômico-social" por outro.

Do ponto de vista de políticas públicas, com suas exigências de democracia, de difusão e de eficácia distributiva, o território parece ser o eixo por excelência de ação visto que é nele que se encontram (ou não) os determinantes da vantagem nacional que PORTER (2000) reuniu no modelo do "diamante da vantagem nacional" quais sejam (i) condições dos fatores, (ii) condições da demanda, (iii) indústrias correlatas e de apoio e (iv) estratégia, estrutura e rivalidade das empresas.

As sinergias produzidas recentemente no Brasil a partir das primeiras rodadas de execução do Plano de Aceleração do Crescimento (PAC), com os planos setoriais que decorreram da sua elaboração, não têm sido inteiramente exploradas em toda a sua dimensão e intertextualidade. O Plano de Desenvolvimento da Educação por exemplo, traz insights poderosos ao operar com o conceito de territorialidade e de enlace. Ele está sustentado por seis pilares: (i) visão sistêmica da educação; (ii) territorialidade; (iii) desenvolvimento; (iv) regime de colaboração; (v) responsabilização e (vi) 
mobilização social - que são desdobramentos conseqüentes de princípios e objetivos constitucionais, com a finalidade de expressar o enlace necessário entre educação, território e desenvolvimento de um lado, e o enlace entre qualidade, equidade e potencialidade de outro. O PDE busca de uma perspectiva sistêmica, dar conseqüência, em regime de colaboração às normas gerais da educação na articulação com o desenvolvimento sócio-econômico que se realiza no território, ordenado segundo a lógica do arranjo educativo - local, regional ou nacional.

A acumulação tecnológica, condição fundamental para o funcionamento dos sistemas de inovação, decorre de uma combinação heterogênea de importação de tecnologias com atividades locais e políticas intervencionistas proativas para fomentar indústrias nascentes. Mas este é apenas um dos componentes da complexa formação dos sistemas nacionais. As reduções de custos e melhorias de qualidade das redes de telecomunicações globais e outras mudanças cada vez mais velozes na economia mundial devem ser levados em consideração para a análise dos sistemas nacionais caso se queria compreender o circulo virtuoso da formação e consolidação dos sistemas nacionais.

\section{NOVO MARCO REGULATÓRIO E FORMAÇÃO DE ENGENHEIROS: O CASO DA UFF}

É num quadro de forte articulação institucional como descrito anteriormente, com conexões que se criam e se ampliam a cada dia, seja movido pelas circunstâncias macroeconômicas que colocaram o Brasil em uma rota de desenvolvimento relativamente sustentável, seja em um contexto de crescimento vertiginoso das tecnologias de informação e de comunicação que viabilizam a formação de redes em uma dimensão inimaginável até mesmo para os mais criativos designers de futuro (CASTELLS, 2007) que os desafios e as oportunidades de novos arranjos formativos ou de encontros cognitivos ocorrem e são aproveitadas ou não.

Nos últimos anos a UFF em geral e a sua Escola de Engenharia em particular têm vivido um ambiente de intensas trocas e parcerias para execução de projetos e programas, tanto com a esfera pública quanto com a esfera privada, particularmente na esteira aberta pela Lei da Inovação e pela Lei do Bem. Tal ambiente foi criado a partir da oferta articulada de formação e capacitação que abrangem desde os cursos regulares de graduação e pós-graduação até uma ampla gama de cursos de especialização e extensão que de certa forma vão ao encontro de necessidades do mercado de trabalho, demandante de recursos humanos com alta qualificação.

Um momento importante na história deste processo na UFF foi a criação do LATEC - Laboratório de Tecnologia, Gestão de Negócios e Meio Ambiente que passou a desempenhar, dentro da Escola de 
Engenharia o papel de uma escola de negócios, atraindo para a universidade não apenas estudantes recém-formados de inúmeras universidades mas também uma gama enorme de executivos dos mais variados segmentos, em busca de capacitação e, por desdobramento natural, dispostos a construção de parcerias para a execução de projetos e programas.

Após o LATEC outros laboratórios ou núcleos de pesquisa com perspectivas semelhantes surgiram e se consolidaram tornando o ambiente acadêmico fortemente permeável às demandas externas no que diz respeito aos problemas de engenharia e de tecnologia. Foi assim com o surgimento do NEICT - Núcleo de Estudos em Inovação, Conhecimento e Trabalho, com o LOGIS, Núcleo de Logística, com o LABCEO, Núcleo de Competitividade, Estratégia e Organização para ficar apenas nos grupos ligados ao Departamento de Engenharia de Produção. Neste contexto também foram criados ainda a AGIR Agência de Inovação da Universidade, o ETCO - Escritório de Transferência de Conhecimento, o Laboratório Initia de Inovação e Empreendedorismo, etc.

Todo esse ambiente influencia e é influenciado pelo curso de graduação em Engenharia de Produção que atualmente está às voltas com a discussão de reforma curricular. Reformas curriculares nunca foram atividades tranqüilas na academia. As disputas corporativas por territórios cognitivos nunca foram nada suaves, particularmente na engenharia de produção, sistêmica e significativamente pluridisciplinar. No entanto, por mais que as disputas locais sejam acirradas, o pano de fundo promissor colocado na linha da "inovação" já fez o seu papel no interior do Departamento e por essa razão não houve maiores dificuldades para se aprovar uma disciplina optativa com o conteúdo de "economia e gestão da inovação".

O objetivo da disciplina é o de fornecer ao estudante de graduação em engenharia de produção um instrumental conceitual e analítico que o capacite a compreender e engajar-se nos esforços públicos e privados em torno da elevação da capacidade inovativa da economia brasileira, quer no âmbito das políticas públicas quer na esfera da gestão organizacional privada.

A primeira ideia de dinâmica da disciplina tinha um recorte marcadamente teórico, realizando-se estudos dirigidos em torno dos livro-textos adotados (FREEMAN \& SOETE, 2008 e TIDD et al, 2008). Esta disposição foi alterada a partir dos contatos com integrantes de um projeto do SEBRAE / REDETEC, quando surge a possibilidade de se articular o aprendizado em sala de aula com os achados empíricos que vinham sendo delineados no projeto. A ementa da disciplina incluia elementos genéricos da economia da tecnologia bem como princípios da gestão da inovação iniciando com a macroeconomia 
da inovação, discutindo neste contexto ciência, tecnologia, crescimento e globalização. Em seguida a discussão vai para a articulação entre inovações e políticas públicas. A segunda parte do curso vai trazer elementos de gestão começando com o tópico "gestão para a inovação" seguido de "gerenciamento dos processos internos" e "avaliação e melhoria do desempenho da gestão da inovação".

Os instrumentos de acompanhamento e avaliação da disciplina são compostos pela leitura prévia dos textos indicados, aula expositiva, verificação de aprendizagem com provas e testes e trabalho em grupo a partir de questões previamente definidas. Todo o trabalho em grupo deve ser coordenado por um relator eleito pelo grupo que conduzirá posteriormente as intervenções nas plenárias pertinentes. Após as plenárias o trabalho entregue pode ser objeto de complementação/correção pelos seus autores, que o registram em espaços previamente determinados no Google Docs, que funciona como uma plataforma de suporte para o trabalho cooperativo. Esses registros e revisões constituem um momento rico de formação de uma espécie de comunidade de prática na turma, aprofundando significativamente a capacidade de diálogo, de diagnóstico e de troca de experiências, permitindo uma contextualização mais dinâmica dos conteúdos estudados no livro texto. Ao longo do curso, em momentos oportunos e conforme o tema em estudo, são convidados palestrantes externos ligados à temática da inovação, preferencialmente buscando cobrir-se as três hélices da "hélice tripla" academia, governo e indústria.

O conteúdo programático da disciplina está na Tabela 2, construída a partir de FREEMAN \& SOETE (2008) e TIDD et al (2008):

Tabela 2: A ementa da disciplina EGI

\begin{tabular}{|c|l|}
\hline \multirow{5}{*}{ Economia da Inovação } & Os sistemas nacionais de inovações \\
& A tecnologia e o crescimento econômico \\
& Inovações e desempenho no comércio internacional \\
& O desenvolvimento e a difusão de tecnologias \\
& A sociedos das políticas públicas para a ciência, a tecnologia e a inovação \\
& Tecnologia e meio ambiente \\
& Para além da economia da inovação industrial \\
\hline \multirow{5}{*}{ Gestão da inovação } & Fatores fundamentais na gestão da inovação \\
& $\begin{array}{l}\text { A inovação como um processo de gestão } \\
\text { Gerenciamento dos processos internos } \\
\text { Pessoas para construir a organização inovadora } \\
\text { Abordagem integrada da inovação }\end{array}$ \\
\hline
\end{tabular}




\section{O ACASO FAVORECE MENTES PREPARADAS}

Enredados no mesmo arranjo formativo e consultivo que envolve a experiência da Escola de Engenharia da UFF existem inúmeros outros atores que compõem o sistema nacional de inovação com papeis específicos, às vezes até mesmo superpostos em algumas dimensões, e essa redundância antes de ser um custo desnecessário configura-se como uma das condições capacitadoras do ambiente criativo (TAKEUCHI \& NONAKA, 2008). Dentre estes atores destacamos o SEBRAE-RJ e a Rede de Tecnologia do Rio de Janeiro (REDETEC), ambos protagonistas do caso que este artigo busca analisar. Essas organizações desenvolvem inúmeros projetos, produtos e serviços voltados ao fortalecimento das Micro e Pequenas Empresas (MPEs) instaladas no Rio de Janeiro e têm como objetivo levar às MPEs o conhecimento desenvolvido nas principais universidades e centro de pesquisa fluminenses, com vistas a apoiá-las no seu processo de inserção da inovação para a sua competitividade.

Por uma dessas coincidências que Carl Jung chamaria de "sincronicidade" e outros estudiosos chamariam de "serendipidade", estas organizações estavam envolvidas em um projeto intitulado "Capital Inovativo" no mesmo momento em que a UFF estava às voltas com a reforma curricular dos seus cursos de engenharia e, consequentemente, com a criação e implantação da sua disciplina de Economia e Gestão da Inovação. Além disso as organizações por sua vez reconheciam que seus esforços ainda não configuram medida plena de sucesso da inserção do componente tecnológico nas empresas, pois a capacidade inovadora depende, também, de vários outros fatores relacionados à capacidade de investimento, à organização do setor e ao sistema de inovação no qual elas se encontram, ou seja, a composição de um ambiente favorável à inovação, que se dá em um determinado território.

A intensidade da interação universidade-empresa (insumo do trabalho inovativo) é influenciada por outros fatores, como as especificidades setoriais, fatores referentes ao setor industrial, ao setor de pesquisa público, à tecnologia (características gerais, estágio de desenvolvimento, dinamismo da área) e às características das próprias empresas. Outro fator amplamente investigado na literatura é a importância da proximidade geográfica na interação universidade-empresa. Trabalhos realizados têm se dedicado a identificar os efeitos de spill-overs de conhecimento gerado nas universidades para as atividades de P\&D industrial; a importância de colaborações informais e contatos corpo a corpo em regiões de alta tecnologia; e a contribuição da infra-estrutura de pesquisa no desenvolvimento de capacidades inovadoras regionais. As contribuições, contudo, variam de acordo com o tamanho da 
empresa e intensidade de P\&D, nível de formalização das interações e a presença de institucionalidades locais.

Neste sentido, as condições que faltavam em um atendimento pontual no apoio tecnológico às MPES estariam em certa medida atendidas pela metodologia de desenvolvimento territorial do SEBRAE/RJ. No entanto fazia-se necessário o desenvolvimento de um método de ação para o componente denominado "capital inovativo", que possuísse foco bem delineado e que se articulasse com os demais componentes "capitais" do modelo "sebraiano". Neste momento a possibilidade de interação com a dinâmica da disciplina recém-criada no curso de graduação em Engenharia de Produção da UFF intitulada "Economia e Gestão da Inovação" passa a ser uma possibilidade promissora não apenas porque disponibilizaria oportunidades para o conhecimento empírico na disciplina mas também porque poderia fortalecer o próprio projeto que passaria a ter o aporte não apenas de um espaço de reflexão acerca da sua prática como agregaria uma massa crítica adicional de pessoas bem formadas estabelecendo uma visão crítica do processo.

A maioria das inovações nas pequenas empresas decorre das necessidades ou oportunidades vivenciadas no seu cotidiano. A inovação se encontra, portanto, no atendimento de novos clientes, na ampliação do negócio existente, numa melhoria organizacional. É, portanto, extremamente salutar desenvolver as competências adequadas nas pequenas empresas para que elas possam tornar-se competitivas, sustentar-se em seus mercados e, consequentemente, utilizar suas capacidades criativas tanto para "inovar" seus produtos, serviços e processos produtivos, quanto para identificar novas oportunidades ou atuar em outros mercados.

\section{O PROJETO “CAPITAL INOVATIVO”: PLANEJAR, AGIR, AVALIAR}

O projeto tinha como objetivo estruturar dois métodos de fortalecimento do Capital Inovativo nos territórios trabalhados pelo SEBRAE/RJ que contribuíssem para promover o desenvolvimento tecnológico e o estimulo à inovação nos referidos territórios e, por conseguinte, nas pequenas empresas localizadas nos mesmos. O método utilizado visava promover o desenvolvimento sócioeconômico do território e estava ancorado nos seis "capitais" do Modelo SEBRAE, conforme mostrado na Tabela 3. 
Tabela 3: Os capitais estruturantes do método

CAPITAL

\begin{tabular}{|l} 
Produtivo \\
Estrutural
\end{tabular}

Social

Empreendedor

Ambiental

Inovativo

\section{AÇÃO ASSOCIADA}

Identificam-se os principais segmentos econômicos geradores de negócios, emprego e renda no território

Analisam-se os pontos fortes e pontos fracos do ambiente de negócios em relação ao capital produtivo do território especificado

Avaliam-se como os atores do território atuam para a promoção de cooperação, articulação e ajuda mútua

Identificam-se as oportunidades de disseminação da cultura empreendedora no município

Avaliam-se as demandas e os gargalos das empresas e do território para que estejam consonantes com as leis ambientais em vigência

Estrutura o tecido econômico local para fomento de relações entre instituições públicas e privadas visando a geração de informações, conhecimentos e inovações no território

O foco do projeto era a formatação metodológica do "Capital Inovativo", que seria feito mediante convênio com a Rede de Tecnologia do Rio de Janeiro (REDETEC), tendo como resultado o desenvolvimento e consolidação de um método de trabalho a ser replicado posteriormente em todos os territórios trabalhados pelo SEBRAE-RJ.

Dentre as etapas previstas para o desenvolvimento do projeto previam-se (i) realização de um workshop interno, em articulação com a equipe do Projeto - SEBRAE/RJ, REDETEC e demais parceiros, como o objetivo de subsidiar a construção do método; (ii) realização de quatro workshops com empresários e representantes de instituições, utilizando a dinâmica de interação, com o objetivo de: levantar as demandas tecnológicas do grupo e individualmente por empresa; fazer um mapeamento dos gargalos técnico/tecnológicos dos setores em intervenção (conforme previamente determinado pela metodologia SEBRAE/RJ); levantar competências para solução dos problemas das empresas e disponibilidades de atuação, pelos tipos de empresas anteriormente citadas.

O planejamento das etapas de implantação do projeto forneciam inúmeras oportunidades para o diálogo inter-agentes e incluíam desde a sensibilização/divulgação até execução, passando pela fase de análise da demanda, diagnóstico da empresa e o plano de ação desenvolvido a partir da consolidação dos dados do relatório do consultor/especialista sobre a análise da demanda, considerando-se as características da empresa, as questões apresentadas como problemas, a forma como a empresa está inserida no setor culminando, como não podia deixar de ser, com avaliação e monitoramento. O produto final seria o próprio método de fortalecimento do Capital Inovativo nos 
territórios trabalhados pelo SEBRAE-RJ visando a promoção da informação tecnológica e o estimulo à inovação nas empresas e no território.

\section{CONSIDERAÇÕES FINAIS}

A economia brasileira no que diz respeito à introdução da "inovação" como instrumento para a construção de vantagem competitiva, a julgar pela quantidade e qualidade de atores, instituições e eventos que têm acorrido ao processo, parece se aproximar da condição do vôo de cruzeiro estável. Isso no entanto não é sinalização ainda de que se possa já ligar o piloto automático. O papel dos agentes, entre eles a Universidade, o SEBRAE e a Rede de Tecnologia do Rio de Janeiro, tanto no nível macro, com a definição e implantação de políticas, quanto no nível micro, com a execução de ações que consolidem o novo paradigma no campo da gestão e das práticas ainda está em construção e um indicador importante disso é a proliferação de ações que, conquanto aparentemente desconexas, acabam por difundir e consolidar em diferentes esferas, desde a própria formação dos novos quadros de engenheiros, o "espírito" do novo paradigma.

Foi assim com a articulação a partir da proximidade cognitiva entre a UFF, a REDETEC e o SEBRAE para a proposição de uma disciplina no âmbito da graduação em Engenharia de Produção que dialogasse com os esforços em curso do SEBRAE e REDETEC para sistematizar metodologias de intervenção em regiões específicas às voltas com o desafio de promover e consolidar a cultura do empreendedorismo inovador.

Embora as ações desde o início já tenham envolvido alunos da pós-graduação, é intenção dos autores expandir a experiência tanto no Programa de Pós-Graduação em Engenharia de Produção quanto no Mestrado Profissional em Sistemas de Gestão, colocando em sintonia ações convergentes e sinérgicas hoje desenvolvidas pelo NEICT - Núcleo de Estudos em Inovação, Conhecimento e Trabalho e pelo LATEC - Laboratório de Tecnologia, Gestão de Negócios e Meio Ambiente.

Com relação às questões levantadas na introdução deste artigo pelo dirigente do IDRC, embora o presente trabalho não tenha tido a pretensão de respondê-las, pôde-se ao longo do seu desenvolvimento colher insights e acompanhar esforços que permitem identificar tendências. Ao menos para uma das perguntas, a que indaga acerca dos investimentos necessários para propiciar diálogos públicos e privados bem-sucedidos, podemos ensaiar uma resposta qualitativa de que os investimentos são aqueles já presentes na própria constituição e consolidação do sistema nacional de 
inovação. O sistema produz a tão desejada e necessária proximidade cognitiva, condição para que haja os diálogos públicos e privados bem sucedidos.

Concluindo, FREEMAN \& SOETE (2008) lembram que os impactos provenientes de um processo de inovação em curso tem alcance não apenas na esfera da produção "mas também em amplas esferas sociais, institucionais e organizacionais". Continuando sua análise eles afirmam ainda que "...durante este processo de "aprendizado", mudanças de estratégias administrativas, assim como do ambiente institucional, influenciarão o sucesso das empresas e das economias nacionais". Na UFF, depois de 50 anos de existência a Pro-Reitoria de Pesquisa e Pós-Graduação, vencendo uma certa resistência ideológica que não vê a inovação como parte do ethos acadêmico, passou a se chamar Pró-Reitoria de Pesquisa, Pós-Graduação e Inovação, criando na sua estrutura a Agência de Inovação - AGIR. 


\section{REFERÊNCIAS BIBLIOGRÁFICAS}

BESSANT, John; TIDD, Joe. Inovação e empreendedorismo. Porto Alegre: Bookman, 2009. 600p.

BRASIL. Lei 11.196 de 21 de novembro de 2005. Disponivel em:

<http://www.planalto.gov.br/ccivil_03/_ato2004-2006/2005/lei/L11196compilado.htm> Acesso em: 18 jul. 2010

CASTELLS, Manuel. Era da Informação, V. 1 - A Sociedade em Rede. São Paulo: Paz e Terra, 2007.

DAVENPORT, Thomas H. Conhecimento Empresarial: como as organizações gerenciam o seu capital. Rio de Janeiro: Campus, 1998.

DAVILA, Tony; EPSTEIN, Marc J.; SHELTON, Robert. As regras da inovação. Porto Alegre: Bookman, 2007. 336 p.

FREEMAN, Chris; SOETE, Luc. A economia da inovação industrial. Costa. Campinas, SP: Editora da Unicamp, 2008.

GIBBONS, Michael; et. Al. The new production of knowledge: the dynamics of science and research in contemporary societies, London: Sage, 1994.

HARVARD Business School Press. Implementando a inovação. Rio de Janeiro: Elsevier, 2007.

LONGO, Waldimir Pirró, DERENUSSON, Maria Sylvia. FNDCT, 40 anos. Revista Brasileira de Inovação, Rio de Janeiro: FINEP (Financiadora de Estudos e Projetos), 8 (2), pp. 515-533, julho/dezembro/2009.

MALONE, D. Uma agenda da cooperação Internacional. Le Monde Diplomatique Brasil.p.. 12-14.. Jul. 2010,

Ministério da Educação. O Plano de Desenvolvimento da Educação: Razões, Princípios e Programas. Disponível em: <http://portal.mec.gov.br/arquivos/livro/livro.pdf> Acesso em: 18 jul. 2010.

PORTER, Michael E. A vantagem competitiva das nações. Rio de Janeiro: Campus, 2000.

TAKEUCHI, Hirotaka, NONAKA, IKUJIRO. Gestão do Conhecimento. Porto Alegre: Bookman, 2008.

TIDD, Joe; BESSANT, John; PAVITT, Keith. Gestão da inovação. Porto Alegre: Bookman, 2008. 


\section{Capítulo 10}

doi $10.37423 / 210704475$

\section{ESTUDO DO COMPORTAMENTO DA MRV OPERANDO COMO MOTOR/GERADOR}


Resumo: O objetivo deste artigo é apresentar uma descrição e simulação de um acionamento para que uma máquina a relutância variável possa ser usada como um motor/gerador. Foram propostas três diferentes estratégias de se obter controle de tensão gerada na saída da máquina a relutância variável. Estas estratégias foram comparadas entre si através do modelo computacional programado. A máquina simulada foi configurada com os parâmetros de um protótipo pré-existente, projetado para ensaios experimentais. Os resultados obtidos com as simulações, incluindo o momento de transição da operação motora para geradora, indicam que a máquina a relutância variável tem potencial para ser utilizada em aplicações automotivas, substituindo o motor de partida e o alternador por apenas uma máquina elétrica.

Palavras-chave - MRV, motor/gerador. 


\section{INTRODUÇÃO}

A indústria automobilística vem incorporando novas tecnologias aos automóveis visando segurança, desempenho e conforto. Como exemplos citam-se: controle de direção, de frenagem e de tração, acelerador eletrônico, suspensão ativa, catalisador eletrostático e função de espera para diminuir a poluição e o consumo. Estes novos avanços têm contribuído com o aumento da potência elétrica requerida pelos automóveis para suprir todos os equipamentos eletro- eletrônicos embarcados.

Atualmente a maioria dos automóveis usa o barramento cc, onde são ligadas as cargas e a bateria do automóvel, com tensão de $14 \mathrm{~V}$, e apresentam consumo médio de potência de $1.2 \mathrm{~kW}$. Alguns estudos prevêem que a potência elétrica média requerida pelas próximas gerações de automóveis será em torno de 3kW [1], o que abrirá um novo campo de pesquisa buscando melhorar a geração, armazenamento e consequentemente a eletrificação adequada à esta crescente demanda [2].

Os estudos apontam para a substituição do barramento cc de $14 \mathrm{~V}$ por um barramento de $42 \mathrm{~V}$, permitindo assim reduzir a corrente elétrica necessária para suprir a demanda crescente de potência. Com isso a bitola dos fios que conduzem eletricidade é diminuída, o que leva a uma economia de cobre e a uma redução de peso e custo da instalação.

Além da modificação da tensão do sistema elétrico dos automóveis, trabalhos contemporâneos estão propondo o uso de motores/geradores (MG), capazes de desempenhar a tarefa do motor de partida e do alternador usando apenas uma máquina elétrica acoplada ao motor à combustão através de polias. [3-4].

Em [5] foi realizado um estudo comparativo reunindo as principais máquinas elétricas com potencial de serem aplicadas como um motor/gerador. A máquina a relutância variável apresenta características que reforçam sua aplicabilidade como MG, como: robustez, baixo custo de produção, baixa inércia do rotor, fácil de ser controlado, alto conjugado de partida, aplicável em situações de altas rotações, tolerância a altas temperaturas e a falta de uma das fases [5-11].

O trabalho relatado em [10], mostrou que o gerador a relutância variável (GRV) apresenta melhor desempenho em velocidades acima de 1000rpm, e após atingir o pico de desempenho, em torno de 1300rpm, a potência gerada decresce lentamente com aumento da velocidade até 5000rpm. Essa característica é importante em aplicações automotivas já que o motor a combustão opera com velocidade variável e em torno de 600-6000rpm (10:1) [11]. 
Este artigo apresenta um estudo feito através de simulação computacional de uma máquina a relutância variável acionada por conversor half-bridge (HB) modificado para permitir a comutação entre a operação motora e geradora. Os resultados encontrados mostraram ser possível a aplicação deste tipo de máquina como um MG que poderá ser aplicado em projetos de eletrificação automotiva [2], veículos híbridos leves [12] e aplicações aeroespaciais [13]. A figura 1 apresenta uma visão geral do acionamento da MRV como motor/gerador desenvolvido neste trabalho.

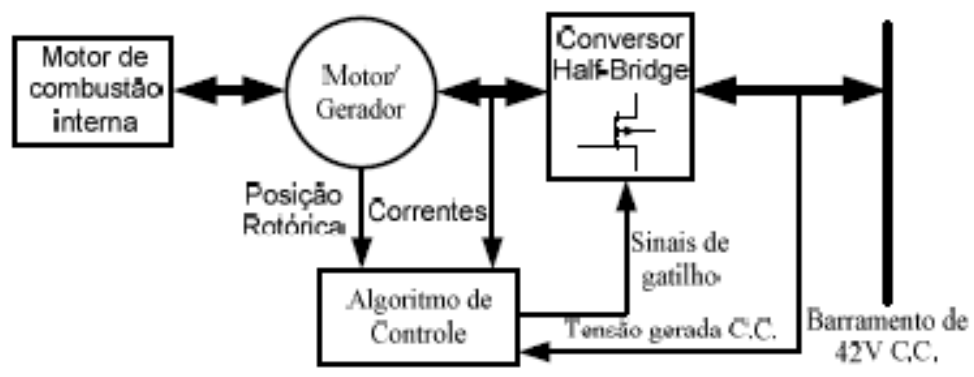

Fig.1. Diagrama de blocos de um MGRV interligado a um veículo.

\section{MGRV - MODELAGEM E FUNCIONAMENTO COMO MOTOR/GERADOR}

A máquina a relutância possui enrolamentos das fases nas saliências do estator. A ausência de enrolamento nas saliências do rotor permite que altas velocidades sejam alcançadas [2-8]. A figura 2 mostra uma representação de uma MARV com um dos enrolamentos de fase presente.

Com relação ao funcionamento da máquina, se um pólo do rotor se alinha com o pólo energizado do estator, a posição é de equilíbrio estável. Assim, na máquina a relutância existe uma tendência natural de a parte móvel permanecer na posição de indutância máxima da bobina excitada [8]. Se o rotor encontra-se em posição de equilíbrio instável em relação a uma determinada fase, e esta é energizada, o rotor tenderá a girar para a posição de equilíbrio, caracterizando uma operação motora. Agora, se da posição de equilíbrio estável, o rotor é forçado a girar por um agente mecânico, o torque produzido é restaurador e resulta em força contra-eletromotriz aditiva à tensão aplicada, e a máquina gera energia elétrica. Em uma máquina a relutância variável, a energia mecânica recebida de uma máquina primária é transformada em energia elétrica forçando o desalinho entre o pólo do rotor e o pólo energizado do estator. Pela figura 3 é possível observar as regiões em relação à variação linearizada da indutância, de uma das fases, em que a MGRV opera como motor ou gerador. 


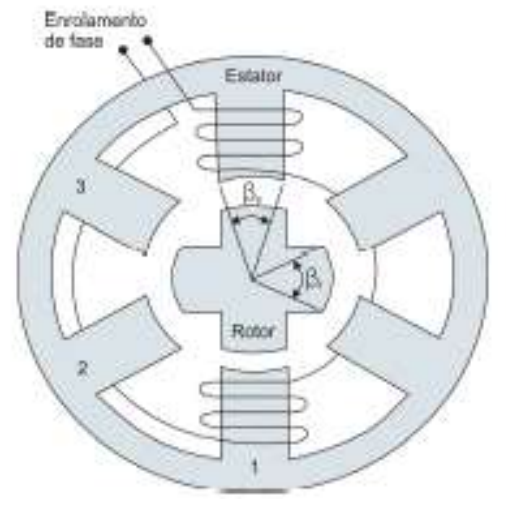

Fig.2. Máquina a relutância variável 6/4.

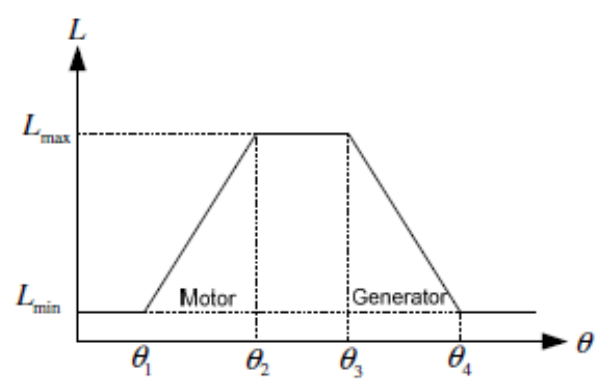

Fig.3. Variação linerizada da indutância de uma fase do MGRV.

\section{A. Modelagem matemática}

O circuito de uma fase do MGRV pode ser equacionado como:

$$
v=R i+L \frac{d i}{d t}+i \omega \frac{d L}{d \theta}
$$

onde $v$ é a tensão aplicada, $i$ é a corrente da fase, $R$ é a resistência da fase, $L$ é a indutância da fase e $R$ é a posição do rotor. O terceiro termo do lado direito da igualdade é a força contra-eletromotriz $e$, que isoladamente pode ser escrita como:

$$
e=i \omega \frac{d L}{d \theta}
$$

onde $\omega=d \theta / d t$ é a velocidade angular do rotor.

O conjugado mecânico produzido pela MGRV, desconsiderando as perdas para efeito de análise, pode ser expresso por (3).

$$
T(\theta, i)=\frac{1}{2} i^{2} \frac{d L}{d \theta}
$$


Algumas conclusões podem ser feitas a partir da equação acima: O conjugado mecânico produzido pela máquina é independente do sinal da corrente que circula na fase, então a corrente aplicada na fase pode ser unidirecional. O sinal do conjugado é determinado pela fase da corrente em relação à variação da indutância $d L / d t$.

Para realização da modelagem matemática usada no programa de simulação, o conjugado mecânico produzido pela máquina foi calculado levando em consideração as perdas por atrito viscoso $D$ e momento de inércia J, conforme apresentado pela equação (4).

$$
T=T_{\text {emag }}-J \frac{d \omega}{d t}-D \omega
$$

Considerando três fases com indutâncias e correntes instantâneas diferentes, o conjugado eletromagnético é dado por:

$$
T_{c m a g}=\frac{1}{2}\left(i_{a}^{2} \frac{d L_{a}}{d \theta}+i_{b}^{2} \frac{d L_{b}}{d \theta}+i_{c}^{2} \frac{d L_{c}}{d \theta}\right)
$$

A equação de velocidade do rotor (6) completa a descrição dinâmica da máquina.

$$
\omega=\frac{d \theta}{d t}
$$

O modelo matemático do MGRV, considerando as três fases, é apresentado por (7).

$$
\begin{aligned}
& {\left[\begin{array}{c}
v_{a} \\
v_{b} \\
v_{c} \\
C_{m} \\
0
\end{array}\right]=\left[\begin{array}{ccccc}
R_{a} & 0 & 0 & 0 & 0 \\
0 & R_{b} & 0 & 0 & 0 \\
0 & 0 & R_{c} & 0 & 0 \\
-i_{a} r_{1} & -i_{b} r_{2} & -i_{c} r_{3} & D & 0 \\
0 & 0 & 0 & -1 & 0
\end{array}\right]+} \\
& +\left[\begin{array}{ccccc}
L_{a} & 0 & 0 & 0 & i_{a} \frac{d L_{a}}{d \theta} \\
0 & L_{b} & 0 & 0 & i_{b} \frac{d L_{b}}{d \theta} \\
0 & 0 & L_{c} & 0 & i_{c} \frac{d L_{c}}{d \theta} \\
0 & 0 & 0 & J & 0 \\
0 & 0 & 0 & 0 & 1
\end{array}\right]\left[\begin{array}{c}
i_{a} \\
i_{b} \\
i_{c} \\
\omega \\
\theta
\end{array}\right] \\
& r_{1}=\frac{1}{2} \frac{d L_{a}}{d \theta} ; \quad r_{2}=\frac{1}{2} \frac{d L_{b}}{d \theta} ; \quad r_{3}=\frac{1}{2} \frac{d L_{c}}{d \theta}
\end{aligned}
$$

Designando por $[V],[R],[I],[L]$ e $[\dot{I}]$ as matrizes na ordem em que aparecem em (6), a matriz de estados do MGRV tem a seguinte forma: 


$$
\dot{[I}]=[L]^{-1}[V]-[L]^{-1}[R][I]
$$

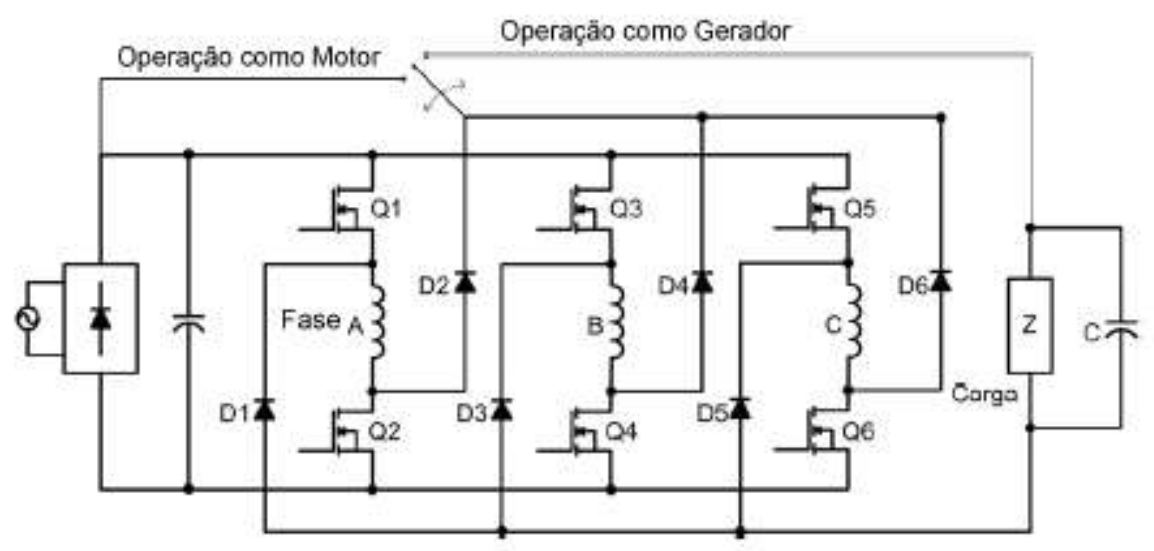

Fig.4. Diagrama de blocos do conversor simulado.

\section{B. Modelagem computacional}

O programa Matlab/Simulink ${ }^{\circledR}$ foi usado para desenvolver a simulação de uma máquina a relutância 6/4 operando como motor/gerador, com a transição entre os modos de operação feita quando uma velocidade de referência é atingida. Os dados da máquina simulada estão na tabela 1 e são de uma máquina projetada para os ensaios experimentais.

O conversor usado para acionar o MGRV é do tipo halfbridge, comumente utilizado para acionar o motor a relutância variável.

A figura 4 mostra uma visão geral do conversor usado para acionar o MGRV, evidenciando o caminho criado para desviar a energia gerada para uma carga resistiva (LR), quando a máquina esta no modo gerador. Esta energia, em aplicações automotivas será usada para recarregar a bateria e/ou suprir equipamentos eletro-eletrônicos. Um capacitor (LC) foi usado para filtrar a tensão gerada, que tem característica pulsada.

\section{CONTROLE DO MGRV}

\section{A. Controle da operação motora e do momento da transição}

Para gerar um ponto de transição do MGRV, foi desenvolvida uma estratégia de comutação do modo de operação como motor para gerador baseado no alcance da velocidade de referência dada ao controlador proporcional integral usado no controle de velocidade da operação motora.

A figura 6 representa o controle de velocidade desenvolvido para acionar a máquina como motor. Quando o sinal de erro produzido pela diferença entre a velocidade de referência e a velocidade do 
eixo da máquina se aproxima de zero, um bit usado para sinalizar a comutação é alterado, indicando que as chaves do conversor que modificam o caminho da regeneração/geração devem ser acionadas, de modo a permitir a máquina gerar energia e entregar esta à carga. A partir deste momento as fases do MGRV passam a ser energizadas na variação decrescente da indutância e a máquina passa a receber conjugado mecânico ao invés de produzi-lo.

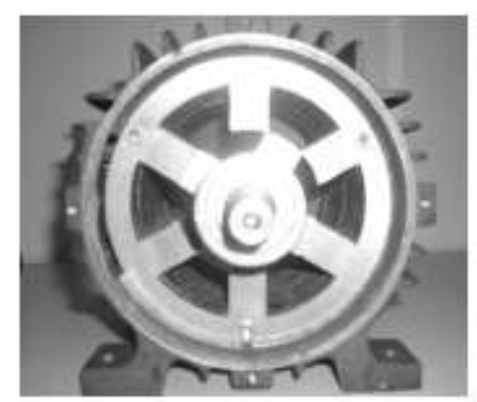

Figura. 5. Máquina a relutância variável usada para obtenção dos parâmetros para a simulação.

Tabela I

\section{Características da MRV}

\begin{tabular}{|c|c|c|}
\hline \multirow{2}{*}{\multicolumn{2}{|c|}{$\begin{array}{l}\text { Parâmetros } \\
\text { Ângulo de Condução }\end{array}$}} & Valor \\
\hline & & 30 graus \\
\hline \multicolumn{2}{|l|}{ Atrito Viscoso } & $0.026 \mathrm{~N} . \mathrm{m} . \mathrm{s}$ \\
\hline \multicolumn{2}{|l|}{ Culatra do Estator } & $12 \mathrm{~mm}$ \\
\hline \multicolumn{2}{|l|}{ Culatra Rotor } & $12,4 \mathrm{~mm}$ \\
\hline \multicolumn{2}{|c|}{ Comprimento da pilha laminada } & $107 \mathrm{~mm}$ \\
\hline \multicolumn{2}{|c|}{ Dentes do Estator } & $22,5 \mathrm{~mm}$ \\
\hline \multicolumn{2}{|l|}{ Dentes do Rotor } & $11,7 \mathrm{~mm}$ \\
\hline \multicolumn{2}{|l|}{ Diâmetro do Estator } & $140 \mathrm{~mm}$ \\
\hline \multicolumn{2}{|l|}{ Diâmetro do Rotor } & $70 \mathrm{~mm}$ \\
\hline \multicolumn{2}{|c|}{ Gap de $\mathrm{Ar}$} & $0,4 \mathrm{~mm}$ \\
\hline \multicolumn{2}{|c|}{ Indutância (posiçâo alinhada) } & $36 \mathrm{mH}$ \\
\hline \multicolumn{2}{|c|}{ Indutância (posiçāo desalinhada) } & $3 \mathrm{mH}$ \\
\hline \multicolumn{2}{|c|}{ Largura dos dentes do Estator } & $19 \mathrm{~mm}$ \\
\hline \multicolumn{2}{|c|}{ Largura dos dentes do Rotor } & $20 \mathrm{~mm}$ \\
\hline \multicolumn{2}{|c|}{ Momento de Inércia } & \multirow{2}{*}{$\frac{0,0028 \mathrm{~kg} \cdot \mathrm{m}^{2}}{100 \mathrm{volta} / \mathrm{fase}}$} \\
\hline \multicolumn{2}{|c|}{ Número de espiras por fase } & \\
\hline \multirow{2}{*}{$\begin{array}{c}\begin{array}{c}\text { Referéncia } \\
\text { de } \\
\text { velocidade }\end{array} \\
\qquad \begin{array}{c}\text { Velocidade } \\
\text { rotónica }\end{array}\end{array} \rightarrow$} & $\begin{array}{c}\text { Referéncis de } \\
\text { corrente }\end{array}$ & \multirow{2}{*}{$\rightarrow \begin{array}{c}\text { Algoritmo } \\
\text { de } \\
\text { Controle }\end{array}$} \\
\hline & Erro & \\
\hline
\end{tabular}

Fig.6. Diagrama de blocos do controle de velocidade da máquina operando como motor. 
Uma simulação do modelo computacional da MRV operando como motor/gerador foi realizada. A figura 7-a apresenta a curva da velocidade do rotor durante toda a simulação. A velocidade em que a máquina passou a gerar energia foi de 130 rad/s, o que ocorreu, aproximadamente com $0.24 \mathrm{~s}$ de tempo simulado. O comportamento de uma das três correntes da máquina durante o momento de transição pode ser observado na figura 7-b, onde é possível perceber que no início da operação como gerador as correntes apresentam amplitudes maiores, que diminuem até se estabilizar com valor próximo a $15 \mathrm{~A}$. Isso ocorre devido à corrente inrush com o capacitor descarregado, usado para filtrar a tensão que será entregue à carga resistiva $(10.8 \Omega)$.

Para evitar uma eventual queima de chaves no momento da transição de motor para gerador, devido à corrente em rush com o capacitor, pode ser adotada a estratégia de iniciar o funcionamento da máquina como gerador com o valor do $\theta_{\text {off }}$ lreduzido. Pela figura 8 é possível perceber o efeito da variação do valor do $\theta_{\text {off }}$ na amplitude da corrente gerada.

A curva tensão gerada e entregue a carga resistiva durante o período de geração pode ser vista através da figura 7-c, e pela figura 7-d, a curva de tensão em uma das fases é apresentada, permitindo observar o comportamento da mesma durante o transitório de modo de operação.

A figura 7-e mostra a curva de fluxo em função da corrente, sendo possível observar o comportamento desta curva durante toda a simulação incluído o período de transição de motor para gerador. A potência consumida pela máquina e gerada podem ser visualizadas na curva 7-f. 


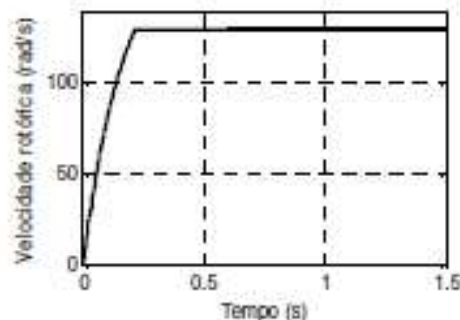

Figura, 7-a. Velocidade do MGRV.

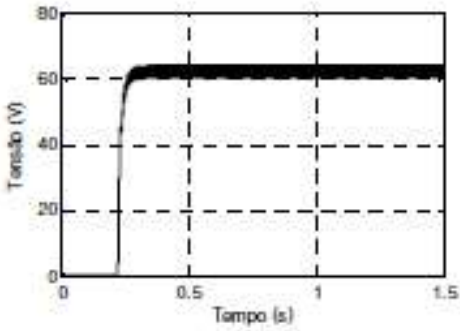

Figura. 7-c. Tensão gerada pela MGRV.

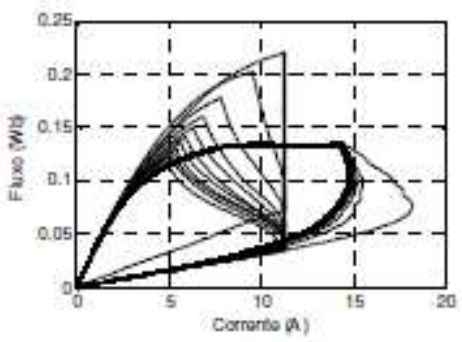

Figura 7-e. Fluxo v.s, corrente

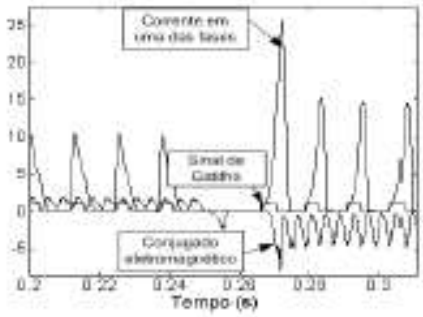

Figura. 7-b. Corrente nas fases.

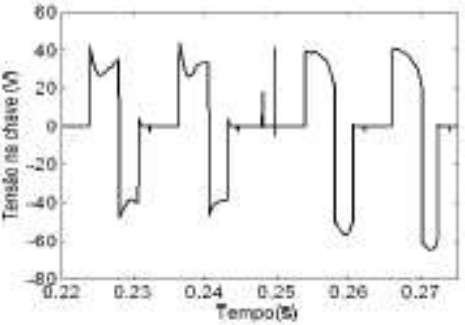

Figura. 7-d. Tensão em uma das fases.

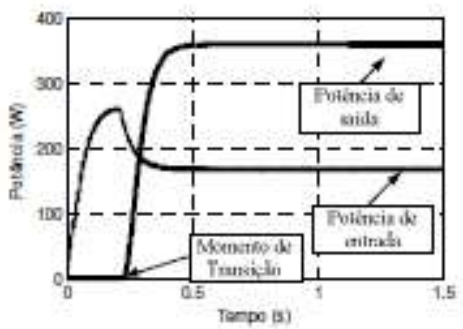

Figura. 7-f. Potência de entrada e potência de saída.

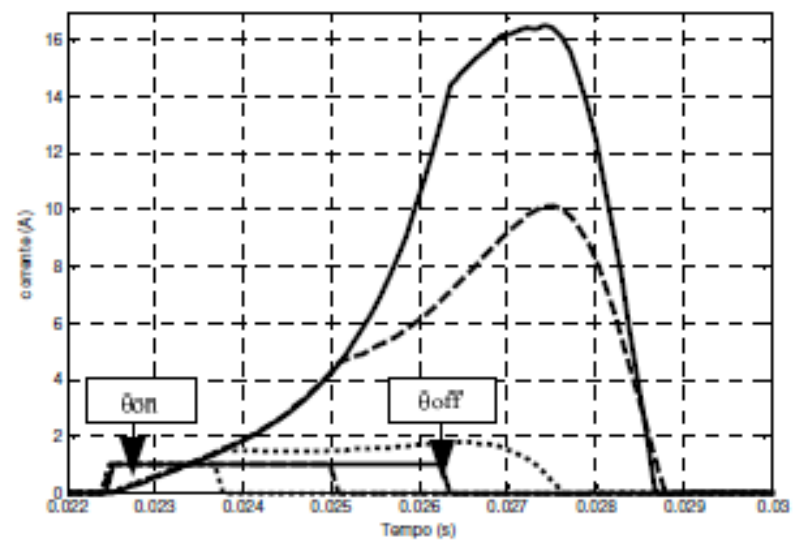

Fig.8. Variação da corrente com a mudança do valor de $\theta_{\text {ogf. }}$

\section{B. Técnicas de controle da tensão gerada propostas}


Em muitas aplicações industriais, automotivas e aeroespaciais é necessário que a tensão gerada tenha um valor constante independente da carga e da velocidade em que o rotor do gerador se encontra. Isso não é possível sem a atuação de um controle capaz de variar a magnetização do gerador a relutância de forma a manter a tensão gerada no referencial desejado.

A variação da magnetização na operação geradora da

MRV pode ser obtida de três maneiras:

1 - Variando a largura do período de magnetização, como por exemplo, alterando o valor do $\theta_{o f f}$.

2 - Variando a tensão do barramento cc, que pode ser implementado utilizando chave controlada.

3 - Chaveando a tensão de magnetização durante um período fixo (valor de ${ }^{\theta_{\text {off }}}$ não varia) e com tensão no barramento cc fixa.

Estas três estratégias foram implementadas através de simulação computacional, utilizando controlador proporcional integral (PI). A figura 9 apresenta através de diagrama de blocos a estratégia que utiliza um PI para variar a tensão do barramento cc que alimenta o conversor de potência. Nesta estratégia o PI gera uma sinal (Gref) proporcional ao erro entre a leitura da tesão gerada entregue a carga e a referência desejada. Este sinal de saída do controlador é usado para acionar o conversor do tipo buck, usado para variar a tensão do barramento cc ligado ao conversor HB.

Pela figura 9-a, é possível visualizar a comportamento da tensão gerada, alimentando uma carga resistiva, adotando a estratégia descrita anteriormente. A tensão de referência adotada foi de $42 \mathrm{~V}, \mathrm{a}$ tensão gerada convergiu para um valor que oscilou em torno da referência conforme pode ser observado. No instante de tempo de simulação igual a 3s, a resistência foi diminuída de $10,8 \Omega$ para $8 \Omega$ e, em $6 \mathrm{~s}$, a resistência voltou ao valor de $10,8 \Omega$, o que permitiu concluir, que o controle atuou nos transitórios de carga, mantendo a tensão em torno da referência.

A corrente em uma das fases da máquina pode ser observada pela figura 9-b, evidenciando grandes oscilações, que são filtradas pelo capacitor na saída do conversor HB.

Através figura 10, pode-se observar a potência de entrada do conversor HB e a potência gerada pelo MGRV após o momento de transição de motor para gerador. 


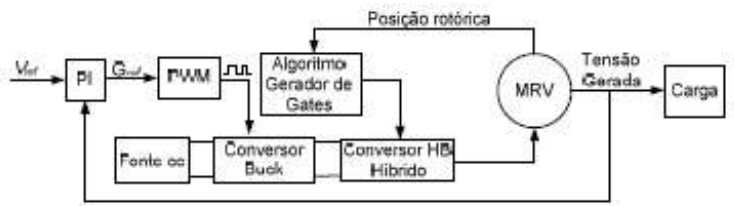

Figura, 9. Estratégia de controle da tensão gerada variando a tensăo do barramento $\mathrm{cc}$.

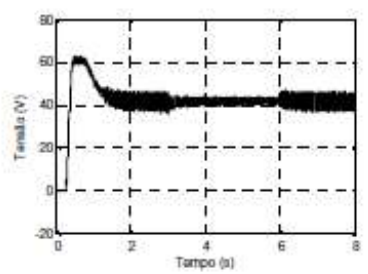

Figura. 9-a. Tensão gerada pela MRV.

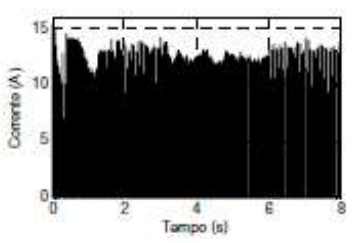

Figura. 9-b. Corrente em uma das fases.

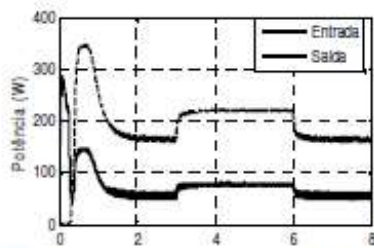

Figura. 10. Potência na entrada e saída do conversor HB.

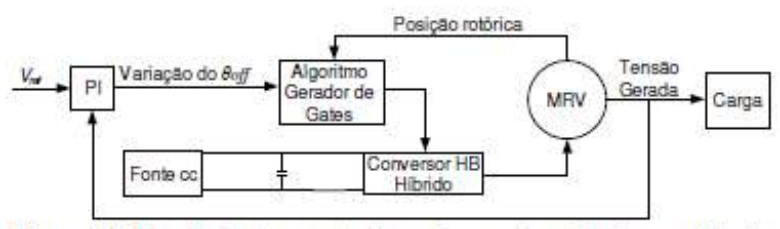

Fïgura. 11. Estratégia de controle da tensão gerada variando o período de magnetização das fases atuando no $\theta_{\text {ocf. }}$

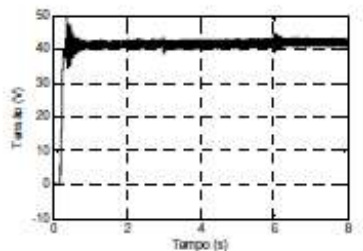

Figura. 12-a. Tensão gerada pela MRV.

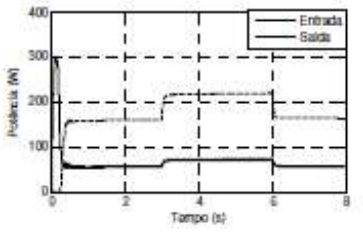

Figura. 12-c. Tensão gerada pela MRV.

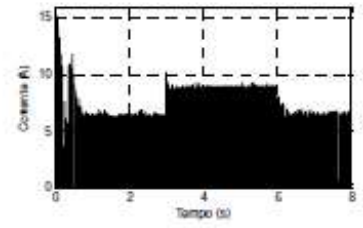

Figura, 12-b, Corrente em uma das fases.

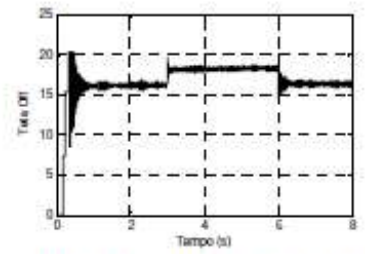

Figura. 12-d. Corrente em uma das fases.

A estratégia de controle da tensão gerada pela MRV, baseada na variação do período de magnetização, a partir da atuação do controlador PI no valor do ${ }^{\theta_{o f f}}$, também foi implementada em forma de simulação e pode ser representada pelo diagrama de blocos da figura 11.

Da mesma forma que foi simulado para estratégia de controle de tensão gerada anterior, nesta simulação a MRV operou como motor até atingir 130rad/s, que ocorreu no instante de tempo de, aproximadamente, $0,24 \mathrm{~s}$. Também foi usado como referência para o controle de tensão gerada o valor de $42 \mathrm{~V}$ e, da mesma forma, a resistência de carga foi variada de $10,8 \Omega$ para $8 \Omega$, em $3 \mathrm{~s}$, e voltou a 10,8 , em 6 s de simulação.

A tensão gerada pela MRV nestas condições pode ser visualizada pela figura 12-a, na qual é possível observar que o controle obteve sucesso em manter a tensão em torno da referência adotada, porem mostrou ser mais lento na eliminação do erro de regime permanente.

O comportamento da corrente de uma das fases pode ser observado na figura 12-b, onde encontramse evidenciados os momentos de transição de motor para gerador e a atuação do controle quando houve variação na resistência de carga. 
Na figura 12-c, estão plotadas as curvas de potência de entrada e saída da MRV durante todo o período de simulação e pela figura 12 -d pode ser observado a atuação do controle no valor do $8 \Omega$ durante toda a simulação. Vale a pena ressaltar que esta variação ocorre da mesma forma para as outras duas fases do motor, já que o sinal de saída do controlador PI é adicionado ao valor do $8 \Omega$ das três fases.

A estratégia de controle de tensão gerada, representada pelo diagrama de blocos disposto na figura 13, também foi simulada com os mesmos critérios das estratégias já apresentadas. Nesta estratégia o valor do $\theta_{\text {off }}$ e da tensão no barramento cc são fixos. O que varia com a atuação do controlador PI é o valor médio da tensão de magnetização, já que ao invés de fechar as duas chaves em série com a fase da máquina durante todo o período de magnetização, uma das chaves será aberta e fechada conforme o sinal PWM gerado pela referência de saída do PI. Com isso é possível controlar a magnetização e consequentemente a tensão gerada.

A figura 13-a apresenta a tensão gerada pela MRV, mostrando que esta estratégia controlou com eficiência a tensão gerada, mesmo durante o transitório de carga na saída do conversor HB. Pela figura 13-b pode-se concluir que esta estratégia conseguiu controlar as correntes de forma eficiente com ausência de grandes oscilações. Conforme foi apresentado para as estratégias mostradas anteriormente, na figura 13-c, são mostradas as curvas de potência de entrada e Potencia gerada, incluindo o período de transição entre o funcionamento como motor e gerador da MRV. A figura 13d apresenta o comportamento da tensão na fase $A$, com intuito de mostrar a atuação do controlador para variar o valor médio da tensão de magnetização.

A figura 14 permite observar o comportamento da potência na saída do conversor durante a geração, quando a velocidade do rotor está variando crescentemente. Nesta simulação a mudança de operação motora para geradora ocorreu a 600rpm e a potência máxima na saída foi atingida quando o rotor atingiu 1300rpm, decrescendo à medida que o gerador ganhou velocidade. 


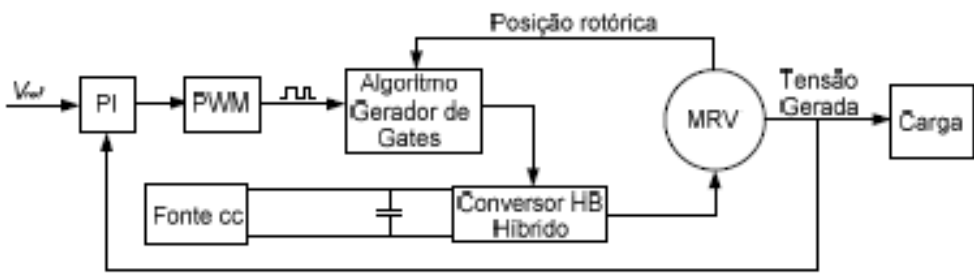

Figura 13. Estratégia de controle da tensāo gerada variando o período de magnetização das fases atuando no $\theta_{\text {off. }}$

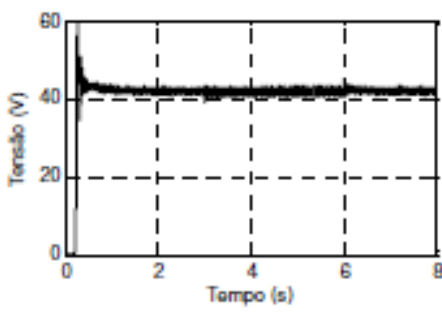

Figura. 13-a. Tensão gerada pela MRV.

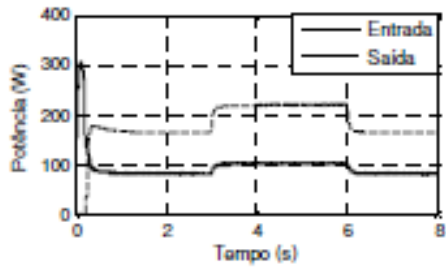

Figura. 13-c. Tensão gerada pela MRV.

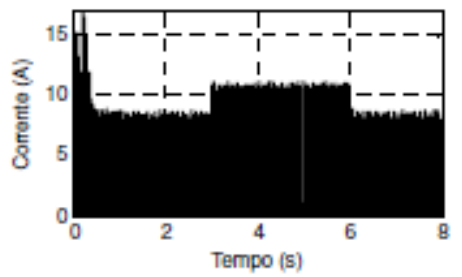

Figura. 13-b. Corrente em uma das fases.

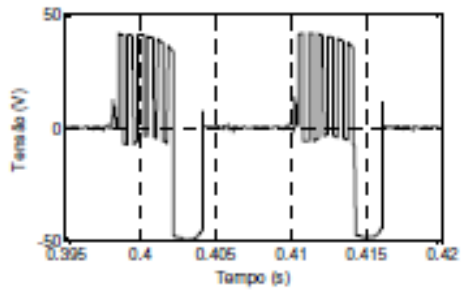

Figura. 13-d. Corrente em uma das fases.

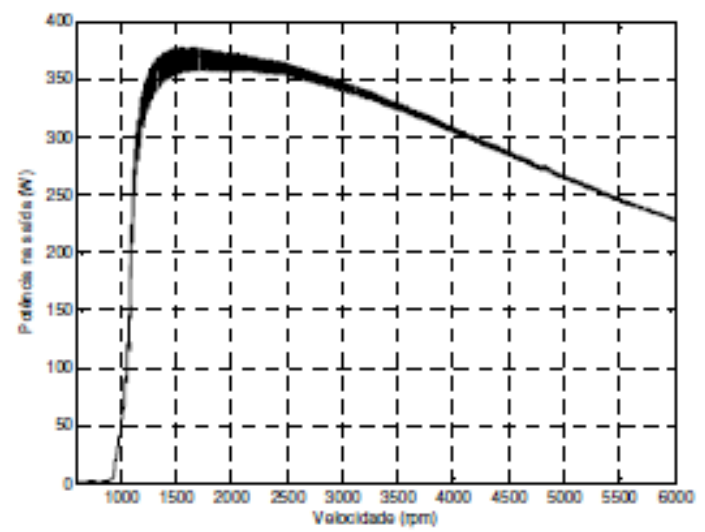

Fig. 14. Curva de potência na saída do conversor por velocidade do rotor.

\section{CONCLUSÃO}

A máquina a relutância variável pode funcionar como motor/gerador (MGRV) e o protótipo disponível foi simulado satisfatoriamente nesta condição. Foi adicionado um relé ao conversor half-bridge, tradicionalmente usado para acionar este tipo de máquina, com intuito de permitir o funcionamento do mesmo, acionando a máquina como motor ou gerador. A energia gerada alimentou uma carga 
resistiva e, no caso de aplicações automotivas, poderia ser usada para suprir os equipamentos elétricos e carregar as baterias ligadas a um barramento de $42 \mathrm{~V}$. Foram propostas três técnicas simples, utilizando controlador PI, de se obter o controle da tensão gerada. Estas estratégias foram comparadas através dos resultados de simulação, por onde pode ser observado que a técnica baseada no controle da tensão do barramento cc ligado ao conversor HB, apresentou os piores resultados, apresentando grandes oscilações na amplitude das correntes de fase e no valor da tensão de saída. A

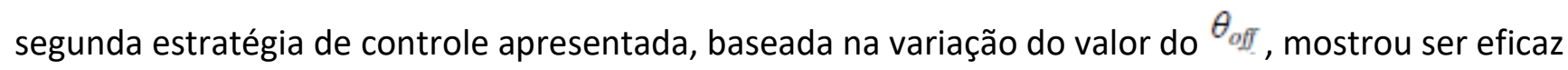
porém, foi mais lenta na eliminação do erro de regime permanente presente na tensão gerada em relação à tensão de referência. A estratégia que apresentou melhores resultados foi a baseada na variação da tensão média de magnetização das fazes a partir de um controle PWM. O estudo realizado neste trabalho também permitiu observar o comportamento das curvas de corrente, tensão, potência e fluxo eletromagnético na MRV durante a transição do modo de operação de motor para gerador, ficando comprovado que esta máquina pode ser utilizada como motor/gerador em diversas aplicações comerciais onde este tipo de acionamento se mostra vantajoso, como em aplicações automotivas e aeroespaciais. Qualquer uma das três técnicas de controle de tensão gerada poderá ser implementada associada ao controle do MGRV, permitindo a eliminação do uso de reguladores de tensão na saída do conversor.

\section{AGRADECIMENTOS}

Agradecimentos à FAPEMIG e ao CNPq pelo apoio financeiro e à Universidade Federal de Uberlândia pela estrutura disponibilizada. 


\section{REFERENCIAS}

[1] J. M. Miller, A. V. Rajarathnam, and M. Ehsani, "Current status and future trends in more electric car power systems," Proc. IEEE Veh. Technol. Conf., Houston, TX, Maio 1999.

[2] B. Fahimi, et. al., "A switched reluctance machine-based starter/alternator for more electric cars" Trans. Energ. Conver., vol. 19, nำ1., março 2004.

[3] Bon-Ho Bae; Seung-Ki Sul, "Practical Design Criteria of Interior Permanent Magnet Synchronous Motor for 42V Integrated Starter- Generator ". IEMDC, Volume 2, 1-4 June 2003 Page(s):656 - 662 vol.2.

[4] Lucache, D.D.; Horga, V.; Ratoi, M.; Albu, M, "Hardware-in-the-loop testing of an integrated starter generator". ACEMP, 10-12 Sept. 2007 Page(s):363 - 368.

[5] Cai. W, "Comparison and review of electric machines for integrated starter alternator applications," IEEE, 2004

[6] J. M. Miller, P. J. McClear, J, H. Lang., "Starter-alternator for hybrid electric vehicle: Comparison of induction and variable reluctance machines and drives," Proc. 33rd IEEE Ind. Applicat. Soc. Annu.

Meeting, Outubro. 1998, pp. 513-523.

[7] K. M. Rahman, B. Fahimi, et. al., "Advantages of switched reluctance motor applications to EV and HEV: Design and control issues," IEEE Trans. Ind. Applicat., vol. 36, pp. 119-121, Jan./ Feb. 2000.

[8] D. A. Torrey, "Switched reluctance generator and their control," IEEE Trans. Ind. Electron., vol. 49, pp. 3-14, Fev. 2002.

[9] M. Ehsani and B. Fahimi, "Elimination of position sensors in switched reluctance motor drives: State of the art and future trends," IEEE Trans. Ind. Electron., vol. 49, pp. 40-48, Fev. 2002.

[10] A. V. S. Fleury, F. S. Silva; W. R. H. Araújo, D.A. Andrade, A. W. F. V. Silveira "Reduced Switch count converter for switched reluctance generators" Eletrônica de Potência, Vol. 13, No. 3, August 2008.

[11] Rahman, K.M.; Fahimi, B.; Suresh, G.; Rajarathnam, A.V.; Ehsani, M, "Advantages of switched reluctance motor applications to EV and HEV: design and control issues". Trans. On Ind. Applications. Volume 36, Issue 1, Jan.-Feb. 2000 Page(s):111 - 121.

[12] Robert B. Inderka, at al, "Control of switched reluctance drives for electric vehicle applications" Trans. on Ind. Electronics, Vol. 49, No. 1, February 2002

[13] S. R. MacMinn and W. D. Jones, "A very high speed switchedreluctance starter-generator for aircraft engine applications" in Proc. IEEE Aerosp. And Electron. Conf., 1989, vol. 4, pp. 1758-1764. 


\section{Capítulo 11}

doi) $10.37423 / 210704491$

\section{USO DE IMAGENS DE PROFUNDIDADE NA BIOMECÂNICA}

Ivana Marcia Oliveira Maia

Yasmin Sousa Silva

Karoline Viana Leão

Anselmo Cardoso de Paiva
Instituto Federal de Educação, Ciência e

Tecnologia do Maranhão

Instituto Federal de Educação, Ciência e Tecnologia do Maranhão

Universidade Federal do Maranhão

Universidade Federal do Marahhão 
Resumo: O artigo apresenta uma proposta de metodologia para avaliação postural com captura de movimento com câmera de profundidade, aplicando os princípios do Método Owas de avaliação ergonômica, baseado em posturas adotadas em atividades laborais, considerando os membros superiores, tronco e membros inferiores associados a cargas e tempo. 


\section{INTRODUÇÃO}

A Biomecânica, além de ser atualmente uma ciência com laboratórios específicos e diversos níveis de pesquisas nas Universidades, é também uma especialidade e uma disciplina oferecida pelos cursos superiores de Engenharia Biomédica, Educação Física, Fisioterapia e Terapia Ocupacional, que pode ser entendida como o estudo da mecânica dos organismos vivos, isto é, o estudo da estrutura e função dos sistemas biológicos, com fundamentos da Física Mecânica. De maneira mais ampla trata do estudo das estruturas e funções dos sistemas biológicos utilizando métodos da Mecânica. Segundo Hay (1978), a Biomecânica é a ciência que estuda as forças internas e externas que atuam no corpo humano e os efeitos produzidos por essas forças. Esta definição trata de uma adaptação da definição de mecânica, aplicada a sistemas biológicos, neste caso o corpo humano. Logo por essa definição se percebe que, na verdade, a Biomecânica se relaciona diretamente com a Biologia e a Física.

Uma importante subárea da biomecânica é a biomecânica ocupacional, que se ocupa do estudo dos movimentos corporais e forças relacionados ao trabalho, revelando subsídios para detecção de postos de trabalho inadequados. Um importante objetivo desses estudos é a analise da ocorrência de distúrbios musculoesqueléticos nos trabalhadores e, para isso, trabalha com a análise de posturas corporais e a aplicação de forças, bem como as suas consequências.

Uma importante aplicação de processamento de imagens em biomecânica é no estudo do sistema musculoesquelético humano. Neste caso, são utilizados processos de aquisição que permitem capturar a posição do sistema musculoesquelético e do seu movimento.

A captura do movimento envolve um conhecimento multidisciplinar, utilizando técnicas de computação e de engenharia. Apesar do seu grande potencial, os sistemas de mocap (motion capture) ainda enfrentam problemas. Devido ao grande número de articulações móveis, captar o movimento humano ainda é, mesmo para as tecnologias mais avançadas, um grande desafio. No geral temos sistemas que captam movimentos de partes do corpo, como, por exemplo, da mão ou do pé, ou sistemas que captam o movimento das grandes articulações, como a cabeça, braços, pernas, etc. Um obstáculo para que essa tecnologia avance, tem sido os altos custos dos equipamentos. Mais recentemente este obstáculo tem sido suplantado com a recente popularização de dispositivos baseados em tecnologia de escaneamento a laser (LIDAR), inclusive já disponíveis em smartphones e tablets de última geração (e.g. Iphone 12, IPad Pro 2020). Nesse sentido, a análise postural é essencial para avaliar prática de atividades em ambientes de trabalho ou outros, sendo particularmente úteis para avaliar movimentos que possam ser potencialmente danosos ao sistema musculoesquelético. 
Os métodos tradicionais de monitoramento manuais dependem de variáveis como análise angular dos membros, tronco e pescoço, aplicação de força, frequência e o tempo gasto em cada postura (PAVANI; QUELHAS, 2006), tornando a avaliação exaustiva, entediante e ineficiente.

Algumas iniciativas no sentido de automatizar o processo de análise postural, como o software Three Dimensional Static Strength Prediction Programme (3D SSPP) modernizaram essa tarefa. Este software é baseado no modelo biomecânico da Universidade de Michigan e prevê requisitos de resistência estática, para tarefas tais como: elevação, pressão, impulso e atração. O software, além de permitir a simulação da tarefa em um ambiente 3D, disponibiliza dados de postura, parâmetros de força e antropometria masculina e feminina. O usuário pode analisar torções e inclinações do tronco e criar entradas complexas de força na mão, porém o 3D SSPP necessita que sejam informados dados antropométricos, ângulos corporais e demais parâmetros, para que os movimentos possam ser simulados quadro a quadro.

Uma abordagem automatizada utilizando uma sequência de vídeo, por outro lado, pode fornecer informações valiosas sobre o comportamento relacionado à atividade da pessoa, no entanto são sensíveis às condições de iluminação. Para superar as limitações de observações visuais, vários autores têm recentemente utilizado sensores de profundidade para segmentação de objetos em movimento. A utilização desses sensores realiza a medição de profundidade independente da iluminação (SCHWARZ et al., 2011).

Assim, este capítulo apresenta uma aplicação de método para avaliação postural baseada na aquisição de imagens de profundidade. Nesta seção introdutória serão apresentados os principais métodos de análise postural e as técnicas de captura de movimento através do uso de câmeras de profundidade. Nas seções seguintes será exemplificada a possibilidade de utilização das imagens de profundidade para exemplificando com uma metodologia automática eficaz para a análise postural utilizando câmeras de profundidade.

\section{MÉTODOS DE ANÁLISE DE POSTURA}

Existem métodos comprovadamente eficazes de registro e análise de informações posturais. Dentre os mais utilizados destacam-se o Ovako Working Posture Analising System (OWAS), Rapid Upper-limb Assessment (RULA) e Rapid Entire Boby Assessment (REBA).

O método OWAS (Karhu et al., 1977) é o mais tradicional método de avaliação postural. Foi desenvolvido pelo grupo siderúrgico Finlandês, denominado OVAKO OY, em parceria com o Instituto 
Finlandês de Saúde. Tem como premissa básica ser simples, para facilitar o seu uso e o seu aprendizado. No início ocorreu através de análise fotográfica das 72 posturas principais, que foram destacadas e observadas em indústrias pesadas. Esse número é resultante de diferentes combinações de dorso, braços e pernas.

O método se destaca por sua praticidade e comprovada eficiência (Karhu et al., 1981), principalmente, para análises posturais em atividades industriais, ambiente para o qual foi desenvolvido. Segundo (lida, 2015), o OWAS é baseado em análises de diferentes posturas, em variados postos de trabalho que, após análise e ordenação, serviu de base para criação de sistema padronizado de classificação das posturas, com combinações de posturas de dorso, braços e pernas. A força exercida pelo trabalhador por meio das mãos, também, foi considerada. As diferentes posturas padronizadas foram então analisadas por dois grupos: trabalhadores experientes e ergonomistas, que sob a ótica do desconforto e efeitos maléficos ao sistema musculoesquelético, definiram uma classificação que varia entre postura normal, sem desconforto, até postura extremamente prejudicial à saúde.

Em resumo, o método identifica as posturas mais comuns para os braços, dorso e pernas. Na Figura 1, tem-se as posturas OWAS do braço, do dorso e das pernas. Nesta figura a primeira coluna é uma representação do modelo humano em uma postura específica dos braços; a segunda coluna, descreve o código OWAS, o qual é usado para representar a respectiva postura; e a última coluna é a descrição da postura de acordo com (Karhu et al., 1977).

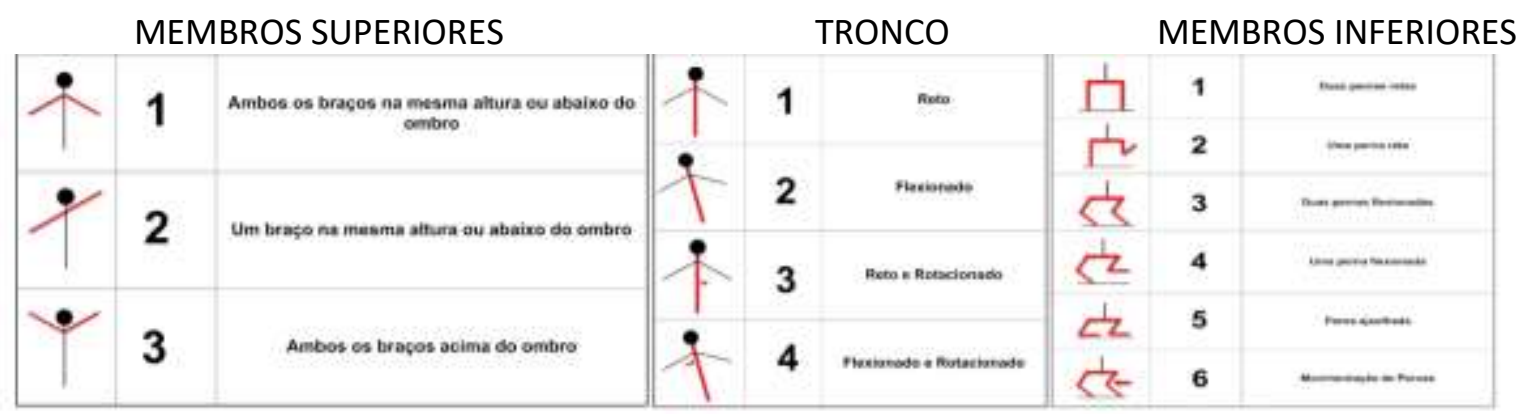

Figura 1. Conjunto das posturas do OWAS para os braços, dorso e pernas com seus respectivos códigos. KARHU ET AL., 1977.

O método OWAS também considera a carga que está sendo levantada. A postura corporal, como um todo, é representada por um código de seis dígitos. O primeiro dígito representa a postura dos braços; o segundo, a postura do dorso; o terceiro, a postura das pernas; o quarto representa a carga levantada e os dois últimos dígitos indicam o local onde a postura foi observada. As observações são feitas por amostragem, usando-se um intervalo de tempo constante. 
O diagnóstico e recomendação de ações são elaborados de acordo com cada uma das quatro classe OWAS, à qual pertence cada postura avaliada. A classe 1 indica postura normal, que dispensa cuidados. A classe 2 indica postura que deve ser verificada durante a próxima revisão rotineira dos métodos de trabalho. A classe 3 indica postura que merece atenção em curto prazo e a Classe 4 representa as posturas que devem ter atenção imediata, pois provocarão desconforto em pouco tempo e podem causar doenças.

As classes OWAS podem ser encontradas usando-se dois métodos diferentes. O primeiro método faz a avaliação pontual da combinação das posturas dos braços, dorso, pernas e carga levantada. 0 segundo método faz a avaliação, baseado no tempo relativamente despendido em uma postura específica, para cada parte do corpo, na execução da tarefa.

Além da avaliação OWAS, pode-se citar os métodos RULA e REBA. Estes métodos também podem ser implementados a partir de imagens de profundidade.

O método RULA (Lynn McAtamney, 1993), faz a avaliação rápida dos danos potenciais aos membros superiores, em função da postura adotada. Usa diferentes faixas de ângulos como parâmetro de identificação de posturas. Avalia a postura do pescoço, tronco e membros superiores (braço, antebraço e mãos), relacionando-a com o esforço muscular e a carga externa a qual o corpo está submetido.

$O$ método REBA tem funcionamento parecido com o RULA, porém compreendem posturas não previstas por este, como as executadas por profissionais da área médica. O método também adiciona ao braço, antebraço e pulso, um fator chamado de interface homem-carga ou acoplamento (Lynn McAtamney, 2000).

\section{CAPTURA DE MOVIMENTO COM CÂMERA DE PROFUNDIDADE}

Nas técnicas de captura de movimento, muitas vezes, os conceitos de movimento, gesto e postura se misturam. Porém, apesar de relacionados, existem diferenças entre eles.

O gesto, no universo da interação homem-computador, é uma forma de comunicação arbitrária e convencional, ou seja, é necessário que um vocabulário seja preliminarmente definido pelo design da aplicação, para que os gestos ou ordens sejam "compreendidos". Tem-se hoje um vocabulário padrão de gestos, como por exemplo, "passar para próxima página", rolar na direção vertical, rolar na direção horizontal, zoom in, zoom out, clique etc. 
Em um conceito mais amplo, gesto pode ser definido como uma sequência de posturas no tempo. A postura é uma pausa temporária e, a exemplo do que ocorre com o gesto, pode ser também uma forma de comunicação. Quando uma pessoa está em uma determinada postura, supõe-se ausência de movimento. Logo, enquanto gesto envolve ação, postura envolve inércia (Jarret Webb, 2012). A postura também pode ser chamada de gesto estático.

Movimento é o conceito mais abrangente. Capturar movimento significa a capacidade de reproduzir, em um ambiente computacional, os mesmos deslocamentos produzidos pelo objeto capturado. Por exemplo, se um humano está parado e mexe a perna, então todo o deslocamento da perna será representado, proporcionalmente, pela aplicação.

As soluções de hardware e software, que trabalham com detecção de movimento, gesto ou postura, são denominadas de Motion Capture ou Captura de Movimento (MoCap). A indústria da animação desponta como a maior usuária desses sistemas, mas seu uso vai além. Como exemplo de áreas de interesse em MoCap, tem-se a cinemetria ${ }^{1}$, interação homem-computador, robótica, análise biomédica etc. Para cada tipo de aplicação existem particularidades e desafios próprios (Schulz, 2010). Segundo Moeslund e Granum (2001), as soluções de MoCap podem ser divididas em três grandes áreas: Monitoramento, Controle e Análise.

\section{- Monitoramento}

A área de monitoramento caracteriza-se pelo monitoramento de movimentos de objetos. Nessa área, as pesquisas focam na captura, identificação e monitoramento de movimento de objetos.

Com o crescimento de roubos, atentados e outros tipos de violência, monitorar pessoas e seus gestos, em ambientes abertos ou fechados, tem sido alvo de muita pesquisa. Hanseny et al. (2005) propõem uma solução que monitora carros e pessoas em um cenário real, ou seja, câmeras foram instaladas em uma rua real e as imagens usadas, com a abordagem multi-visão, para extrair características invariantes dos objetos (pessoa e veículos), como tamanho, posição e velocidade. A ideia é desenvolver sistemas de monitoramento inteligente, que sejam capazes de, por exemplo, prever colisões entre carros e pedestres.

\section{- Controle}

$\mathrm{Na}$ área de controle usa-se o movimento e a posição humana para controlar algo, dando, ao objeto ou imagem controlada, o mesmo deslocamento e precisão do objeto fonte das ações. A robótica abrange muitos dos projetos de MoCap, uma vez que, capturar o movimento humano, é uma das formas de 
manipulação de robôs. A Telemedicina é uma das áreas que está se aprimorando com o crescimento dessa tecnologia aplicada a robôs. Nanda et al. (2009) usam captura de movimento, para guiar um robô que está na forma de uma mão mecânica, ajudando pacientes que precisam de reabilitação.

Nas tecnologias desenvolvidas para jogos, o lançamento dos videogames de sétima geração, como PlayStation 3 da Sony Computer Entertainment (SCE), Wii da Nintendo e o Xbox 360 da Microsoft, revolucionaram a interação. Cada um deles desenvolveu uma tecnologia própria, para capturar os movimentos do usuário. No PlayStation 3 tem-se o PlayStation Move (PS3, 2013), um sensor de movimento baseado no uso de uma câmera, chamada de PlayStation Eye (olho) e um bastão que é segurado pelo jogador. Nesse bastão estão os sensores que são rastreados pela câmera. Para o Wii, tem-se o WiiRemote (WII, 2013), que funciona de forma semelhante ao PlayStation, porém usa a tecnologia de acelerômetros, associada a um sensor ótico. Já o Xbox 360, consegue capturar os movimentos dos jogadores com o uso de apenas uma câmera de profundidade, chamada Kinect (KIN, 2013). Essa tecnologia permitiu a construção a partir de imagens de profundidade, de um modelo do esqueleto do jogador, no qual é possível capturar até vinte juntas do seu corpo, em coordenadas de três dimensões: $X, Y$ e $Z$, possibilitando a interação do usuário com o jogo, sem a necessidade de nenhum outro equipamento.

\section{- Análise}

Os sistemas de análise conseguem descrever parâmetros cinemáticos dos movimentos executados, tais como posicionamento, aceleração, velocidade e deslocamento do corpo. A grande maioria das aplicações desenvolvidas visa compreender os déficits dos movimentos realizados pelos seres humanos, possibilitando tanto a geração de novos diagnósticos, como a melhoria dos métodos de tratamento. Adicionalmente, quando aliados a outros métodos, podem relatar a integridade muscular, articular e cinestésica dos segmentos envolvidos.

\section{TECNOLOGIAS PARA CAPTURA DE MOVIMENTO}

A captura de movimentos pode ser feita através de diferentes tecnologias. Existem sistemas mecânicos, magnéticos e os mais utilizados óticos. Atualmente, os sistemas óticos são conhecidos como sistemas inside-out (Schulz, 2010), ou seja, os sensores ficam localizados no corpo e as câmeras posicionadas fora dele. Subdividem-se em ativos, nos quais temos o uso de Light Emitting Diode (LED) como marcadores, ou passivos, quando refletores como usados como marcadores. 
Nesses sistemas, para que ocorra captura do movimento, é necessário posicionar marcadores no corpo, enquanto câmeras fazem a captura 2D dos dados de cada marcador. Todos os dados gerados, por cada marcador, são analisados por um software que fornece suas respectivas coordenadas 3D.

Sistemas óticos, como o Vicon (VIC, 2013) (passivo), ou o Optotrak (ativo) são considerados o "padrão", na análise do movimento humano, mas apesar de fornecerem informações precisas, possuem limitações.

A principal limitação é o alto custo, seguido de problemas de oclusão. A necessidade de um laboratório especializado, com equipamentos fixos, também impede o desenvolvimento de muitas aplicações. Além disso, esses equipamentos possuem complexidades inerentes à tecnologia de cada fabricante (Gomide et al., 2009).

Câmeras de profundidade possuem tecnologia ótica mais recente, conhecida por markerless ou semmarcadores. Essa tecnologia possibilita identificar o corpo humano e seus respectivos movimentos, sem o uso de marcadores. Para isso, monitoram as características da superfície ou componentes estruturais do corpo, como cabeça, ombro, perna, mãos etc. e, associando outras técnicas computacionais, infere os movimentos. Esses sistemas são conhecidos também como MoCap "puros".

De um modo geral, os sistemas sem-marcadores possuem os seguintes estágios de processamento (Fernandes, 2002):

- Captura dos dados de entrada a partir de câmeras de vídeo;

- Remoção do fundo da cena e deteç̧ão dos objetos em movimento;

- Análise da silhueta dos objetos em movimento e localização da possível figura humana;

- Segmentação da silhueta para identificação do posicionamento 2D das partes do corpo do ator;

- Identificação do posicionamento 3D das partes do corpo;

- Reconstituição dos movimentos do ator.

A câmera de profundidade pode ser classificada como um sistema ótico sem-marcadores, de baixo custo e mobilidade, quando comparado com outras tecnologias óticas de MoCap. Foram desenvolvidas para o uso em videogames, porém, devido ao seu grande potencial em outras áreas, logo ganharam atenção da comunidade acadêmica e profissional ligada à captura de movimento. 0 
Kinect é a câmera de profundidade mais popular atualmente e foi lançada pela Microsoft para ser usada no videogame Xbox 360.

Os componentes principais do Kinect são uma fonte de luz infravermelha, uma câmera colorida e um sensor de profundidade, conhecido também como câmera infravermelha. Este último é usado para capturar a distância percorrida pela luz infravermelha. Essa distância corresponde à profundidade dos pontos do quadro gerado pela câmera. A câmera colorida possui resolução máxima de 1028x960 pixels, enquanto o sensor de profundidade possui resolução máxima de 640x480 pixels. A taxa de geração de quadros pode alcançar até 30 frames por segundo (fps).

O Kinect possui capacidade de capturar movimentos de corpos que estejam entre 0,8 e 4 metros de distância, porém, os limites práticos recomendados na literatura (Microsoft, 2012a) são de 1,2 até 3,5 metros. $O$ ângulo de visão na horizontal é de 57,5 graus e o ângulo de visão na vertical é de 43,5 graus, sendo que existe um motor de inclinação vertical, esse ângulo de visão pode variar de -27 até +27 graus.

Os dados capturados pela câmera são representados por quadros. O quadro é composto de pixels. A quantidade de pixels é o que determina a resolução do quadro. Existem dois quadros principais: de vídeo e de profundidade. No quadro de vídeo, cada pixel representa a intensidade de vermelho, verde e azul que compõem cada par de coordenada $(x, y)$ da imagem. No quadro de profundidade, cada pixel contém a distância, em milímetros, de uma posição particular $(x, y)$ do plano da câmera para o objeto mais próximo desse ponto.

A profundidade de cada pixel é a distância entre o plano da câmera e o objeto mais próximo encontrado por um ponto desse plano. Cada pixel da imagem resultante contém essa distância em milímetros. As coordenadas $(x, y)$ do quadro de profundidade não representam a unidade física da sala, em vez disso, representam a localização do pixel no plano da câmera.

A partir do quadro de profundidade é gerado o quadro do esqueleto, o qual possui um sistema de coordenadas tridimensional próprio representado pelos eixos $\mathrm{X}, \mathrm{Y}$ e Z, sendo Z a profundidade. Nesse espaço geométrico, o ponto $\mathrm{O}=(0,0,0)$, que é o centro do sensor, representa a origem e os pontos $(x, y, z)$ têm a coordenada de cada plano $X, Y$ e $Z$, variando entre $[-2,2,2,2],[-1,6,1,6]$ e $[0,4]$, respectivamente (Jarret Webb, 2012). Cada quadro de esqueleto contém um conjunto composto por vinte juntas do corpo humano, onde cada junta é representada por um ponto $P=(x, y, z)$, no espaço geométrico do quadro do esqueleto. 
A figura 2 mostra o esqueleto gerado pelo Kinect com todas as suas juntas especificadas.

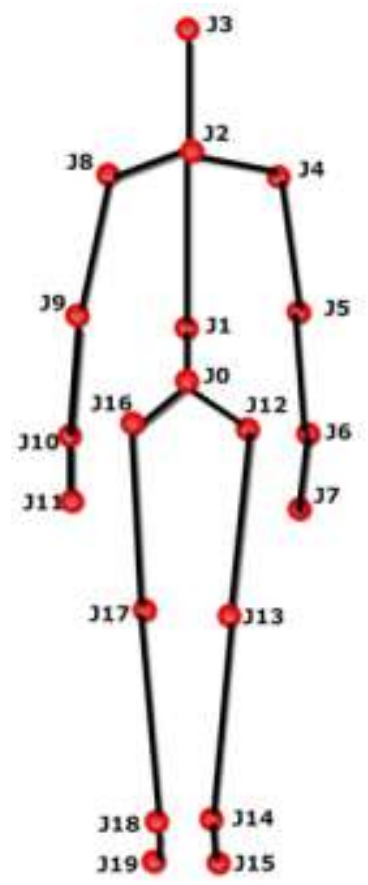

\author{
J0 : Quadril Central \\ I : Coluna \\ 32: Ombro Central \\ 13: Cabeça \\ 34 : Ombro Esquerdo \\ 15 : Cotovelo Esquerdo \\ 36 : Punho Esquerdo \\ J7 : Mão Esquerda \\ 38 : Ombro Direito \\ 19: Cotovelo Direito \\ 310: Punho Direito \\ J11:Mão Direita \\ 312:Quadril Esquerdo \\ 313: Joelho Esquerdo \\ J14:Calcanhar Esquerdo \\ 15:Pé Esquerdo \\ 16:Quadril Direito \\ J17: Joelho Direito \\ 18: Calcanhar Direito \\ 19: Pé Direito
}

Figura 2. Juntas do esqueleto gerado pelo Kinect.

Assim, o conjunto $R_{3}$ do quadro de profundidade do Kinect, ao qual pertencem todos os pontos das juntas, é composto de termos ordenados de números reais, resultado do produto cartesiano:

onde:

$$
R_{x} \times R_{y} \times R_{z}=R_{3}
$$

$$
\begin{gathered}
R_{x}=\{x \mid x \in R,-2,2<x<2,2\} \\
R_{y}=\{y \mid y \in R,-1,6<x<1,6\} \\
R_{z}=\{z \mid z \in R, 0<x<4\} \\
R_{3}=\left\{(x, y, z) \mid x \in R_{x}, y \in R_{y}, z \in R_{z}\right\}
\end{gathered}
$$

Em 2020, a Apple anunciou o LiDAR (hardware especial para registrar a profundidade de uma imagem), integrado no iPhone 12 Pro e iPad Pro 2020 com um aplicativo para avaliação profissional de membros médicos. A figura 3 apresenta um exemplo de uma ferramenta pela 3D4Medical. 


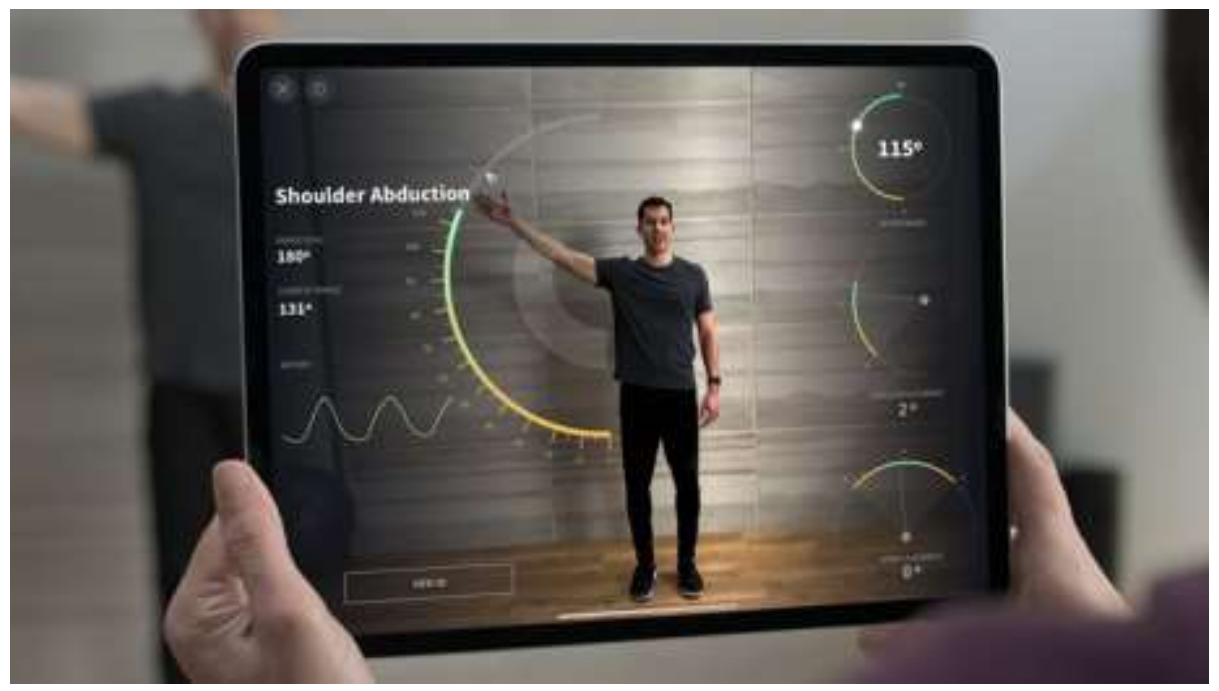

Figura 3: Recursos do Complete Anatomy no lançamento do iPad Pro 2020

Fonte: Apple Inc. 2020.

\section{DETECÇÃO E CLASSIFICAÇÃO DE POSTURAS, CONFORME MÉTODO OWAS, USANDO CÂMERAS DE PROFUNDIDADE}

Essa seção apresenta a exemplificação da metodologia, proposta por Leão (2013), baseada em visão computacional e câmeras de profundidade, para classificação semiautomática de posturas de trabalho, segundo a metodologia OWAS.

A metodologia proposta por Leão (2013) é dividida em 4 etapas principais: a Inicialização consiste na deteç̧ão do equipamento e obtenção dos quadros do esqueleto; a segunda etapa é a Remoção de ruídos, que consiste na aplicação de filtros nos quadros de esqueleto, para obtenção do quadro que será usado nas etapas posteriores; a terceira é a etapa de Classificação, que engloba o referencial usado para classificar as posturas segundo o OWAS e, por último, a Análise OWAS, que contém as regras de identificação das classes OWAS.

\subsection{INICIALIZAÇÃO E OBTENÇÃO DOS QUADROS}

A etapa de inicialização consiste, primeiramente, na detecção e configuração da câmera, para obtenção dos quadros de vídeo e de profundidade e, posteriormente, na captura do vídeo de profundidade, da atividade executada pelo trabalhador, com cálculo da posição do esqueleto.

A aquisição do quadro do esqueleto é implementada no Software Development Kit (SDK) da Microsoft. Shotton et al. (2011) explicam as tecnologias usadas, para extrair quadros do esqueleto, a partir de quadros de profundidade. 
De uma imagem em profundidade simples, uma distribuição por pixel das partes do corpo é inferida e, por fim, são geradas propostas para as juntas (Shotton et al., 2011).

São inferidas 31 partes para o corpo e, para obtenção desse feito, usou-se aprendizado de máquina, para treinar um classificador com milhões de imagens de pessoas dos mais variados tipos e tamanhos, onde as partes já estavam nomeadas.

O classificador emprega dois métodos: comparação de características entre pixels e árvores de decisão. A comparação de características entre pixels é um indicador fraco da parte do corpo à qual pertence o pixel, porém, quando combinado com árvores de decisão, revela um resultado suficientemente acurado para qualquer parte do corpo.

Uma vez detectadas as partes do corpo, o algoritmo encontra o centro de massa de cada uma dessas partes, os quais são usados para inferir as coordenadas tridimensionais de cada junta do corpo.

\subsection{REMOÇÃO DE RUÍDOS DO QUADRO DO ESQUELETO}

A etapa de aquisição consiste no uso de filtros para remoção dos ruídos do quadro do esqueleto.

Ruído existe em qualquer sistema que faz medições através de sensores. Existem dois tipos de ruídos nos dados gerados pelo Kinect. O primeiro é relativamente pequeno e está presente em todas as juntas, sendo consequência da imprecisão nativa do sensor. O segundo tipo origina-se, quando o sensor não consegue, por oclusão ou outro motivo, capturar a posição da(s) junta(s), isto gera inexatidão e picos temporários.

Um passo importante, antes do uso do quadro do esqueleto pela aplicação, é o uso de filtros para remoção de ruídos. Esses filtros são chamados filtros de suavização de sinais, pois eles suavizam os sinais no decorrer do tempo, reduzindo os ruídos. Segundo Azimi (2012), é necessária uma combinação de duas ou três técnicas de filtragem, para obter bons resultados em uma aplicação que faz uso do Kinect.

O filtro utilizado na metodologia de Leão (2013) foi o Holt duplo exponencial, pois na literatura é o que provê a menor latência (Azimi, 2012), com menor oscilação das juntas, estando também disponível no SDK.

Também é sugerido por Azimi (2012), o uso de um filtro por estado de rastreamento da junta, uma vez que grande parte dos ruídos acontece quando uma junta é inferida ou quando não foi rastreada. 
Uma junta fica com o estado de inferida quando, por oclusão ou outro problema, ela não consegue ser rastreada, sendo suas coordenadas calculadas de acordo com os valores de outras juntas.

\subsection{CLASSIFICAÇÃO DA POSTURA SEGUNDO O MÉTODO OWAS}

A principal contribuição do trabalho de Leão (2013) é a metodologia de classificação das posturas do corpo do trabalhador, através da análise do quadro do esqueleto obtido na etapa anterior. Cada quadro obtido durante o tempo estabelecido para análise da postura do trabalhador é considerado. $\mathrm{E}$ após cada quadro passar pela etapa de remoção de ruídos, é realizada a classificação da postura dos braços, dorso e pernas, gerando um código de três dígitos, onde cada dígito representa, respectivamente, a posição OWAS de cada uma destas três partes.

A seguir são descritas as técnicas para classificação da postura dos braços, dorso e pernas, segundo o método OWAS, utilizando as juntas do quadro do esqueleto. As juntas seguem a nomenclatura apresentada na 2 .

\subsection{CLASSIFICAÇÃO DA POSTURA DOS BRAÇOS}

Para classificar as posturas OWAS dos braços, o método da posição relativa das juntas mostra-se eficaz. Esse método consiste na comparação direta dos valores da posição de uma junta com outra ou de várias juntas.

A comparação, usando as coordenadas y (altura) dos pontos relativos às juntas do modelo do corpo humano, é suficiente para obter os resultados desejados. Um exemplo da aplicação do método da posição relativa da junta, usando o plano $Y$, é a detecção da postura "mão direita acima do ombro direito". Basta comparar o valor da coordenada y da junta da mão direita com o valor da coordenada y da junta do ombro direito e, se a coordenada y da junta da mão direita for maior, a postura foi reconhecida.

As coordenadas y das juntas do ombro (J4 e J8) foram usadas como limite de altura para classificação da condição abaixo ou acima. Assim, temos as regras principais de classificação:

I. Braço direito acima do ombro: Coordenada y da junta da mão (J11) e do cotovelo direito (J9) estão acima dos ombros (J4 e J8);

II. Braço esquerdo acima do ombro: Coordenada y da junta da mão (J7) e do cotovelo esquerdo (J5) estão acima dos ombros (J4 e J8); 
III. Braço direito abaixo do ombro: Coordenada y da junta da mão (J11) e do cotovelo direito (J9) estão abaixo dos ombros (J4 e J8);

IV. Braço esquerdo abaixo do ombro: Coordenada y das juntas da mão (J7) e do cotovelo (J5) estão abaixo dos ombros (J4 e J8).

Para o OWAS o braço é o segmento formado desde a mão até o cotovelo, então, as condições acima e abaixo levam em consideração todo o segmento. Dessa forma, se apenas a mão ou o cotovelo estiver acima do ombro, o braço é considerado abaixo do ombro.

Classificação da postura do dorso

Para a detecção da postura do dorso, no método OWAS existem 4 possibilidades: reto, flexionado, reto e rotacionado, e flexionado e rotacionado. Segundo a metodologia de Leão (2013), deve-se primeiro definir as posturas de quando o dorso está flexionado. Pois a postura dorso reto é igual à negação da postura flexionada. A seguir a postura rotacionada, que complementa as duas últimas possibilidades.

Para a determinação da postura flexionada do dorso, calcula-se o ângulo entre dois vetores:

tendo:

$$
\theta=\arccos \left(\frac{\vec{v}_{1} \cdot \vec{v}_{2}}{\left\|\vec{v}_{1}\right\| \cdot\left\|\vec{v}_{2}\right\|}\right), \text { onde } 0<\theta<\pi
$$

$$
\vec{v}_{1}=J 2-J 0 \text { e } \vec{v}_{2}=J 0^{x y}-J 0
$$

O ponto $J 0^{x y}$ representa a projeção ortográfica da junta JO no plano XY (ponto J0, com z = 0).

Tendo-se o ângulo $\theta$, a postura do dorso é classificada como flexionada quando $|90-\theta| \geq \alpha$, sendo $\alpha$ um valor ajustado pelo ergonomista, que define o limiar entre o dorso reto e flexionado.

Para a determinação da postura rotacionada do dorso, usa-se a mesma equação anterior para calcular o ângulo entre dois vetores, Equação 1. Entretanto, agora os vetores são definidos pelas juntas dos ombros e dos quadris, respectivamente, projetados no plano XZ:

$$
\vec{v}_{3}=J 8^{x z}-J 4^{x z} \text { e } \vec{v}_{4}=J 16^{x z}-J 12^{x z}
$$

O dorso é classificado como rotacionado quando $\theta \geq \beta$, onde $\beta$ é um valor ajustado pelo ergonomista e que define o limiar entre rotacionado e não rotacionado.

Classificação da postura das pernas 
As posturas OWAS para as pernas são: as duas pernas retas, uma perna reta, duas pernas flexionadas, uma perna flexionada e pernas ajoelhadas. Leão (2013) determina primeiro se a perna está flexionada ou reta e se está com um ou ambos os pés no chão. Após, tenta detectar se as pernas estão ajoelhadas.

Para

está flexionada, usa-se a Equação 1, para o cálculo do ângulo entre os vetores $\vec{v}_{5}$ e $\vec{v}_{6}$, onde para a perna direita têm-se:

$$
\vec{v}_{5}=J 17-J 17^{x y} \text { e } \vec{v}_{6}=J 17-J 18
$$

e para a perna esquerda:

$$
\vec{v}_{5}=J 13-J 13^{x y} \text { e } \vec{v}_{6}=J 13-J 14
$$

A postura da perna é classificada como flexionada quando $|90-\theta| \geq \gamma$, onde $\gamma$ é um valor ajustado pelo ergonomista e define o limiar entre a perna reta e flexionada.

Para determinar se uma ou ambas as pernas estão em contato com o chão é calculada a distância entre as juntas dos pés J14 e J18 em relação ao plano que define o chão. É importante destacar que o SDK do Kinect insere em cada quadro capturado uma tupla com informações referentes ao plano do chão.

A postura perna ajoelhada poderia ser encontrada, aplicando-se a distância do ponto da junta do joelho esquerdo, J17, ou joelho direito, J13, em relação ao plano do chão. Porém, quando ocorre a postura perna ajoelhada, devido à oclusão total do segmento pé-joelho, o corpo humano é representado, erroneamente, por um corpo em pé, com encurtamento dos membros inferiores, como pode ser observado na figura 4. 


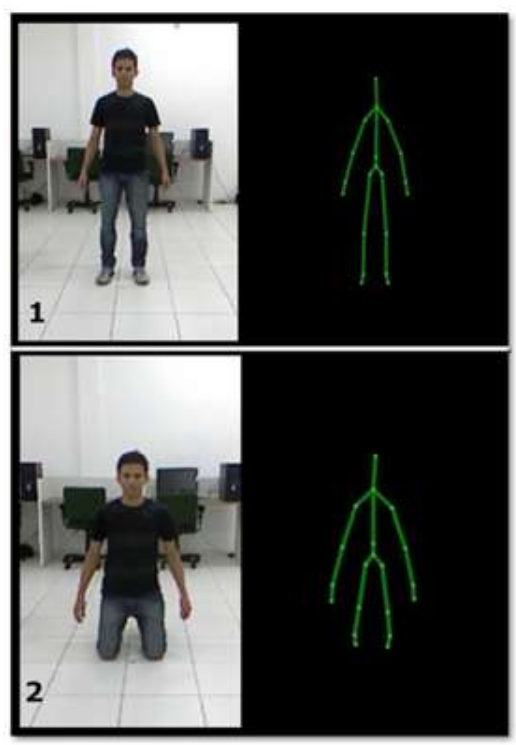

Figura 4. 1 Representação do esqueleto na postura em pé. 2. Representação do esqueleto na postura de joelhos.

Por esse motivo, para detecção da postura perna ajoelhada, usou-se a fórmula que calcula a distância entre juntas, a seguir:

$$
d(A, B)=\sqrt{\left(x_{a}-x_{b}\right)^{2}+\left(y_{a}-y_{b}\right)^{2}+\left(z_{a}-z_{b}\right)^{2}}
$$

onde $d(A, B)$ é a distância entre os pontos $A=\left(x_{a}, y_{a}, z_{a}\right)$ e $B=\left(x_{b}, y_{b}, z_{b}\right)$.

Desse modo, a distância entre o quadril e o joelho, representada por $d(Q, J)$, quando a pessoa está em pé, segue a seguinte regra $d(Q, J) \geq \omega$, onde $\omega$ é a menor distância que pode ser encontrada entre estas duas juntas, definida pelo ergonomista. Assim, quando há deformação do quadro do esqueleto, por encurtamento do segmento quadril-joelho, tem-se $d(Q, J)<\omega$ e a perna é classificada como ajoelhada.

Análise da classe OWAS

A etapa de análise OWAS consiste na geração das classes OWAS a partir das posturas identificadas na etapa anterior. O ergonomista usa as classes geradas como ponto de partida para obter um diagnóstico e estabelecer recomendações de ação, para a atividade de trabalho que está sendo analisada.

Segundo o método de registro e análise postural OWAS, as classes podem ser geradas de duas formas: pela avaliação pontual da combinação de posturas ou pelo tempo relativo despendido em uma postura específica para cada parte do corpo. 
A segunda forma de geração de classes, onde é considerado o tempo relativo despendido em uma postura específica para cada parte do corpo, é a mais usada pelos ergonomistas, pois consegue determinar o efeito do tempo sobre o sistema musculoesquelético e, por isso, é a forma utilizada na metodologia apresentada por Leão (2013).

\begin{tabular}{|l|c|c|c|}
\hline & Braço & Dorso & Perna \\
\hline Avaliador 1 & $100 \%$ & $93,33 \%$ & $98,33 \%$ \\
\hline Avaliador 2 & $100 \%$ & $93,33 \%$ & $93,33 \%$ \\
\hline Avaliador 3 & $100 \%$ & $86,66 \%$ & $93,33 \%$ \\
\hline Sistema & $100 \%$ & $86,66 \%$ & $96,66 \%$ \\
\hline
\end{tabular}

Tabela 1. Resultados obtidos na avaliação da metodologia de Leão (2013).

Na avaliação da metodologia apresentada por Leão (2013), foram testados com voluntários a eficiência de um sistema utilizando tal metodologia. Ao total foram testadas 180 posturas de um voluntário, estas posturas incluíam variações entre posturas de braço, pernas e dorso e foram analisadas por três ergonomistas e pela metodologia apresentada, seguindo o método OWAS.

Na Tabela 1 podem ser observados os percentuais de acerto de cada um deles.

\section{CONCLUSÃO}

A metodologia de avaliação postural através de captura de movimento, proposta por Leão (2013) vem possibilitar a detecção de riscos mediante análise das posturas adotadas nas atividades desenvolvidas ao longo da jornada em seu posto de trabalho sem interrupção nem interferências que podem intervir na produtividade do trabalhador. Dividida em 4 etapas principais, a metodologia é de simples aplicação e traz resultados eficientes. A primeira etapa trata da Inicialização, que consiste na deteç̧ão do equipamento e obtenção dos quadros do esqueleto; a segunda é a Remoção de ruídos, quando são aplicados filtros nos quadros de esqueleto, para obtenção do quadro que será usado nas etapas posteriores; na sequência, a etapa de Classificação engloba o referencial usado para classificar as posturas segundo o OWAS e, por último, a Análise OWAS, que contém as regras de identificação das classes OWAS.

\section{AGRADECIMENTOS}

Os autores agradecem às instituições brasileiras: Coordenação de Aperfeiçoamento de Pessoal de Nível Superior (CAPES), Conselho Nacional de Desenvolvimento Científico e Tecnológico (CNPq), Fundação de Amparo à Pesquisa e ao Desenvolvimento Científico e Tecnológico do Maranhão (FAPEMA) e à PRPGI do Instituto Federal de educação, Ciência e Tecnologia do Maranhão, pelo apoio. 


\section{REFERÊNCIAS}

Apple Inc. (2020). Apple unveils new iPad Pro with LiDAR Scanner and trackpad support in iPadOS, Apple Newsroom, [Online]. Available: https : / / www . apple .com / newsroom / 2020 / 03 / apple unveils - new - ipad - pro - with - lidar - scanner - and - trackpad - support - in - ipados/ (visited on 12/05/2020).

Azimi, M. Skeletal joint smoothing white paper.

http://msdn.microsoft.com/en-us/library/jj131429.aspx, 2012.

Fernandes, L., A., F. Protótipo de sistema óptico de captura do movimento humano, sem utilização de marcadores especiais. TCC. Centro de Ciências Exatas e

Naturais, Universidade Regional de Blumenau, Blumenau, Junho 2002.

Gomide, J. B., Flam, D. L., Pacheco, D., Araújo, A. A. Captura de movimento e animação de personagens em jogos. VIII Brazilian Symposium on Games and Digital Entertainment, pages 50-55, 2009.

Hanseny, D.M., P.T. Duizery, S. Parkz, T.B. Moeslundy, and M.M. Trivediz. Multi-view video analysis of humans and vehicles in an unconstrained environment. 2005.

Hay, J.The Biomechanics of Sports Techniques. Prentice-Hall. Englewoo Cliffs, N.J. 1978.

Ilida, I. Ergonomia, Projeto e Produção. São Paulo: Edgard Blücher, 2015.

iPad Pro 2020 - Technical Specifications, iPad Pro 2020 - Technical Specifications, [Online]. Available: https : / / www . apple . com / ipad - pro / specs/ (visited on 12/05/2020).

iPhone 12 Pro and 12 Pro Max - Technical Specifications, iPhone 12 Pro and 12 Pro Max - Technical Specifications, [Online]. Available: https: //www.apple.com/iphone-12-pro/specs/ (visited on 12/05/2020).

Karhu, O. et al. Observing working postures in industry: Examples of owas

application. Applied Ergonomics, v. 12, n. 1, p. 13\{17, 1981. ISSN 0003-6870. Disponível em: <http://www.sciencedirect.com/science/article/pii/0003687081900880>.

Lidar, inWikipedia, Dec. 31, 2020. [Online]. Available: https://en.wikipedia. org/w/index.php?title=Lidar\&oldid=997485760 (visited on 01/03/2021).

McAtamney L., Corlett E.N. RULA: A survey method for the investigation of work-related upper limb disorders. Appl. Ergon. 1993;24:91-99. doi: 10.1016/0003-6870(93)90080-S.

Moeslund, T. B. and Erik Granum. A survey of computer vision-based human motion capture. Computer Vision and Image Understanding, 81(*):231\{268, 2001.

Nanda, P., Alan Smith, and Adey Gebregiorgis. Design and development of an upper extremity motion capture system for a rehabilitation robot. IEEExplorer, 2009. 
Pavani, A. R.; Quelhas, G. L. O. A avaliação dos riscos ergonômicos como ferramenta gerencial em saúde ocupacional. In: XIII SIMPÓSIO DE ENGENHARIA DE PRODUÇÃO, 2006, Bauru, SP.

Schwarz, L. A. et al. Estimating human 3d pose from time-of- ight images based on geodesic distances and optical ow. In: Automatic Face Gesture Recognition and Workshops (FG 2011), 2011 IEEE International Conference on. [S.I.: s.n.], 2011. p. 700\{706.

Shotton, J. et al. Real-time human pose recognition in parts from single depth images. In: Computer Vision and Pattern Recognition (CVPR), 2011 IEEE Conference on. [S.I.: s.n.], 2011. p. 1297 \{1304. ISSN 1063-6919.

Schulz, A. Motion capture - technical report. INSTITUTO NACIONAL DE

MATEMÁTICA PURA E APLICADA, May 2010.

Webb J., Ashley J. (2012) Skeleton Tracking. In: Beginning Kinect Programming with the Microsoft Kinect SDK. Apress. https://doi.org/10.1007/978-1-4302-4105-8_4

Owas, 1990. URL http://turva.me.tut.fi/owas.

Kinect, 2013. URL http://www.xbox.com/pt-br/kinect.

Motion, 2013. URL http://www.autodesk.com/motionbuilder.

Phase, 2013. URL http://www.phasespace.com.

playstation, 2013. URL http://us.playstation.com/ps3/accessories/

playstation-move-motion-controller-ps3.html.

Vicon, 2013. URL http://www.vicon.com/.

Wii, 2013. URL http://www.nintendo.com/wii. 


\section{Capítulo 12}

doi $10.37423 / 210704527$

\section{CONSCIENTIZAÇÃO INFANTIL NO USO RACIONAL E SEGURO DA ENERGIA ELÉTRICA}

Yuri da G. Santos

Raphael D. C. Silva

Filipe D. Oliveira

\section{Edcleide S. P. Pereira}

Michele M. Sales

Débora P. Mercês
Instituto de Estudos Superiores da Amazônia - IESAM

Instituto de Estudos Superiores da Amazônia - IESAM

Instituto de Estudos Superiores da Amazônia - IESAM

Instituto de Estudos Superiores da Amazônia - IESAM

Instituto de Estudos Superiores da Amazônia - IESAM

Universidade da Amazônia - UNAMA 
Resumo: Este trabalho busca apresentar por meio de dinâmicas de grupo e materiais expositivos, orientações sobre utilização de forma consciente e segura da energia elétrica, apresentando situações cotidianas onde o desperdício não deve ser um parâmetro positivo na constituição da educação $e$ atitudes. O projeto ao interagir na escola com crianças, além consolidar uma metodologia de conscientização e aprimoramento dos conceitos sobre energia elétrica, deverá influenciar diretamente em sua utilização, acarretando em possíveis diminuições no número de acidentes causados por uso indevido da energia elétrica por crianças, adolescentes e futuros pais.

Palavras-chave: Conscientização, Energia Elétrica, Utilização. 


\section{INTRODUÇÃO}

Ao abraçarmos jovens e crianças, uma melhor perspectiva de eficiência no dia a dia se torna mais plausível. Partindo do pressuposto que "eficiência é o que se têm quando há um saldo positivo na divisão entre resultados obtidos e os recursos empregados." (Eletrobrás. Curso de Eficiência Energia).

Desta forma, necessária se torna a conscientização para se evitar o desperdício de energia, para que em longo prazo as construções prejudiciais e maiores desmatamentos venham a ser evitadas. Não se fixando em desmatamentos e obras, ao darmos o primeiro passo para a Eficiência Energética - voltada a conscientização e entendimento da importância da Eletricidade -, o trabalho com fontes de energia renováveis e não degradantes ao meio ambiente estará mais próximo.

Este projeto tem por base apresentar uma situação de produção de energia, seu caminho a nossas casas e como isso é realizado. Explicitando o que e como são realizadas essas etapas.

Deste modo encontraremos o objetivo, que é o de ensinar a jovens e crianças o porquê de não desperdiçá-la, para que assim seja propiciada a oportunidade para um discernimento de suas atitudes. - "Seu objetivo está relacionado ao fornecimento de elementos para compreensão de uma situação ou estrutura de um problema" relata Duarte (2006, p. 63).

O caminhar em direção aos mais novos, parte do princípio que devido ainda estarem em formação, se é possível ensinar-lhes como não destruir e degradar a vida como um todo. Abrange-se vida, toda e qualquer possibilidade de melhoria na saúde.

Tomando como ponto de partida a conscientização nas escolas, a priori pretende-se atingir uma turma de jovens e crianças, para que estes ao chegarem a sua casa, se lembrem de desligar a luz, a TV, o ventilador, entre outros aparelhos, e sempre buscarem produtos que possuam o Selo Procel Eficiência Energética em Equipamentos -, analisando se o produto também tem a Etiqueta Nacional de Conservação de Energia (ENCE), esta que os classifica em " $E$ " (menos eficientes) até " $A$ " (mais eficientes).

Pareado a esta meta, a divulgação da engenharia e sua importância para o dia a dia, acrescerá de esclarecimentos quanto ao papel do engenheiro participando ativamente na busca pela melhora de empreendimento, segurança e bem estar, enfatizando-se a conscientização para eficiência. 


\section{O PROJETO}

\subsection{LOCAL DE APLICAÇÃO DO PROJETO}

O ambiente escolar em que será aplicado o projeto é o Lar de Maria de Belém do Pará, situado na Praça Floriano Peixoto, 33, no bairro de São Brás em Belém. Instituição esta que abriu as portas e se propôs ajudar na interação entre crianças e energia elétrica, realiza trabalhos no âmbito educacional, de forma alternativa, buscando tirar crianças das ruas oferecendo-lhes oficinas e atividades recreativas em horário alternado em que as crianças estão na escola.

\subsection{METODOLOGIA DE APLICAÇÃO}

O trabalho terá em seu primeiro passo um estudo dos atuais costumes de crianças, perante a energia elétrica, seja em atitudes ou em sua utilização. Este será implementado através de simples perguntas, onde imagens - com situações ocorridas no dia a dia - serão apresentadas para que sejam selecionadas entre Certas e Erradas. Ressalta-se que a aplicação das perguntas, mediante as imagens será feita de aluno a aluno, para que a opção de um não venha a influenciar na de outro estudante. Sendo assim, de forma inconsciente, estarão respondendo a um 'questionário' sobre suas opiniões para que possamos consolidar um primeiro banco de informações. Deste modo, poderá ser feito um estudo sobre quais os principais pontos, onde e como abordá-los. Tendo-se em mente que não devemos chegar a uma sala e disseminar a ideia de que 'ao sair, deve-se apagar a luz' ou 'desconectar o plug de força de um objeto da tomada'.

No segundo contato, ocorrerão visitas explicativas sobre como a energia elétrica é produzida (em hidrelétricas) e como esta chega a nossa casa. Para assim instruir-Ihes ao 'por que economizar?'. Não satisfeito, elaborar-se-ão cartazes para que fiquem espalhados pela escola com mensagens que consigam ser facilmente interpretadas e assimiladas por estudantes. Desenvolvendo-se assim, outra forma de ajudá-los a não se esquecer do compromisso com a segurança e economia.

Analisando em outra perspectiva, busca-se um meio de lembrar, diariamente, os futuros cidadãos que desperdício é um desperdício para a vida.

Para o primeiro momento do trabalho, serão utilizados vídeos e apresentações, por meio de recursos computacionais. Ao continuar do trabalho, uma maquete didática deve ser implementada, pois crianças e jovens podem ter um melhor entendimento "vivenciando" um fato, além de assistirem vídeos e apresentações sobre o presente tema. 
Na busca pelo apoio do PROCEL, espera-se a obtenção dos direitos para divulgação dos livros sobre o tema para as crianças. Livros estes que são totalmente didáticos, bem ilustrativos e contém histórias interessantes, não somente a crianças, mas também ao jovem, adulto e idoso.

Complementando o trabalho de conscientização, valerá a pena ressaltar porque é importante valorizar o profissional engenheiro (não fazendo diferença quanto a área de atuação), qual o seu papel no mercado e porque se deve procurar um profissional habilitado para projetar e executar um serviço no âmbito da engenharia.

\subsection{CRONOGRAMA}

O período de aplicação e desenvolvimento do projeto será conforme segue na Tabela 1:

Tabela 1 - Cronograma de implementação do Projeto.

\begin{tabular}{|c|c|c|c|}
\hline Período & JUNHO & JULHO & AGOSTO \\
\hline $\begin{array}{c}\text { Estudos sobre o primeiro contato e como } \\
\text { abordar crianças para o desenvolvimento do } \\
\text { trabalho; }\end{array}$ & $\mathrm{X}$ & & $\mathrm{X}$ \\
\hline $\begin{array}{c}\text { Primeira visita ao Lar de Maria para } \\
\text { levantamento do primeiro banco de dados; }\end{array}$ & & $\mathrm{X}$ \\
\hline $\begin{array}{c}\text { Consolidação do primeiro banco de dados e } \\
\text { apresentação ao Professor Orientador; }\end{array}$ & & $\mathrm{X}$ \\
\hline $\begin{array}{c}\text { Segunda visita a escola para dinâmica e } \\
\text { apresentação sobre conscientização na } \\
\text { utilização de energia elétrica; }\end{array}$ & & $\mathrm{X}$ \\
\hline $\begin{array}{c}\text { Terceira visita a instituição de ensino para } \\
\text { levantamento de um banco de informações } \\
\text { sobre as atitudes, pós-dinâmica de instrução; }\end{array}$ & & $\mathrm{X}$ \\
\hline $\begin{array}{c}\text { Reunião para análise e debate sobre o efeito do } \\
\text { projeto diante crianças e suas atitudes; }\end{array}$ & & $\mathrm{X}$ \\
\hline $\begin{array}{c}\text { Construção de um protótipo de uma } \\
\text { hidrelétrica para próximas realizações do } \\
\text { projeto no decorrer do ano. }\end{array}$ & & $\mathrm{X}$ \\
\hline
\end{tabular}

\subsection{RECURSOS}

Informações disseminadas por boletins da Associação Brasileira de Conscientização para os Perigos da Eletricidade - ABRACOPEL, transparecem periodicamente, constantes acidentes envolvendo crianças e adolescentes em uso de forma indevida na energia elétrica, portanto, este recurso recebido serve 
como respaldo na localização de uma necessidade de orientação enquanto jovens sobre os perigos presentes na eletricidade.

Além dos Boletins Informativos, outros recursos serão anexados para acrescentar o projeto, a exemplo de camisas, uma maquete didática sobre como a energia chega a nossas casas, cartazes que serão espalhados na escola, visando lembrar diariamente do compromisso que as crianças e educadores têm com a vida, dentre outros conforme necessidade no trabalho.

Ressalta-se que os recursos a serem indexados ao projeto serão fornecidos por empresas que apoiam o mesmo: Automattic Control, MFolha Engenharia, Speed Sign e Zeus Quality Engenharia.z

Além das empresas citadas acima, conta-se com o apoio do Designer Gráfico Derick Diniz. Estima-se também o apoio do PROCEL, tendo-se os materiais desenvolvidos por esta instituição como modelo, pela sua excelente qualidade para a utilização no trabalho de conscientização no uso racional e seguro de energia elétrica.

\section{CONSIDERAÇÕES FINAIS}

Espera-se através deste projeto uma maior aceitação da ideia do não desperdício de energia e de uma forma de utilizá-la com segurança. Seja a criança, jovem ou adulto.

Acidentes com a eletricidade, em sua maioria, podem vir a ser evitados. Principalmente com quem solta pipas próximo a rede de distribuição de energia, sendo este apenas um exemplo dentre tantos que cotidianamente acompanhamos em jornais.

Desta forma, com a justificativa e organização dos motivos para se tornar consciente, acredita-se que, tal como uma notícia do dia a dia, a conversa em torno de atitudes para com a economia e segurança se tornará mais presente. Ganhando assim espaço em exemplos na sala de aula, temas de redações e principalmente, reavaliações e alterações nos hábitos diários.

\section{AGRADECIMENTOS}

Um primeiro "obrigado" se direciona aos familiares e amigos por acreditarem em minhas ideias e vontades; ao Prof. Msc. Raphael Comesanha, que sempre me incentivou no desenvolvimento do trabalho; às empresas: Zeus Quality Engenharia, Automattic Control, Speed Sign e MFolha Engenharia; e ao Designer Gráfico Derick Diniz, por se disporem a ajudar e auxiliar no que fosse preciso para que o trabalho realmente acontecesse. 


\section{REFERÊNCIAS BIBLIOGRÁFICAS}

[1] Boletins Informativos ABRACOPEL. Disponível em: <http://www.abracopel.org.br > Acesso em: 15 mai. 2012.

[2] CREDER, Hélio. Instalações Elétricas. 14 ed. Rio de Janeiro: LTC - Livros Técnicos e Científicos Editora S.A., 2002.

[3] DIDONET, Marcos. História Inspirada no Programa de Educação Ambiental: PROCEL nas Escolas A natureza da paisagem - Energia: Ziraldo - O Clique: Rio de Janeiro: CIMA, 2006. 16p.: il. color; $28 \mathrm{~cm}$.

[4] DIDONET, Marcos. PROCEL nas Escolas - A natureza da paisagem: Energia: Recurso da Vida: Livro 01. Rio de Janeiro: CIMA, 2010. 16p.: il. color; $28 \mathrm{~cm}$.

[5] DIDONET, Marcos. PROCEL nas Escolas - A natureza da paisagem: Energia: Recurso da Vida: Livro 02. Rio de Janeiro: CIMA, 2010. 32p.: il. color; $28 \mathrm{~cm}$.

[6] DIDONET, Marcos. PROCEL nas Escolas - A natureza da paisagem: Energia: Recurso da Vida: Livro 03. Rio de Janeiro: CIMA, 2010. 32p.: il. color; $28 \mathrm{~cm}$.

[7] DIDONET, Marcos. PROCEL nas Escolas - A natureza da paisagem: Energia: Recurso da Vida: Livro 04. Rio de Janeiro: CIMA, 2010. 64p.: il. color; $28 \mathrm{~cm}$.

[8] DIDONET, Marcos. PROCEL nas Escolas - A natureza da paisagem: Energia: Recurso da Vida: Livro 05. Rio de Janeiro: CIMA, 2010. 80p.: il. color; $28 \mathrm{~cm}$.

[9] DIDONET, Marcos. PROCEL nas Escolas - A natureza da paisagem: Energia: Recurso da Vida: Livro do Professor. Rio de Janeiro: CIMA, 2010. 76p.: il. color; 28 cm.

[10] DUARTE, Jorge; BARROS, Antonio - organizadores -. Métodos e técnicas de pesquisa em comunicação. 2. ed. - São Paulo: Atlas, 2006.

[11] ELALI, Gleice. O ambiente da escola - o ambiente na escola: uma discussão sobre a relação escolanatureza em educação infantil. Estudos de Psicologia, Natal, 2003.

[12] ElETROBRÁS/PROCEL. Curso de Eficiência Energética. PROCEL - Programa Nacional de Conservação de Energia Elétrica.

[13] Histórico do Lar de Maria de Belém do Pará. Disponível em: <http://www.lardemaria.org/site/larde-maria/historia.html> Acesso em: 29 mai. 2012

[14] ROCHA, D. Campanha da Conscientização da Influência da Mídia e do Consumo Excessivo no Desenvolvimento Infantil. Monografia apresentada para aquisição do grau de Bacharel em Design Gráfico, Porto Alegre, 2010.

[15] SANT'ANNA, I. M.; MENEGOLLA, M. Didática: Aprender a ensinar. 7 a ed. - São Paulo: Edições Loyola, 2002. 


\section{Capítulo 13}

doi $10.37423 / 210704540$

\section{TRILHA ECOLÓGICA PARA PRESERVAÇÃO DAS ABELHAS (HYMENOPTERA: APOIDEA)}

\section{Maildo Barbosa Coelho}

Nádilla Gonçalves Andrade

Joelson Sousa Junior

\section{Laiza Bezerra Lima}

Waldesse Piragé de Oliveira Junior
Universidade Federal do Tocantins

Universidade Federal do Tocantins

Universidade Federal do Tocantins

Universidade Federal do Tocantins

Universidade Federal do Focantins 
Resumo: As abelhas com sua importância nos ecossistemas, vem ao longo dos anos desaparecendo por ações antrópicas e a falta de suas funções polinizadoras vem afetando diretamente o meio ambiente. Sua conservação sendo de extrema necessidade para a preservação de várias espécies vegetais diretamente dependentes da polinização das abelhas. Com isso objetiva-se neste trabalho, fazer um mapeamento dos ninhos, criando trilhas ecológicas e utilizando a educação ambiental como ferramenta de conscientização para a comunidade acadêmica e demais interessados no munícipio de Palmas-TO, Brasil, onde visualizando as abelhas em seus habitats, o funcionamento da sua estrutura de ninhos, a preservação dos mesmos e seu grande valor na manutenção do bioma, tem se a necessidade de desconstruir o pensamento de que abelhas são um perigo para a sociedade. Com essa atitude, utilizando ferramentas simples como a educação ambiental, possibilita demostrar a sociedade como cada espécie pode contribuir para que tenhamos um ecossistema equilibrado dentro da universidade.

Palavras-chave: Educação ambiental; Abelhas; Polinização; Conservação. 


\section{INTRODUÇÃO}

As abelhas (Hyminoptera: Apoidea), ocupam o ambiente urbano e são as mais numerosas na América Tropical, sendo que algumas espécies de polinizadores são beneficiadas com moderada perturbação ambiental, pois são capazes de utilizar os recursos que ocorrem em paisagens dominadas pelo homem, em áreas agrícolas, urbanas ou suburbanas (DIAS, 2015). No Brasil são conhecidas mais de 400 espécies de abelhas sem ferrão que apresentam heterogeneidade na cor, tamanho, forma, hábitos de nidificação e população dos ninhos (SANTOS, 2010).

Para Santos (2010) a conservação das abelhas é de extrema importância para a manutenção de diversos habitats, estes vão desde florestas à áreas de mangue, já que todos apresentam espécies vegetais que necessitam da polinização de alguma espécie de abelha. Na reconstituição de florestas tropicais e conservação dos remanescentes, estas abelhas podem ser de fundamental importância, pois além de atuar como bioindicadoras da qualidade ambiental, precisam das plantas para a sua alimentação e de suas crias e também para a construção de seus ninhos (SILVA e PAZ, 2012).

A polinização por abelhas tem destaque em ecossistemas naturais e agrícolas, sendo capazes de polinizar 30\% a 90\% da polinização da flora nativa (SANTOS, 2010). Apesar da grande importância das abelhas, elas encontram-se em um processo rápido de desaparecimento. Tal fato põe em risco a manutenção do nível de prestação de serviços da polinização realizada pelas abelhas, além das consequências da aceleração a que se assiste nos sistemas de produção agrícola.

Uma das formas de minimizar esse problema é a partir da educação ambiental, processo por qual o indivíduo de forma comunitária constrói valores sociais, conhecimentos, atitudes e competências voltadas para a conservação do meio ambiente. Esse gênero de trabalho é um dos principais instrumentos para o processo de sensibilização da sociedade. Mas, segundo o Ministério da educação e cultura, a "Educação Ambiental" poderia constar no currículo (BRASIL, 1997).

\section{OBJETIVOS}

Fazer mapeamento dos ninhos e analisar a diversidade de diferentes espécies de abelhas sem ferrão, no Campus Universitário de Palmas (CUP) e constituir um processo participativo de construção de uma trilha ecológica, como uma estratégia de educação ambiental para conscientizar os alunos, docentes e o público do Campus Universitário de Palmas - CUP e demais interessados, sobre a importância das abelhas no meio ambiente e assim, construir coletivamente ideias e alternativas para a compreensão da importância da conservação dos recursos ambientais. 


\section{MATERIAL E MÉTODOS}

\section{ÁREA DE ESTUDO}

O estudo foi realizado no município de Palmas-TO, Brasil, que se encontra na região norte do país e apresenta um clima tropical onde há muito mais pluviosidade no verão que no inverno. A classificação climática de Palmas é do tipo clima úmido com moderada deficiência hídrica no inverno C2WA'a', segundo Köppen e Geiger (1948), sendo caracterizada por duas estações bem definidas, uma seca e a outra chuvosa e $26.7^{\circ} \mathrm{C}$ é a temperatura média (ESTAÇÃO,2018).

A área amostral foi a área do Campus Universitário da Universidade Federal do Tocantins - CUP que fica localizado na região norte da capital à margem do Rio Tocantins (10¹0'42.41"S; 48 $\left.21^{\prime} 38.98^{\prime \prime} \mathrm{W}\right)$, (Figura 1).

Figura1: Mapa da área amostral (Campus Universitário) delimitado em amarelo

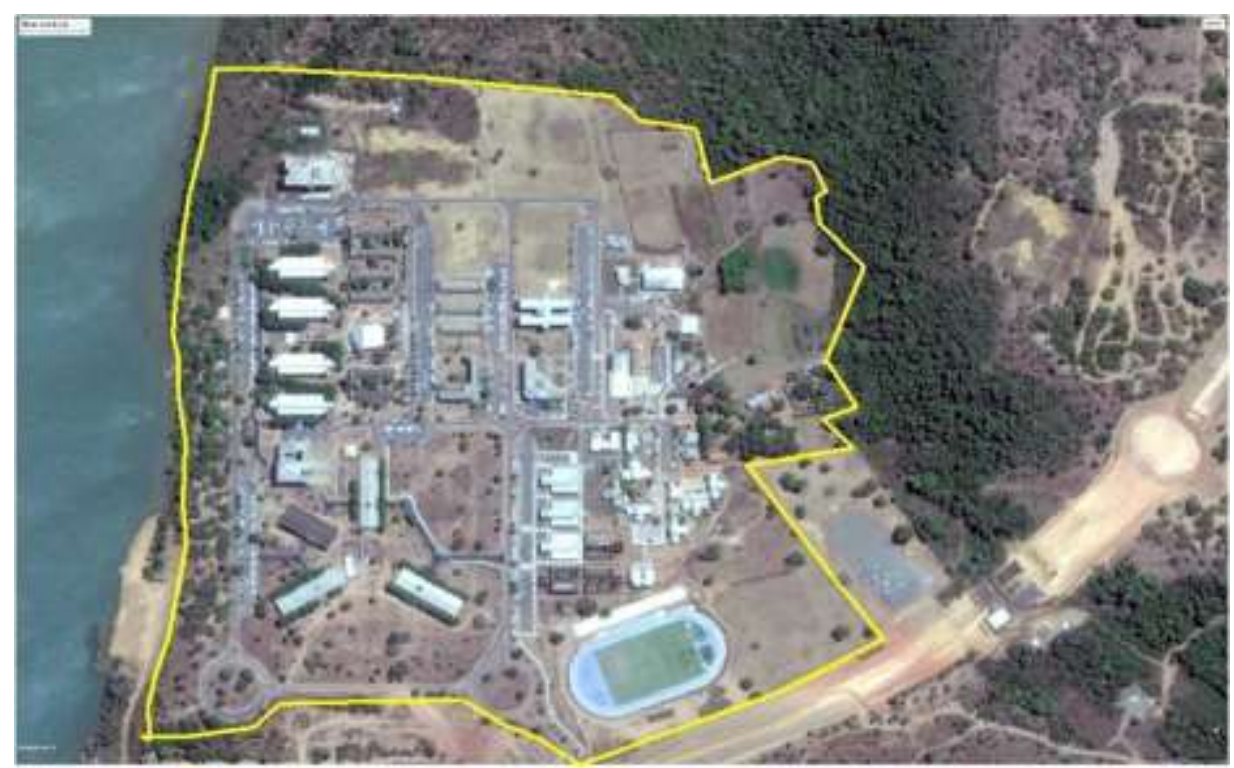

Fonte: Google Earth

Para realizar o estudo, inicialmente, houve o mapeamento da área interna do campus, que compreende edificações, muros, pátios de estacionamento, prédios, vias, e áreas de plantações experimental, totalizando uma área de 50,2801 ha.

Foi realizado um detalhamento da área a ser estudada pois, apesar de ser uma área grande, compreende vários aspectos a serem levados em consideração, principalmente, as ações antrópicas que se desenvolvem no CUP. 
Os critérios usados para definir o mapeamento foram as áreas adjacentes de cerrado dentro do campus e as instalações prediais onde acontece a maior circulação de pessoas, tanto discente como docentes. Com isto, foi possível saber em que ambientes há maior concentração de nidificações das abelhas e fazer um índice de variabilidade das mesmas.

Após ter feito o mapeamento dos ninhos das abelhas, foi feito uma trilha ecológica mostrando a importância das abelhas para a biodiversidade do nosso planeta. Para a elaboração dos mapas e posterior testes de geoanálise dos ninhos foram utilizados os softwares SIG, Google Earth Pro v.7.3.1 e ArcGis v.10.3.1.

Contudo alguns alunos participaram dessa trilha, tendo condigo conhecimentos e preparos de como manusear abelhas sem ferrão, tendo em vista a preservação das mesmas e assim, com a educação ambiental, aprendendo um pouco sobre as abelhas e seu habitat natural.

\section{RESULTADOS E DISCUSSÃO}

Foram encontrados 22 ninhos ativos referentes a 6 espécies distribuídas em quatro gêneros de Meliponinae, Tetragona clavipes (Nogueira-Neto, 1970) (3 ninhos), Trigona spinipes (Nogueira-Neto, 1970) (9 ninhos), Partamona helleri (Friese, 1900) (5 ninhos), Tetragona quadrangula (Lepeletier, 1836) (1 ninho), Trigona pallens (Fabricius, 1798) (2 ninhos), Scaptotrigona sp. (Moure, 1942) (2 ninhos). $\mathrm{O}$ índice de heterogeneidade Shannon- Wiener foi $\mathrm{H}^{\prime}=1,55$ e de equitabilidade Pielou foi $\mathrm{J}=$ 0,86. A figura 2 indica a abundância das abelhas.

Figura 2. Abundância de ninhos de abelhas sem ferrão localizados em ambiente urbano

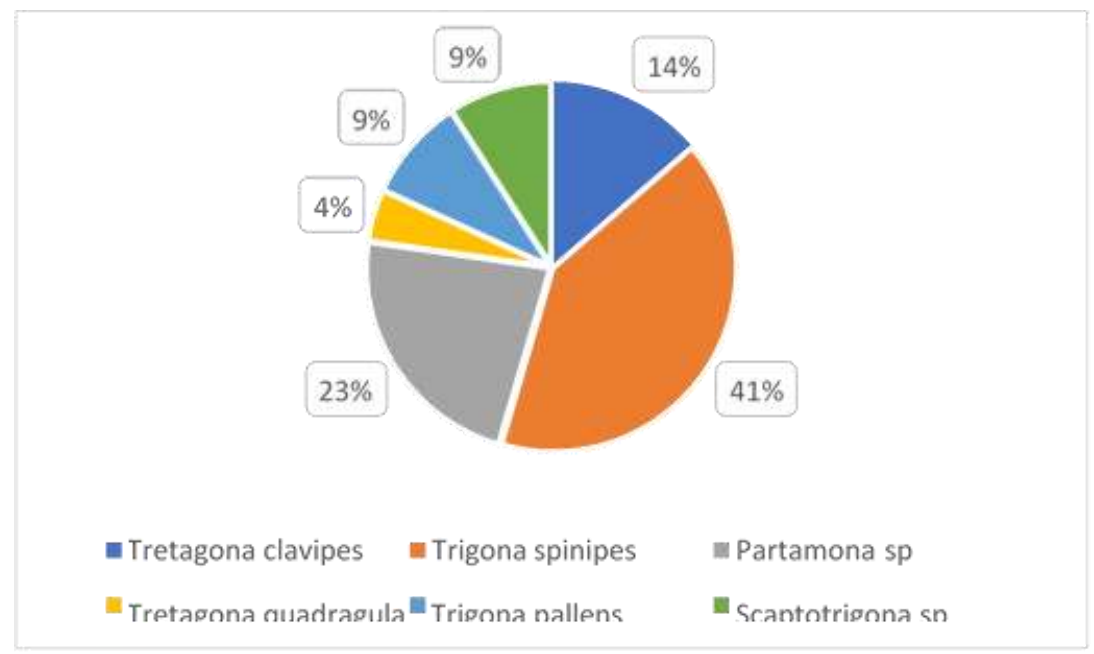

Fonte 1: Próprio autor 
Dos 22 ninhos ativos, 5 (23\%) estavam em fundação artificial (concreto, rocha, construções prediais) os demais 17 ninhos (77\%) estavam em fundação tipo natural. Destes, 14 ninhos (63\%) estavam em ocos e copas das árvores e outros 3 ninhos (14\%) se encontravam no solo (cupins) como mostra a figura 3.

Figura 3. Distribuição dos ninhos em função do tipo de sítio de nidificação

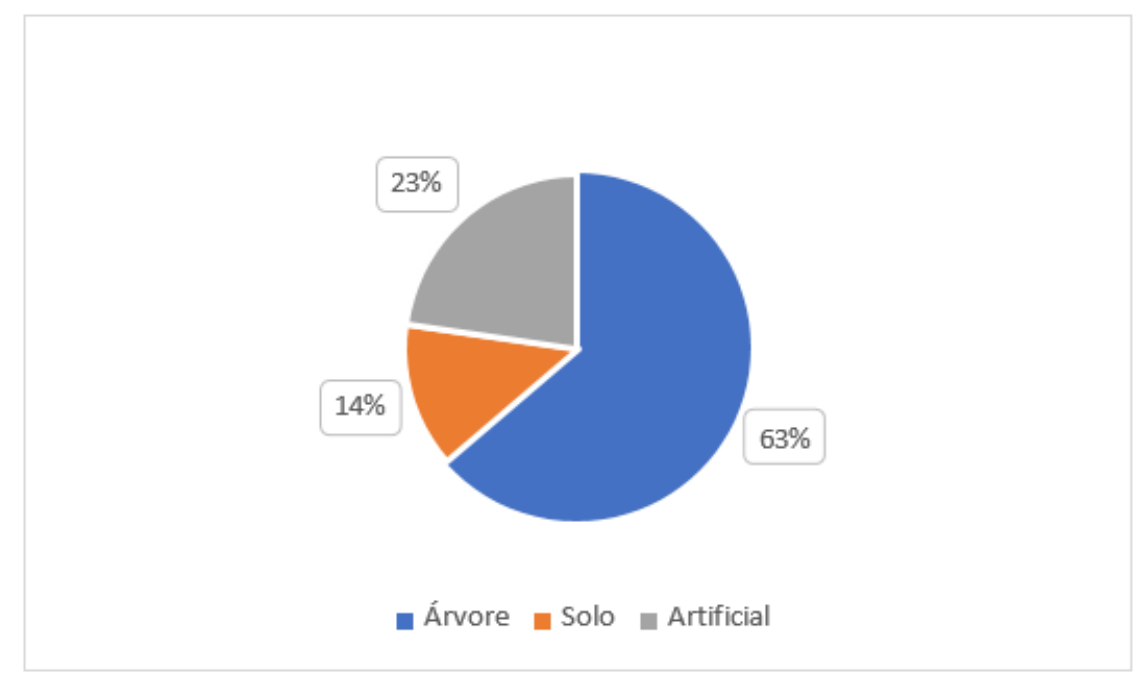

Fonte: Próprio autor

Somente a Trigona spinipes nidificou em fundação artificial. Para nidificar a espécie utilizou uma ampla gama de materiais da construção civil, como colunas de sustentação, fendas e ocos nas áreas concretas e paredes.

Assim, a partir das coordenadas adquiridas por meio do equipamento de Sistema de Posicionamento Global (GPS), foi possível saber a localização exata dos ninhos das abelhas sem ferrão existentes no CUP tendo assim maior facilidade para futuros manejos caso seja necessário e também para a construção da trilha ecológica. Figura 4. 
Figura 4: Pontos georreferenciados - CUP

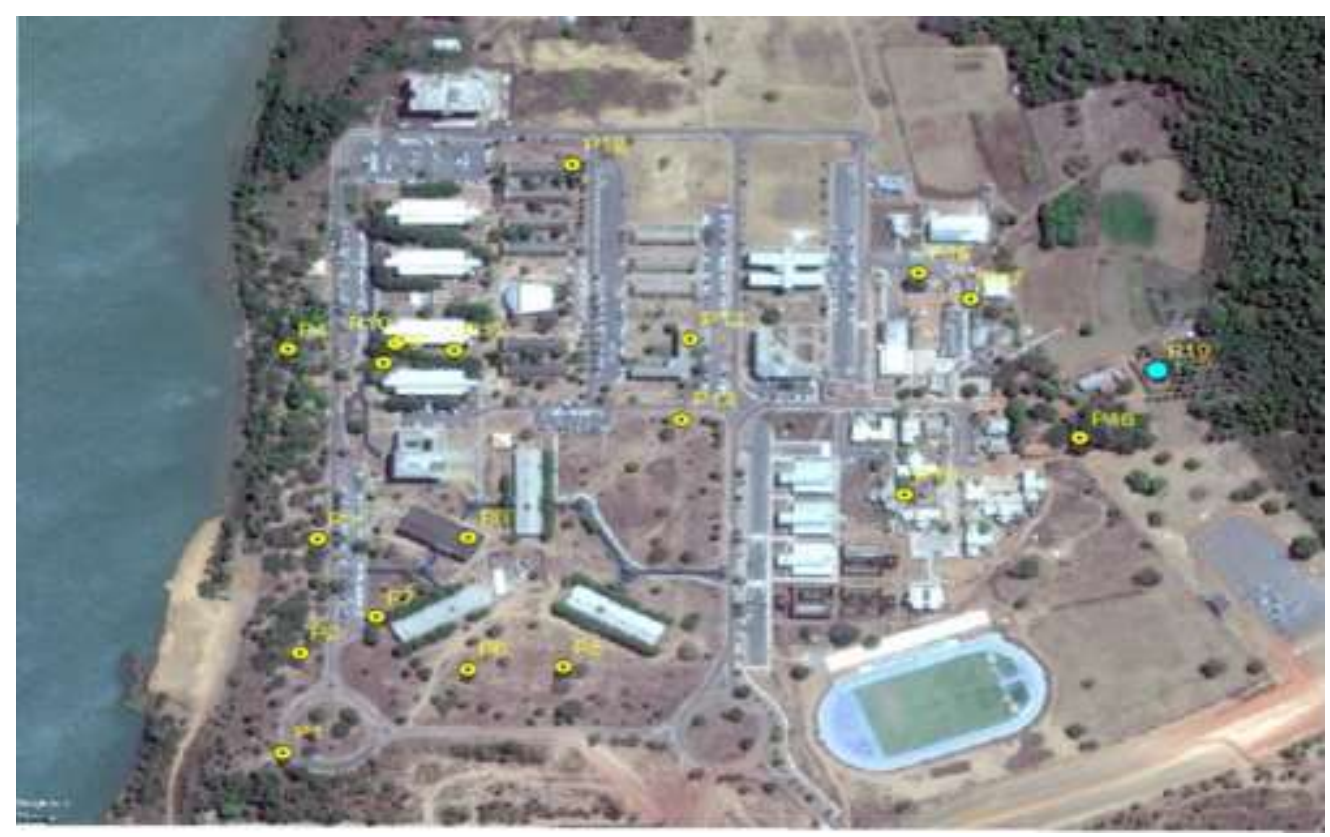

Fonte: Google Earth

Ao localizar todos os ninhos e georreferenciar todos eles, foi feito pequenas placas de identificação (Figura 5), para que quem passe por ali possa identificar e conhecer mais um pouco sobre as abelhas, tendo em vista que elas são benéficas para o meio ambiente.

Figura 5: Placa de identificação

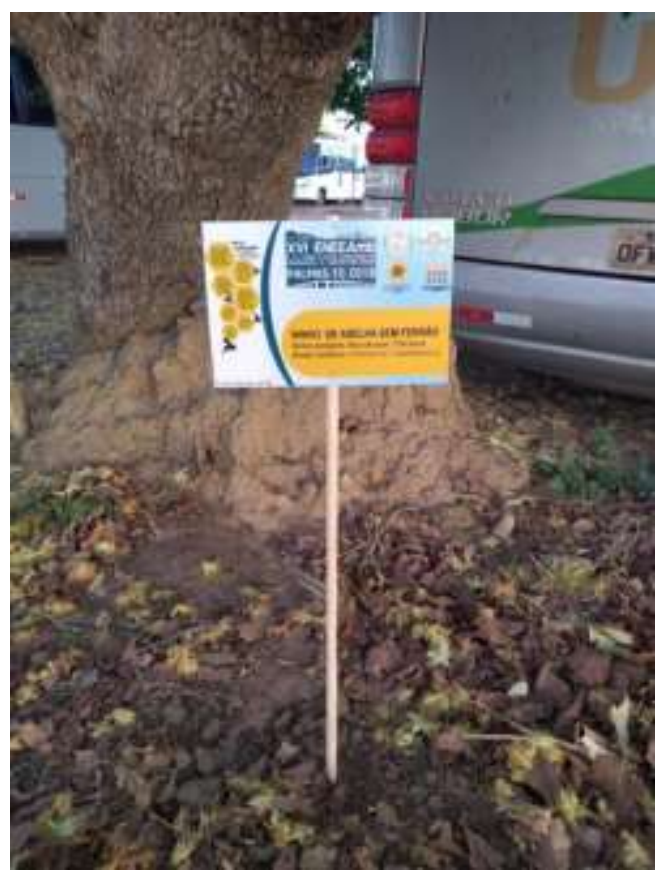

Fonte: Próprio autor 
Após todos os ninhos terem suas placas de identificação foi recebido na universidade a turma de alunos do 1 o ano do curso técnico integrado ao meio ambiente do Instituto Federal do Tocantins Campus de Porto Nacional, onde os mesmos tiveram uma palestra sobre a importância das abelhas um pouco sobre educação ambiental e preservação do meio ambiente e também fizeram o percurso da trilha ecológica, onde puderam ter um contato direto com as abelhas, assim reforçando o conhecimento adquirido anteriormente na palestra.

Ao iniciar a caminhada pela trilha ecológica foram sanadas várias dúvidas dos alunos a respeito das abelhas, como também puderam conhecer mais sobre as mesmas, tendo assim uma noção de como funciona o ambiente onde as abelhas estão inseridas, e tendo uma compreensão da conservação da flora para a preservação das abelhas-sem-ferrão.

Figura 6 e 7: Alunos conhecendo a trilha ecológica.

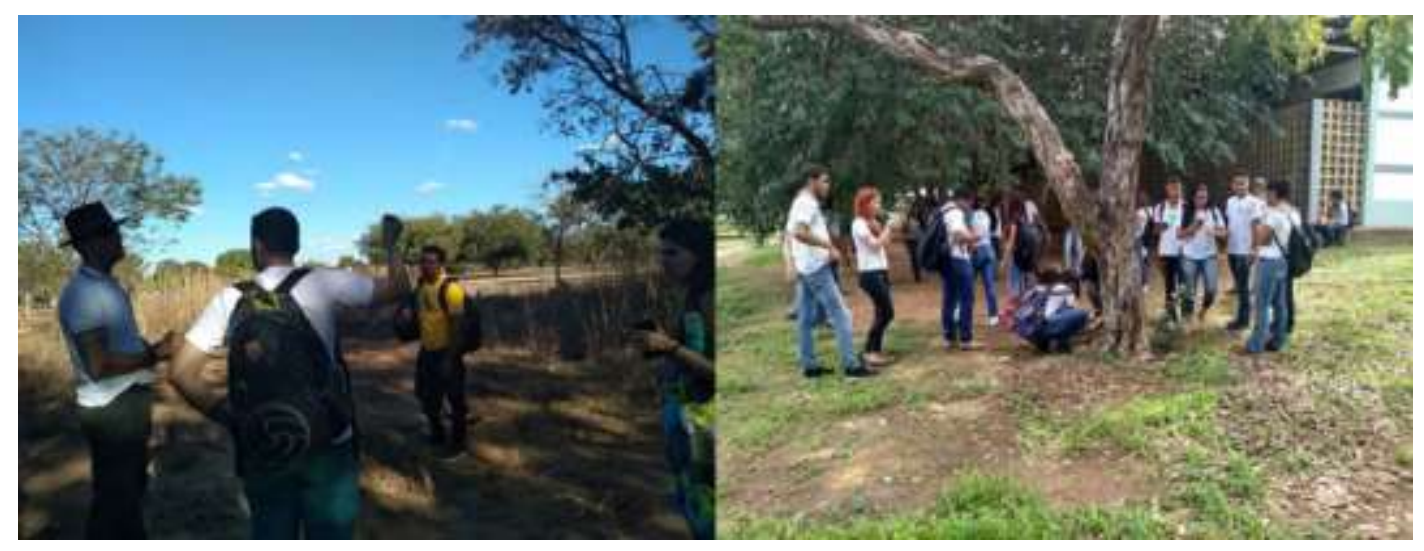

Fonte: Próprio autor.

Com esse exercício e com os conhecimentos recebidos, os alunos descobriram a importância das abelhas sem ferrão para a humanidade e ecossistema e que as mesmas estão presentes no nosso dia a dia, sem causar qualquer dano. Ao contrário do que a maioria das pessoas acreditam, elas são benéficas e não apresentam nenhum risco. Desconstruir esses conceitos foi fundamental para os alunos aprenderem a lidar com esses organismos, de forma a contribuir para a sua preservação. Os alunos que participaram do projeto aprenderam a reconhecer, de forma lúdica, as abelhas sem ferrão, a sua importância na polinização e como conservar esses e outros animais.

A Educação Ambiental possibilitou o entendimento das crianças e de todos os evolvidos e reafirmou que o maior inimigo das abelhas nativas, assim como de outros seres vivos é o desconhecimento, é preciso fornecer visibilidade da importância das abelhas sem ferrão para toda a cadeia trófica. 


\section{CONSIDERAÇÕES FINAIS}

As espécies de abelhas sem ferrão apresentam muitas características distintas na biologia de nidificação, como ninho exposto, entrada críptica, operárias defensoras agressivas, operárias defensoras pairando, altura da entrada do ninho em relação ao solo (ROUBICK, 2006), tráfego de abelhas externas e tamanho populacional dos ninhos, podem facilitar ou dificultar uma real amostragem da diversidade de ninhos de abelhas sem ferrão.

Os polinizadores fornecem um serviço essencial ao ecossistema e também trazem muitos benefícios à sociedade, através da produção de alimento na agricultura, além de melhorias nos meios de subsistência, desenvolvimento científico, cultural e recreacional e na conservação da diversidade biológica. (IMPERATRIZ-FONSECA, 2004).

Com essa prática e com as informações recebidas, os alunos perceberam a importância das abelhas sem ferrão para a humanidade e ecossistema e que as mesmas estão presentes no nosso dia a dia, sem causar qualquer prejuízo. Ao contrário do que a maioria das pessoas imagina, elas são benéficas e não apresentam nenhum risco. Desconstruir esses conceitos foi fundamental para os alunos aprenderem a lidar com esses organismos, de forma a contribuir para a sua preservação. Os alunos que participaram do projeto aprenderam a reconhecer, de forma divertida, as abelhas sem ferrão, a sua importância na polinização e como conservar esses e outros animais. 


\section{REFERÊNCIAS BIBLIOGRÁFICAS}

BRASIL. Ministério da educação e do desporto. Secretaria da Educação Fundamental. A Implantação da Educação Ambiental no Brasil: meio ambiente e saúde. Brasília, 1997.

BRÜGGER, Paula. Educação ou adestramento ambiental? 2. ed. Florianópolis: Letras Contemporâneas, 1999.

DIAS, Alan Bronzeri. Ninhos de abelhas nativas sem ferrão (Meliponineae) em ambiente urbano. 2015. 33 p. Relatório de Iniciação Científica (bacharelado em Ciências Biológicas) - INSTITUTO DE BIOCIÊNCIAS, UNIVERSIDADE ESTADUAL PAULISTA “JÚLIO DE

MESQUITA FILHO”, Botucatu, [2014]. Disponível em:

<https://repositorio.unesp.br/handle/11449/142880>. Acesso em: 15 abr. 2019.

ESTAÇÃO de Palmas - Climatologia Local. Disponível em:

<http://sonda.ccst.inpe.br/estacoes/palmas_clima.html>. Acesso em: 22 fev. 2019.

IMPERATRIZ-FONSECA, Vera Lucia. Serviços aos ecossistemas, com ênfase nos polinizadores e polinização. Disponível em:

<http://www.ib.usp.br/vinces/logo/servicos\%20aos\%20ecossistemas_polinizadores_vera.pdf>

. Acesso em: 01 fev. 2019.

PEREIRA, Fábia de Melo. Abelhas Sem Ferrão a Importância da Preservação, 2005. Disponível em: < http://www.cpamn.embrapa.br/apicultura/abelhasSemFerrao.php >. Acesso em: 25 abr. 2019.

ROUBIK, D. W. 2006. Stingless bee nesting biology. Apidologie, v. 37, p. 124-143.

SANTOS, Aline B. Abelhas nativas: polinizadores em declínio. 2010. 4 p. Artigo Cientifico (Laboratório de Entomologia) - Cidade Universitária Prof. "José Aloísio Campos", Pólo de Gestão, Universidade Federal de Sergipe, São Cristóvão, Sergipe, [2010]. Disponível em:

<http://www.naturezaonline.com.br/natureza/conteudo/pdf/01_SantosAB_103106.pdf >.Acesso

em: 14 abr. 2019.

SILVA, Wagner Pereira; PAZ, Joicelene Regina Lima da. Abelhas sem ferrão: muito mais do que uma importância econômica. 2012. 8 p. Artigo Cientifico (Mestre em Zoologia.)- Departamento de Ciências Biológicas, Laboratório de Entomologia (LENT), Universidade Estadual de Feira de Santana (UEFS), Feira de Santana, BAHIA, [2012]. Disponível em:

<http://www.naturezaonline.com.br/natureza/conteudo/pdf/09_Silva_Paz_146152.pdf>.Acesso em: $10 \mathrm{abr} .2019$ 